\title{
Making Business Work for Development: Issues for small to medium enterprises
}

\author{
Paul Thompson
}

Thesis submitted to

Victoria University of Wellington in partial fulfilment of the requirements for the degree of Master of Development Studies

School of Geography, Environment and Earth Sciences Victoria University of Wellington June 2008 


\section{Abstract}

This thesis examines the question of whether business can be made to work for development. Can the standards that are used to measure development projects be applied to the outcomes of business ventures in developing countries? Proponents of neoliberal economic globalisation claim that economic growth is, by definition, good for the poor, and that the opening of global markets gives unprecedented opportunities for poverty reduction. 'Aid for Trade' is now a significant proportion of ODA funding. This is aid that is directed at assisting developing countries to be able to enter the global market. The claim is that the removal of trade barriers and the facilitation of smooth trade processes will be the key to achieving the MDG targets for poverty alleviation. Literature however suggests that such claims are much exaggerated, and that the global market does not automatically work to benefit the poor. Even where good rates of growth are achieved in a country, the poor are left behind, with widening income gaps between the rich and poor. This thesis examines these issues before investigating the concept of 'pro-poor business'. Economic growth can be structured to have positive benefits for the poor. It does not happen automatically, but it can be intentionally built into economic growth structures. There are some basic and fairly simple steps which all business could adopt to assist in poverty alleviation. Beyond this there are business ventures that are proactive in targeting the needs of poor communities.

The thesis looks at case studies of six businesses started by expatriate entrepreneurs in six Asian countries. The businesses are investigated by a qualitative study that uses an emailed questionnaire followed up by further email and phone discussions. The businesses have been chosen to illustrate the possibilities over a range of types and sizes of business, and the degree to which they are intentional in targeting specific poverty issues. The businesses are asked questions both about their business structures and also about the extent to which they achieve development oriented goals. Issues faced by the businesses in this melding of business and development concerns are examined. The conclusion is that there are opportunities arising from globalisation that can be taken and shaped to enable the poor to become participants in the global economy. 


\section{Acknowledgements}

I need to say thank you first to the development organisation which started me on this journey by turning me down for a job because, although I had "an interesting CV and lots of relevant experience", I had no qualifications in development! That comment got me into the academic study of development issues, and so to the writing of this thesis.

Having said that, I want to thank also the people and organisations of Bangladesh for giving this 'bideshi' (foreigner) twenty years of practical experience of what does and doesn't work in development. People like Sadhon, Sudhir and the producer women of the Chandpur Cottage Industries project where we worked together through issues like group formation, microcredit savings and loans schemes, and the issues of marketing to Fairtrade organisations. People like Monindra and Mamun, and the members of the Chandpur Rotary club, as we worked together more than once on the issues of emergency relief distribution after flood or cyclone. Thanks also to my Kiwi colleagues in Bangladesh who were part of working through these lessons. In particular thanks to John and Susan Osborne. John has been an advocate of the business model for a long time, and is part of several of these case studies. They have been the best of friends.

Thank you to Professor Vijay Naidu for his introduction to the academic study of development issues. In the 1970s when I was an undergraduate I struggled with academia, but Vijay's classes were stimulating and encouraging. Thanks also to Professor John Overton for his support and encouragement in this work on Making Business Work for Development. When I was struggling to find the way forward he was able to point me in the right directions.

I have a particular debt to the busy people who took time to answer my questions about their business ventures. To Jim, Rob, Kerry and Annette, Chris and Rachel, I hope that you will find the comparisons with others who have similar dreams to your own helpful and encouraging. There were others who have not been specifically included here, but who took time to write to me about their work thank you.

The last two and a half years of study would not have been possible without the part time work given to me by the Churches' Agency on Social Issues (CASI). In addition to the salary, it was a valuable experience in research and advocacy on social issues. I am sorry that CASI was closed down, and I think that the churches in New Zealand are poorer for its absence.

Finally to family. Thanks first to my parents, for bringing me up in places where poverty was real. They didn't shelter me from the issues of Eritrean communities affected by both drought and civil war.

When I decided to return to university my children (three of them with degrees of their own, and one still in high school) decided to equip their father with the items needed for a return to student life - a beanie in the Hurricanes colours, a pencil case, notepaper and a back-pack. Their interest and encouragement has helped me through.

Finally and most importantly, my thanks go to Adrienne. She has been my wife and partner for 31 years. Without her none of it would have been possible. 


\section{Contents}

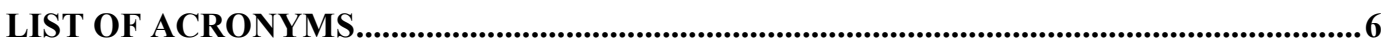

CHAPTER 1: INTRODUCTION - MAKING BUSINESS WORK FOR DEVELOPMENT .8

CHAPTER 2: GLOBALISATION, URBANISATION AND POVERTY ...............................15

IS GLOBALISATION LEVELLING THE ECONOMIC PLAYING FIELD? ........................................... 15

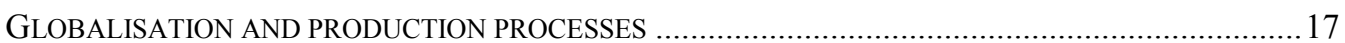

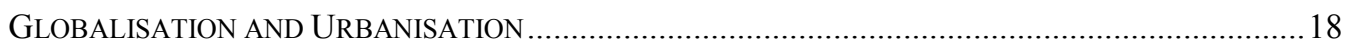

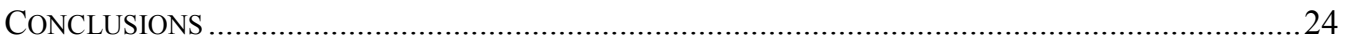

CHAPTER 3: IS GLOBAL TRADE THE ANSWER TO GLOBAL POVERTY? .................27

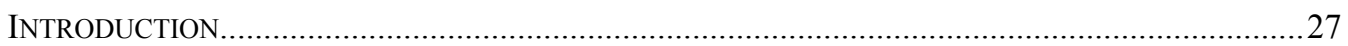

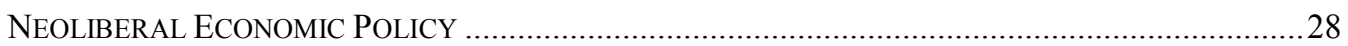

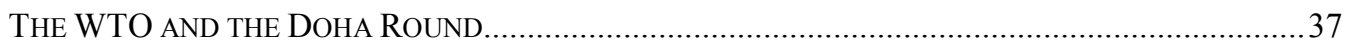

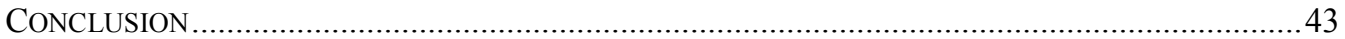

CHAPTER 4: CAN TRADE BE MADE PRO-POOR? ........................................................44

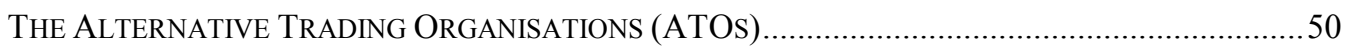

SMALL TO MEDIUM ENTERPRISE (SMES) AS AN OPPORTUNITY ….........................................5

SOCIAL ENTREPRENEURS - AGENTS OF CHANGE ................................................................ 55

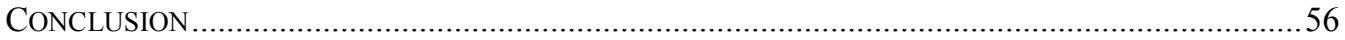

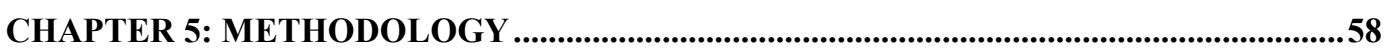

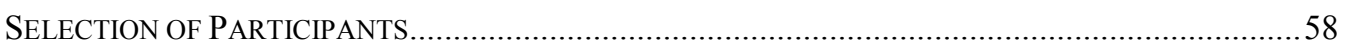

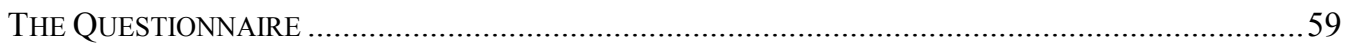

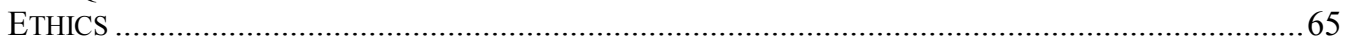

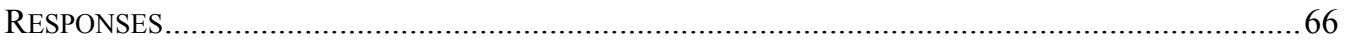

CHAPTER 6: ENTREPRENEURS IN ASIA - THE CASE STUDIES ..................................68

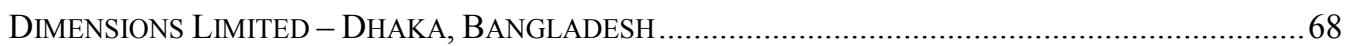

FREESET BAGS/TRIPLENINE SOFTWARE PRIVATE LTD - KOLKATA, INDIA .................................76

THE ACEH COFFEE COMPANY / INDONESIAN SPECIALTY COFFEE COOPERATIVE DEVELOPMENT

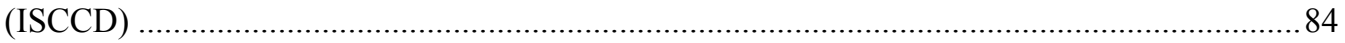

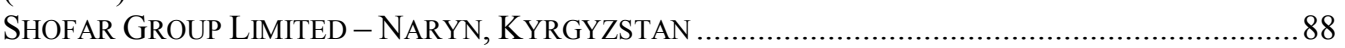

CORNERSTONE WORKPLACE ENGLISH (CWE) - CHIANG MAI, THAILAND ................................99

HAGAR INTERNATIONAL - PHNOM PENH, CAMBODIA................................................................96

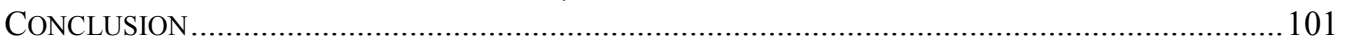

CHAPTER 7: THE CASE STUDIES - ANALYSIS OF ISSUES..........................................102

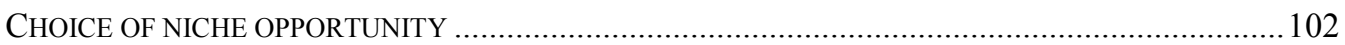

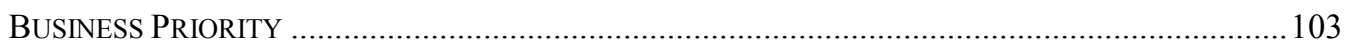

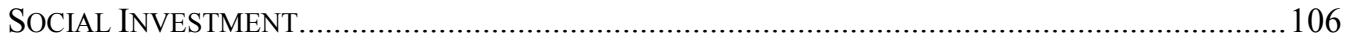

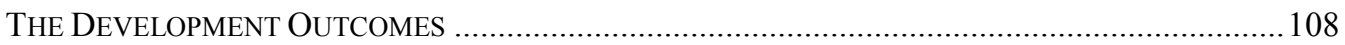

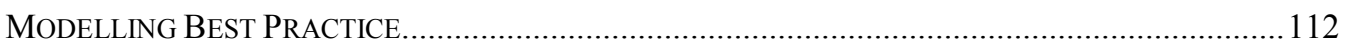

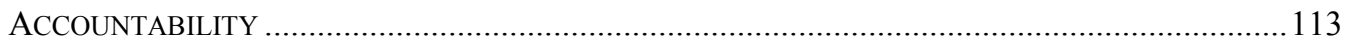

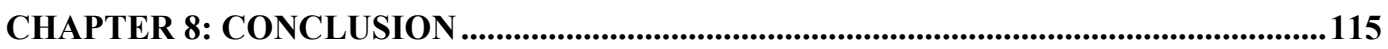

APPENDIX 1: THE QUESTIONNAIRE, CONSENT FORM AND INFORMATION

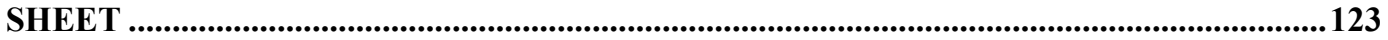

APPENDIX 2: COMPARATIVE COUNTRY STATISTICS .............................................129

APPENDIX 3: COUNTRY INFORMATION ................................................................... 131

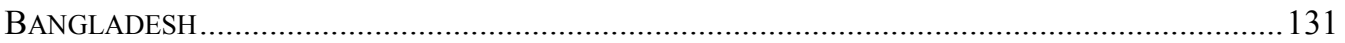

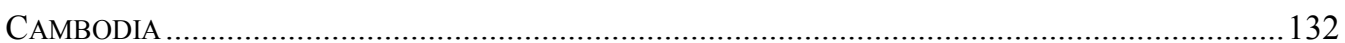

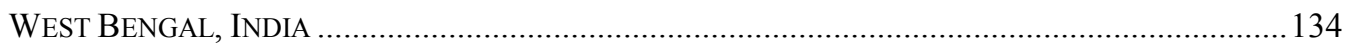

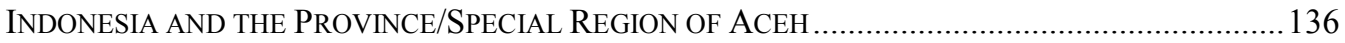

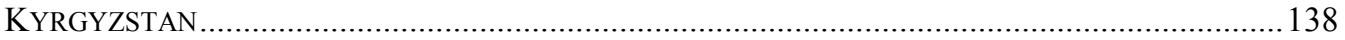

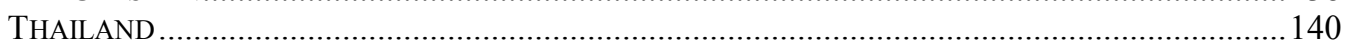

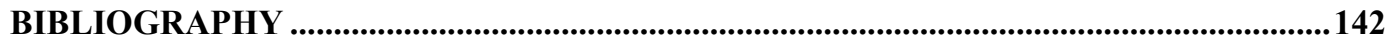




\section{List of Figures}

FIGURE 4:1 PRO-POOR BUSINESS PRACTICE.......................................................................4

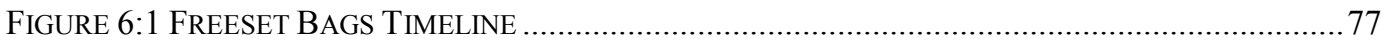

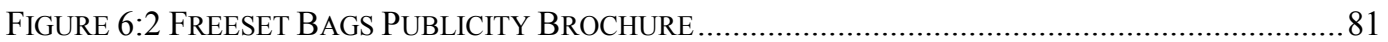

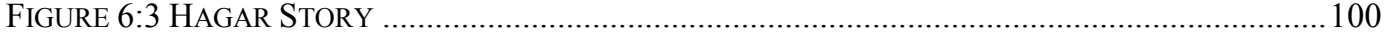

FIGURE 7:1 SOCIAL INVESTMENT VS ETHICAL INVESTMENT ......................................................... 107

\section{List of Tables}

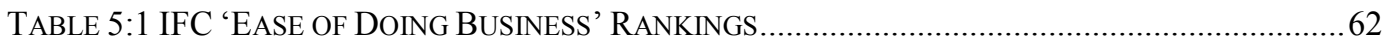

TABLE 5:2 RESPONSES FROM CASE STUDY COMPANIES ………...................................................67

TABLE 6:1 HAGAR SALES ...................................................................................................99

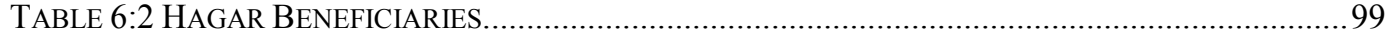




\section{List of Acronyms}

ACP, African, Caribbean and Pacific Nations / African, Caribbean and

ACPA Pacific Alliance

APEC

Asia Pacific Economic Cooperation - APEC members are Australia, Brunei Darussalam, Canada, Chile, China, Indonesia, Japan, Korea, Malaysia, Mexico, New Zealand, Papua New Guinea, Peru, the Philippines, Russia, Singapore, Taiwan, Thailand, the United States and Viet Nam.

ATO Alternative Trading Organisation - the proponents of 'Fair Trade'

BDS Business Development Services - assistance to small businesses with technical advice and services

CAFTA Central American Free Trade Agreement

CSR Corporate Social Responsibility

EPA Economic Partnership Agreements

FLO Fairtrade Labelling Organisations

G10 Belgium, Canada, France, Germany, Italy, Japan, the Netherlands, Sweden, the United Kingdom, and the United States are the original G10 countries

GATT General Agreement on Trade and Tariffs

GDP Gross Domestic Product - one of the measures of a country's income

IFAT International Fair Trade Association

IFC International Finance Corporation

ILO International Labour Organisation

IMF International Monetary Fund

IT Information Technology

IUF International Union of Food Workers

MDG Millennium Development Goals

MNE Multi-national enterprise

MPDF Mekong Private Sector Development Facility

MPIL MarketPlacers International Limited, a New Zealand based company set up to promote and support small scale business enterprises in the developing world

NFIDC Net Food Importing Developing Countries

NGO Non-Government Organisation

NZAID New Zealand's International Aid and Development Agency

ODA Official Development Assistance

OECD Organisation for Economic Co-operation and Development. The 30 member countries are: Australia, Austria, Belgium, Canada, Czech Republic, Denmark, Finland, France, Germany, Greece, Hungary, Iceland, Ireland, Italy, Japan, Korea, Luxembourg, Mexico, the Netherlands, New Zealand, Norway, Poland, Portugal, Slovak Republic, Spain, Sweden, Switzerland, Turkey, United Kingdom, United States.

SME Small to medium enterprise

SOE State Owned Enterprise

SPS Sanitary and Phytosanitary - WTO regulations allowing restrictions on certain imports based on health issues 
SRI Socially Responsible Investment - business investment that takes into account ethical concerns of the investor regarding the actions of the company, for example a refusal to invest in armaments or the gambling industry, or a preference for pro-poor investments

TNC Trans-national Corporation

UHT Ultra high temperature processing, a process that gives a longer unrefrigerated shelf life to certain food products

UNDP United Nations Development Programme

UNESCAP United Nations Economic and Social Commission for Asia and the Pacific

UNIDO United Nations Industrial Development Organization

WBCSD World Business Council for Sustainable Development

WTO World Trade Organisation 


\section{Chapter 1: Introduction - Making Business Work for Development}

Globalisation has resulted in seemingly unlimited opportunity for new ventures. The developing nations feature regularly in the news for the opening of new production centres. The second half of the twentieth century was a period of spectacular economic growth with incredible amounts of wealth generated - for some countries, and even more particularly for some individuals. The millionaire list grows every year, and now includes many individuals from third world countries. Not all of this wealth is being buried in Swiss bank accounts. There are signs of it appearing in the corporate growth of significant companies in parts of the developing world. For example, the Indian company, Tata, has bought into British Steel, and is expanding into the luxury car market by acquiring the iconic British Jaguar and Land Rover brands for a net consideration of US\$2.3 billion ${ }^{1}$.

An NZAID brochure says "The potential gains from trade far outweigh the gains from international aid" (NZAID, n.d., p. 2). It quotes an Oxfam study showing that a $1 \%$ increase in world export share for each developing region could potentially reduce poverty by $12 \%$. This is a view widely shared in the ODA community. 'Aid for Trade' is the proportion of ODA directed to building market capability in the developing countries. A recent OECD/WTO study puts this at an average of $31 \%$ of OECD sector allocable development assistance, and $50 \%$ of World Bank sector programme allocation (OECD \& World Trade Organisation, 2007). The Oxfam study quoted shows that the NGO community is in general agreement (although with qualifications about unfair terms of trade that we will return to in chapter three). The optimism about the potential for trade to reduce poverty would seem to have plenty of justification.

\section{Neoliberal Economic Globalisation}

However the furore that there has been about the WTO and trade liberalisation indicates that there are issues that deserve careful examination. There is a strong counter argument that the liberalisation of global trade has in general worked to

\footnotetext{
${ }^{1}$ See www.tata.com/tata motors/releases/20080602.htm
} 
the advantage of the rich, and against the interests of the poor, both internationally and within the developing nations. Global movements have protested the injustices that have resulted from trade liberalisation. Sometimes trade liberalisation has been a drive to the bottom that has forced out the weakest from the edges. The advantages of cheaper prices accrue not to the primary producers, but to the wealthy consumers. The economist Joseph Stiglitz argues very forcefully that neoliberal economic policies have been applied in the developing world without first ensuring that the necessary regulatory frameworks were in place. A part of the neoliberal policy agenda is that regulatory frameworks should be reduced to a minimum, as any regulation may introduce inefficiencies. Stiglitz shows that there are basic legal structures without which neoliberal economic freedoms merely allow the rich and powerful to exploit the weak and the poor (Stiglitz, 2003). Too often trade liberalisation has been imposed on the developing countries without adequate preparation and without the necessary protections, with disastrous results for the poor. Misha Glenny argues that in fact the lack of protections has opened the way for the criminal underworld to pillage the economies of some countries (Glenny, 2008).

This thesis examines the opportunities of globalisation and the problems of neoliberal economic policy to see if there are indeed ways that global business can be used as a tool in development. Moving beyond the micro-credit/microenterprise push that has been so successful as a means of development, are there larger scale business ventures that can make use of the opportunities of globalisation in ways that, instead of exploiting the low wage environments, will work positively for poverty alleviation? Can business be made to work for development?

\section{Development Outcomes}

Looking at business from a development perspective poses some different questions. The purely business questions of course remain: availability of raw materials; availability of skilled workforce; availability of capital investment; supply and distribution issues; regulatory and compliance environment; competition and profit margins; etc. (Begley, Wee-Liang Tan et al., 2005), but a new perspective needs to be included. These are the questions that would be asked 
of a development project. What are the development outcomes, and how should they be assessed? If business is going to be seen as good for development, and as a way forward that "... outweighs the gains from international aid", and if one third of ODA is being put to facilitating the growth of business opportunities, then it is a valid and indeed essential exercise to ask these development questions.

For the purposes of this thesis I have taken the Millennium Development Goals (MDGs) as defining the basic development agenda. While there is plenty of debate around many of the specifics of the MDGs, they do in broad brushstrokes define a list of development priorities. They bring together the discussions and commitments made at a variety of international fora, and establish a sense of the most urgent needs. The core of the MDGs may be summarised as: poverty alleviation; education; human rights - and in particular gender equity issues; health - starting with child and maternity health, and moving to the issues of the major diseases such as HIV/AIDS and malaria; environmental impact and sustainability issues; and finally the goal of building partnerships and cooperation between the developed and the developing countries in ways that will bring positive development outcomes ${ }^{2}$.

Using these as a starting agenda and looking to define outcomes that can reasonably be expected of a 'pro-development' business venture the thesis develops the following criteria:

Poverty alleviation: the primary contribution any business can make to poverty alleviation is by generating employment opportunities. These include the number of people employed directly in the company, the indirect effect of the business on the employment environment in the surrounding community, and also the number of dependents supported by those wage earners. Within this are of course the issues of level of wages and conditions of employment. Many people in poor communities will accept 'sweatshop' conditions because for them any employment is better than none, but any assessment of a business as 'prodevelopment' will expect to see these issues dealt with as a part of corporate social responsibility (CSR) policy.

2 A good summary of the MDGs may be found on the UNDP website: www.undp.org/mdg/basics.shtml 
Education: The MDGs give a high priority to education. Business ventures may not be actively involved in children's education, but they should have active programmes of training and capacity building for their staff, and ensure that the children of their staff have access to education.

Human rights and gender equity issues should be addressed as part of corporate social responsibility policy. This should obviously be true for any company, whether operating in developing or developed world environments. The sort of pro-development business looked for in this study goes beyond such standard policy to targeting business and employment opportunities at specific human rights or gender disadvantage situations in the wider community.

Health Care Issues: Healthy staff will be better workers. 'Pro-development' businesses, working in countries with low standards of health care, will ensure that their staff have access to quality health care at prices they can afford. This may take a variety of forms depending on the circumstances, and the conditions in the country/district/town where the business is sited.

Environmental issues: Issues of environmental impact have increasingly become a part of the development agenda. As for human rights and gender issues, any business in today's world should have an active policy regarding their environmental footprint, but a 'pro-development' business should be looking at ways to have a positive influence on environment issues in the wider community where it operates.

Global Partnership and Cooperation: The businesses being discussed here are working within the global context, and so they are inevitably a part of the final MDG target. They are working in cross-national contexts, and as part of good business practice need to see themselves as building models of partnership and cooperation. However the development question moves beyond what is just good business. Good development practice addresses two related concerns. The first is the question of community participation and empowerment by the project. The second is the question of accountability, where the development model requires an acknowledgement of accountability to the beneficiaries of the project. What 
accountability does a pro-development business have, not just to its investors and board of directors, but also to its employees and to its local community?

These are the core development questions which this thesis uses as a lens through which to examine the concept of 'pro-poor' business. There is clearly here a continuum of degrees of consideration of poverty issues by companies. At one extreme is pure commercialism where success is measured solely by the greatest return on investment by whatever means - the 'profit motive' as the over-riding driver of business activity. Staff become a commodity to be treated like any other commodity in the production process. Moving away from this position are companies that adopt CSR policies. These commit the company to levels of ethical and socially responsible behaviour. CSR policy is a good and necessary step forward, and has been shown to have a major impact on behavioural change within companies. This has been encouraged by the promotion of the concept of socially responsible investment, where investors are encouraged to look for companies with good CSR policies (Blowfield, 2007), although other studies show that unless investors and customers follow up with requests for details of compliance with such codes, they can become more of a window-dressing exercise (Andersen \& Skovgaard, 2008). Even then, the focus is still on company behaviour, and does not necessarily include any consideration of global poverty issues ${ }^{3}$.

The next stage in the continuum is the insertion of specifically pro-poor considerations into company practice. The Australian Allen Consulting Group report Business for Poverty Relief says that these do not need to involve any level of philanthropy for the company. Rather it can make good business sense to configure company practice with consideration for long-term sustainable impacts that take into consideration the development needs of the people and the countries

3 There have been instances where CSR policy has been used as 'window-dressing' by corporates to present a face of responsible policy that has not been carried through in actual practice. At an ILO sponsored forum on socially responsible labour relations in 2007, Nestlé was challenged about discrepancies between their CSR policy and factory practice in developing countries. "The ethics of any company are best tested not in Europe, but in areas of the world where best practice is often worlds away" said IUF General Secretary Ron Oswald (See www.iuf.org/cgibin $/ \mathrm{dbman} / \mathrm{db}$. cgi? $\mathrm{db}=$ default\&uid $=$ default $\& \mathrm{ID}=4648 \&$ view records $=1 \& \mathrm{ww}=1 \& \mathrm{en}=1)$. A study of companies involved in the UK Ethical Trading Initiative found that CSR codes can improve labour standards for workers, but often do little to protect or develop issues of worker rights (Barrientos \& Smith, 2007). 
where the business is working. They talk of these as 'positive business practices' which will have a positive effect for poverty reduction.

At the other end of the scale from pure commercialism are companies which have been started specifically to target identified poverty issues. They are on the boundary between being a business and being a development project. They are businesses. They do need to be commercially sustainable, but their investors are not necessarily looking for any financial return on their investment. Any profits made will be returned to the business or to the target community. They will often be associated with social projects which they may fund from the business profits, but which may also get continued outside, development project style, funding.

\section{The Case Studies}

These two levels of the spectrum, the application of 'positive business practices' and specific poverty targeted businesses, are the context for the case studies examined in this thesis. The thesis has chosen six business ventures started in Asia by expatriate entrepreneurs with the specific aim of being 'pro-poor'. These businesses cover four areas of primary agricultural production, producing goods for export, introducing/supporting technology transfer, and service provision in the form of English language services. These are not micro-credit enterprises, but SME (small to medium enterprises). The smallest of the case studies is very small, barely more than micro-enterprise level. The largest is reaching medium enterprise level. The thesis investigates the effectiveness of these ventures both as businesses and as tools for development.

\section{Structure of the Thesis}

Chapter two examines the claim that globalisation has opened unlimited opportunity for developing countries to eliminate poverty by joining the global economy. Technological advances have flattened the playing field so that anyone, anywhere, can take part. The spectacular growth of the mega-cities of Asia are seen as illustrating this opportunity, but a more detailed study shows that the functional inequalities of production, distribution and consumption continue to leave 'deep craters of poverty' in the global landscape (Birdsall, 2005). 
Chapter three examines the economic structures of globalisation and the degree to which these have impacted on global poverty. The free market advocates of neoliberalism propose trade liberalisation as the solution to poverty issues. These are the policies of the global financial organisations, the World Bank and the International Monetary Fund, and are supported by the World Trade Organisation (the WTO). The arguments for and against neoliberalism are discussed, along with a study of the practical impacts of the WTO Doha Round talks on the situation in Africa.

Chapter four looks at the concept of 'pro-poor' trade. What makes pro-poor business? What are the options and the opportunities that will balance the inequalities revealed in chapters two and three?

Chapter five describes the methodology used for the case studies that are described in detail in chapter six. The case studies are of six business ventures in Asia that have attempted to be 'pro-poor' in their focus.

Chapter seven identifies and discusses common issues from these case studies. How successful are they in poverty alleviation? To what degree can they be considered as tools for development? Do they in fact show that business can be made to work for development?

Chapter eight is the concluding discussion. The assertion of this thesis is that the NZAID brochure quoted at the start is only partly right. Trade, by and of itself, does not have any necessary effect on poverty reduction. Unregulated, uncontrolled, commercial enterprise is as likely to exploit the poor and force them into still deeper levels of poverty. However pro-poor business is not just possible, there is a good argument that in the long term pro-poor business makes sound business sense. Pro-poor business does indeed offer the potential for enormous and sustainable gains in poverty reduction, and can be seen as a valid development tool. 


\section{Chapter 2: Globalisation, Urbanisation and Poverty}

\section{Is globalisation levelling the economic playing field?}

Modern technology and globalised production systems offer unparalleled opportunities for poverty reduction. The rise of information technology, accompanied by modern transport and logistics systems means that producers anywhere in the world are able to compete in the global market. The global economy has generated opportunities for the creation of enormous wealth. Surely in this global era there is an opportunity to bring an end to situations of extreme poverty? This chapter and the next look at the opportunities of globalisation, but also show that far too often the poor are squeezed out at the fringes.

Thomas Friedman argues that globalisation is flattening out the world. He came to this discovery on visiting the Indian 'Silicon Valley' in Bangalore, where he was taken to a facility with the capacity to teleconference company operations globally. The company CEO talked to him about the 'playing field being levelled' in terms of the company's ability to operate in the global market. Friedman lists the 'flatteners' - global events and discoveries that have been responsible for this opening up of opportunity for anyone, anywhere in the world to compete in the global marketplace. These 'flatteners' all evolve from the rise of information technology (IT). The ability to put information into a digital format which can then be transferred anywhere in the world through the internet and the worldwide web has enabled 'outsourcing' (work can be segmented and assigned to other companies anywhere in the world); 'offshoring' (production can be moved to follow cheaper labour markets); 'supply-chaining' (where the flow of work from order to manufacture, to assembly, to world-wide delivery can be monitored and ordered for greatest efficiency); and 'insourcing' (where even small companies are able to function globally with the support of service companies that provide logistic services) (Friedman, 2006).

This is the opportunity of globalisation. The new shape of IT facilitated technology means that anyone, anywhere, can compete in the global market. 
Those living in third world countries are no longer disadvantaged by their distance from the centres of research and the development of new products. Rather, because of their lower cost structures, they are in an advantageous position to compete against developed world industry. Laptop computers sold in New Zealand can be assembled from parts made in several Asian countries, and delivered on the basis of orders placed through a call centre in India. An Indian accountancy firm can process the tax returns for an American businessman in such a way that, because of time zone differences the returns can be filed the following day in America. Viewed from this angle the picture of globalisation depicts a significant opportunity for reduction of global poverty. Proponents of globalisation as the answer to world poverty point to the spectacular growth of the Asian mega-cities. These cities have sprung up as centres for global trade and growth, offering western companies all the services that they need for off-shore production, and as a result exhibit tremendous growth in wealth. They are seen as the success story of globalisation.

It is necessary to distinguish globalisation from internationalisation. According to Gary Gereffi “'Internationalisation' referred to the geographic spread of economic activities across national boundaries", and is not something new. He traces 'internationalisation' back to the beginning of the colonial era, and the search by the colonial powers for control of raw materials and markets (Gereffi, 1999, p. 1). Patterns of international trade can of course be traced in the trading systems of the ancient world. The empires of the ancient world came and went largely on their control of trade routes. 'Globalisation' is understood to be something not just quantitatively, but qualitatively different to these historic processes of international trade. Definitions of globalisation are quite varied, depending on the particular perspective of the writer. However there is general agreement that it involves new levels of "functional integration" across international boundaries (Gereffi, 1999, p. 1); that it involves economic, political and cultural processes (Larner \& Le Heron, 2002); and that a significant part of it involves the formation of new economic and social networks (Amin, 2002). Drawing these together, there are two different models of globalisation. One model is based on studies of production processes in the global economy, while the other is based on studies of 
the role of cities in networks that connect information and knowledge flows in ways largely unrelated to traditional nation state boundaries.

\section{Globalisation and production processes}

Gereffi analyses globalisation in terms of the commodity chains used by global industrial and commercial capital. A commodity chain is the whole process involved in the "design, production and marketing of a product", and he identifies two types. One is the "producer-driven" chain required for the production of capital and technology intensive items such as cars, aircraft, computers or heavy machinery. These are controlled by large transnational corporations who coordinate and drive a process that may involve multiple smaller firms in a number of different countries supplying parts of the final product. The other is the "buyer-driven" commodity chain which is the pattern for the production of labourintensive consumer goods such as garments, footwear, toys and the smaller items of household equipment. In these cases typically a company based in the developed world is responsible for the design and marketing of the product, but the manufacture is contracted out to networks of companies in less developed countries where labour costs are cheaper. Gereffi calls the companies in the developed world end of this chain "manufacturers without factories", as they have separated out the physical production of goods from the rest of the process.

Gereffi draws significant differences between these two types of commodity chain, and sees these differences flowing through to affect development strategies: The lead firms in producer-driven commodity chains control the process at the point of production. They are industrial producers, capital intensive, and establish investment based vertical control networks. Even where parts of the process are contracted out to subsidiary firms, they exercise close control over the whole process from raw materials, to component supply, through to distribution and retail. When invited to invest in developing countries they have established advanced manufacturing industries, like vehicle assembly, petrochemical and pharmaceutical plants. The production of these plants has been largely directed at the domestic markets of the region, rather than any export orientation. They are directed at import substitution, producing goods in the country and for the country, while the ownership and profits of the company are still in the hands of 
the transnational corporation. Gereffi sees this pattern operating particularly in Latin America through most of the middle period of the twentieth century.

Import substitution as a development policy has been discredited by neoliberal economics which sees the processes of import and export as being fundamental to economic growth. We need to note here that the establishment of such transnational production units has been brought into disrepute by the policy of some corporations of juggling stated production costs to gain maximum tax advantages, and to maximise the return of profits to investors in the developed world, and away from the developing countries. On the positive side, given the right conditions and incentives, import substitution production has been used by countries like Korea, India and China to get their own industries established to the point where they are able to supply not just domestic demand, but also to join the global market. These are issues that will be discussed further in the next chapter.

By contrast, the buyer-driven commodity chain is much more horizontal in structure, although the main control is still exercised by the retailers and marketers at the sales end of the process. Production systems are highly competitive and globally decentralised. Production is labour intensive, and so moves to the cheapest labour sources. In the development context the focus is on production for export, not for the domestic market. Gereffi sees this as having been the pattern for the newly industrialised nations of East Asia. Industrialisation in these countries has been largely export oriented, and aimed at the European and US consumer goods markets. This form of production is the highly visible face of globalisation, and the one which is most promoted as bringing opportunities for poverty reduction (Gereffi, 1999).

\section{Globalisation and Urbanisation}

Ash Amin, quoting D Held, defines globalisation as "the stretching and deepening of social relations and institutions across space and time such that, on the one hand, day to day activities are increasingly influenced by events happening on the other side of the globe and, on the other hand, the practices and decisions of local groups can have significant global reverberations" (Amin, 2002, p. 385). Globalisation is about the "spatiality of contemporary social organisation" and 
issues of "global connectivity". This global connectivity is probably most clearly seen in the so called "World City" networks. World cities are defined not by their role in the nation state, but by their role in cross boundary connections. They are defined less by their infrastructure (buildings, roads, etc.) than by what flows through them in terms of capital, information, and the control functions of the global economy. They are the control centres for world capital accumulation (Beaverstock, Smith et al., 2000), and the global service centres, the "places where financial and business service flows converge in the process of contemporary globalisation" (Taylor \& Walker, 2004, p. 146).

When seen from this perspective, globalisation is largely urban, both in its nature and in its impact. While the technological advances in agriculture have been significant, the overwhelming difference that globalisation has made to the world has been in the cities. The significance for this discussion is in looking at the role of the Asian cities in the global networks and in the processes of globalisation. At first glance it would be tempting to think that the global cities of the world are all much the same, and play much the same roles in the world economy. In Manila, Singapore, Bangkok, Hong Kong, Kuala Lumpur or Mumbai one can see the same models of vehicles on the roads, and experience the same traffic problems as in Amsterdam, London, New York, or indeed Auckland and Wellington. The same ads on the billboards, the same global products in the shops. The same companies have their offices in all the major cities. The climate may be different, but in an air-conditioned, multistorey building who is to know that? The languages on the street may be different, but there will always be those who can speak English fluently.

In the recent period Asia has seen a massive growth of urban populations. There are now twelve cities in Asia with populations of over ten million. These are Tokyo, Mumbai, Kolkata, Dhaka, Delhi, Shanghai, Jakarta, Osaka, Beijing, Karachi, Metro Manila, and Seoul (Laquian, 2005). Studies of these cities identify significant differences from the developed world cities, both in the processes and the state of urbanisation in Asia, and in the role of these cities in the global economy. Abu-Lughod and Hay identify a number of basic propositions related to urbanisation in third world countries. These propositions recognise that 
urbanisation is indigenous to the third world, with a history of significant urbanisation which preceded European urban growth; that while European urbanisation was driven by the "dual motors" of industrialisation and empirebuilding, third world urbanisation has been based around administrative and trade requirements; economic development in Third World cities has wide regional differences; and finally, that the cities of Asia begin with handicaps inherited from the colonial era (Abu-Lughod \& Hay, 1977, p. 38).

Discovering the differences between developed world and developing world cities requires moving out from the commercial centre to the fringes, where the people of the slums do not drive the cars or buy the products of the globalised world. It also requires some effort to dig deeper into the statistics. For a start, despite the publicity around the news that globally we have passed the point where $50 \%$ of the world population lives in cities, that figure itself covers some significant differences. In the Western, developed world, the figure is $75-80 \%$ and more. In some of the Asian countries which have shown the most rapid development over the last two decades the figure has climbed above 50\% (Malaysia and the Philippines reached $50 \%$ urban population in the early $1990 \mathrm{~s}$, but were still below $65 \%$ urban by 2005); in the least developed countries of South Asia, South America and Africa the percentages are well below this. Even India (28.7\%) and China $(40.8 \%)$ are both still well below the point of having 50\% urban population ${ }^{4}$. In the developed countries rural populations shrank in absolute numbers as well as in proportion to urban growth. In Asia the total population growth has been such that both urban and rural numbers continue to grow.

In many instances the colonial empires built new cities in new locations in Asia. These cities were built to meet the needs of the colonial powers for access to the raw materials which they needed, and for regional military control. They were built on significant coastal or river port sites, as economic bases for the European founders, and were planned and laid out with that intention (McGee, 1967). They were 'gateway' cities with strategic locations. In many cases through their economic links they were closer to the European cities than they were to their own hinterlands. They were not themselves industrial centres, and so did not provide

${ }^{4}$ See http://globalis.gvu.unu.edu/ Urban population statistics; accessed 27 May 2008 
the employment opportunities of the industrial centres. "The smoking chimney stacks of the Western industrial cities were replaced by the long, corrugated iron godowns (warehouses) of the port city" (McGee p56). Despite these limitations, it is the former colonial port and administrative centres which have become the great 'primate' cities of Asia.

There are both quantitative and qualitative differences between Asian and developed world urbanisation. Quantitatively, the primate cities of Asia grew out of proportion to all other cities in their regions, to the extent that "in Southeast Asia the urban population is most clearly associated with the largest cities" (McGee p.55). Urban population densities in the developing countries are on average more than double those of the developed world. A World Bank study gives averages of 8000 people per square kilometre for the developing world cities, and only 3000 per square kilometre in the developed world cities (Angel, Sheppard et al., 2005). These are the "Mega-urban" regions which are so significant to Asian globalisation. It is necessary to reiterate that while in absolute numbers there has been enormous growth in these cities to bring them to megaurban status, it has not resulted in the net decrease in rural numbers as experienced in the developed world.

The qualitative difference is seen in the form that the economic growth has taken. When McGee was writing in 1967 the situation for the Southeast Asian cities was not looking positive. In fact he called this immediate post-colonial period one of pseudo-urbanisation. By 1995 when he writes of the mega-urban regions of Southeast Asia the situation has changed enormously. There is a new vibrancy to the Asian city. There are still issues of enormous poverty and huge slums, but there has definitely been an economic change (McGee, 1967, 1995). Globalisation has resulted in the ability of multinational companies to utilise the cheap labour forces of the developing world. Much industrial production has moved from the developed countries to the developing world, to the point where it is possible in some countries to talk about the 'post-industrial' society. 'Post-industrial' does not mean that industrial production is no longer required, but that it no longer takes place in the consumer society. 
There are several points to make about this situation. The first is that industrialisation in Asia has not taken the same form as it had in the West. The so called 'Fordist' policy meant that in the process of industrialisation in the developed world industrial workers were paid a high enough wage that they were able to purchase the products of their own labour. This is not true of globalised 'off-shore' production. The largest part of modern-day economic globalisation is based on the exploitation of inequality. A Michigan University paper says “... urban poverty serves a distinct function for the benefit of global capital" (University of Michigan, 2006). Asian industrial production is not primarily for the benefit of Asia, but for the developed world. The colonial empires exploited the raw materials of the Third World; the 'empires' of the modern multinational company exploit both the raw materials and the cheap labour of the under employed populations of Asian countries.

The second point to make relates specifically to the mega-urban regions. As mentioned above, the major mega-urban 'primate' cities of Asia are mostly the cities established by the colonial powers as strategic economic bases. They were strategic for their port functions in providing access to interior regions. In the new era of globalisation this 'tertiary' function is still true to a significant degree. While the mega-cities have worked to increase their own industrial production, they still have a larger role as control or processing centres for production in other regions. Bob Jessop and Ngai Ling Sum discuss this in the context of Hong Kong trying to market itself as an entrepreneurial city (Jessop \& Ngai-Ling Sum, 2000).

Urban regions in general always account for a major portion of trade flows. This was one of the functions of cities from pre-historic times, but is even more true in the globalised era. There is an increased fragmentation and specialisation of production, distribution and consumption which depends on highly specialised transport networks and global trading functions. Jean-Paul Rodrigue talks of the mega-urban regions as emerging corridors of urbanisation, linked around interdependent trade flows. He distinguishes between regions based on production and those based on consumption:

"This implies that mega-urban regions are structurally and operationally similar, but since they have different spheres of production and consumption, 
they have specific geographies of distribution. For instance, while mega-urban regions in East and Southeast Asia provide significant production and export functions going through major hubs (Hong Kong, Singapore, Shanghai, Kaohsiung and Pusan), mega-urban regions in developed countries have expanded their import and consumption functions"(Rodrigue, 2004 p150-151).

This is illustrated by a study which examined the interlinking of producer service organisations on a global level. The "Urban Hinterworld Mapping" project (Taylor \& Walker, 2004; Taylor, 2007) studied 100 'global' service companies with 15 or more international offices, covering between them 123 cities around the world. Traditional cities rely on a 'hinterland' region on which they depend economically. The 'hinterland' for the World Cities is global in nature, crossing state political boundaries, hence the term 'hinterworld'. The resulting maps start from each city in turn and trace the ease of doing business in each of the other cities through the companies of the study. The maps are very interesting for the patterns of priority that are revealed. London, New York and Tokyo, as the three major league players in global trade show their closest connections with each other, and then with the East Asian Pacific rim cities. For each of these three cities, six of their 'Top ten' linked cities are the mega cities of East Asia. This is the core of the global trade network, based on different economies of production and consumption.

It is this network which is at the heart of the modern mega-urban developments of Asia. While gaining political independence, the role of the network in the global economy has not changed significantly. Within the cycle of production and consumption, the Asian cities carry an unequal role in facilitation of production rather than consumption. It is interesting to think about the possible shape of globalisation without inequality. If there was 'equal pay for equal work', and a balance of production and consumption across the globe, what would be the shape of global trade?

The significance of these inequalities of economy and of role is important as we look at the development opportunities that are created by globalisation. There are significant implications for policy makers, whether at government levels, the decision makers of the transnational corporations, or those with concerns for poverty issues in these cities. 
"... there is a danger that our understanding of urban expansion and the actions chosen to confront it will be unduly influenced by established concerns or by tested policies that are largely irrelevant to developing-country cities. In these cities, public and private resources, development priorities, and modes of governance to name a few are quite different from those prevailing in the industrialized countries and, as such, merit different analyses and different policy responses. (Angel et al., 2005 p. 4)

\section{Conclusions}

Nissanke and Thorbecke point out the need to make a distinction between the usage of the term globalisation simply to reflect the shrinking of space and time relations through the use of modern technology, and the networking ability that this brings, from the economic, political and social policy choices reflected in neoliberal economic theory. In popular usage the latter tends to be identified as globalisation and so to be depicted as some sort of an inevitable and neutral process of market forces. They agree with Neilson who says “...it is a mistake to consider the current development of a neoliberal globalization project as politically neutral" (Neilson, 2007).

Globalization is not purely driven by new technological innovations and progress or by 'neutral' market forces and other inescapable sociopolitical forces, as often depicted in popular writings. In particular, the contemporary phase of globalization is, to a certain extent, an outcome emerging from the global consolidation and diffusion of the economic policy paradigm, which emphasizes benefits and positive features of the liberalized policy regime. In this paradigm, trade and financial liberalization is seen, along other marketbased institutional reforms such as privatization, legal and other regulatory systems, as the sine qua non of a successful integration into a globalizing world economy. (Nissanke \& Thorbecke, 2005, p. 2)

Neoliberal economics is the subject of the next chapter, and will be dealt with in detail there. This chapter has been more concerned with the opportunities that are seen in the technological advances. These advances have enabled the global networking of cities and of the companies responsible for the production processes. However as we have seen there is here an inherent imbalance between production and consumption. This imbalance means that while there are new opportunities for poverty reduction coming from the technological advances, there are also situations of exploitation and defined limits to what is being achieved as a result of the technology. 
There is a telling sentence right in the beginning of Friedman's description of his visit to the Infosys campus outside Bangalore. He describes the drive out to the facility on a typical Indian road, with cows, horse drawn carts and motorized rickshaws, and then he says "Once you enter the gates of Infosys, though, you are in a different world." (Friedman, 2006, p. 5). It is this 'different world' created by globalisation that misses the needs of the poor and creates such stark divisions as the rich grow richer and the poor grow poorer. Nancy Birdsall, in the 2005 WIDER lecture talks of the "deep craters that mar the global landscape" (Birdsall, 2005). These craters have their source in issues of inequality, both within and across countries.

Birdsall argues that globalisation itself is one of the causes of growing inequalities. She sees three reasons for this. The first is that a level of higher education is needed for people to be able to take advantage of the opportunities of globalisation. "The most able children of the less rich miss out on the education and skills that would maximise their own economic prospects and their countries' own growth". The second is that global markets are susceptible to crises that inevitably have a bigger impact on the poor than on the wealthy ${ }^{5}$. She points to two things in this area. One is the financial crises of the 1990s that left poorer countries with unsustainably high debt levels that hinder growth opportunities. The other is the environmental issue, where the high polluting countries have reaped the benefits of high pollution industry without paying the full costs, and now with growing awareness of global warming, they are trying to introduce limits on greenhouse gas pollutants by transferring the polluting industries from their own territories to the developing world countries.

Birdsall's third reason for globalisation causing inequality is that global markets reflect the economic power of the rich. At the individual level the wealthy are able to exploit investment opportunities that are not available to middle or low income

\footnotetext{
5 "The downside of globalization is most vividly epitomized at times of periodical global financial and economic crises. The costs of the repeated crises associated with economic and financial globalization appear to have been borne overwhelmingly by the developing world, and often disproportionately so by the poor who are the most vulnerable. On the other hand, benefits from globalization in booming times are not necessarily shared widely and equally in the global community." (Nissanke \& Thorbecke, 2005, p. 1)
} 
households. At a country level wealthy countries are able use market power to limit access to technology or to maintain discriminatory subsidies.

Alan Gilbert agrees that globalisation is a significant cause of global inequalities. "In changing the world, globalisation has simultaneously created wealth, poverty and inequality" (Gilbert, 2007, p. 7). He analyses the much debated poverty statistics and shows that while on an international level the poverty percentages can be shown to be declining, much of this is related to growth in China and India, and that much of the apparent national level growth has been at the cost of growing inequalities within countries. Ioannis Glinavos, in his review of Craig and Porter's book Development beyond Neoliberalism says that "The authors conclude that liberal developmentalism is still committed to the market and to governance mechanisms that make inequalities of wealth a permanent feature of the global economy", and that the current state of security fears and the "war of terror' are likely to continue to exclude those on the margins (Glinavos, 2007). I will come back to this in the next chapter, with several studies indicating that unequal distribution of the gains from GDP growth can leave the poor in the same or a worse position than they were before.

Nissanke and Thorbecke conclude that "While the opportunities offered by globalization can be large, a question is often raised as to whether the actual distribution of gains is fair, in particular, whether the poor benefit less than proportionately from globalization - and could under some circumstances actually be hurt by it." (Nissanke \& Thorbecke, 2005). All this is of course saying that in fact the playing field is still not level. There has certainly been an enormous levelling for those with the right qualifications and access to resources, but generally those opportunities are still not available for the poor. The question is, is it possible to configure globalisation to be 'pro-poor'? Are there ways to make globalisation work for the poor? Clearly it cannot be considered as an automatic process. Those who are concerned with poverty alleviation will need to ensure that specific protections are in place to enable the poor to reap the benefits of globalisation. We will return to this in chapter four, as we look at what constitutes 'pro-poor' business. 


\section{Chapter 3: Is Global Trade the Answer to Global Poverty?}

\section{Introduction}

"In today's globalised world there is clear evidence that trade is a powerful engine for economic growth which is essential for poverty reduction"

Aid For Trade at a Glance 2007 (OECD \& World Trade Organisation, 2007, p. 31)

Numerous sources today promote the growth of world trade as the answer for global poverty. These range from the global monetary organisations like the IMF, the World Bank and the WTO, to the ODA providers from most of the developed countries, to NGOs involved in civil society responses to poverty, as well as writers on development theory. Each of these groups has a different perspective on how trade issues should be managed. This chapter will look at these groups, and the issues raised in relation to the promotion of trade as a solution to poverty. It begins with a discussion of neoliberal economic policy as the core philosophy behind the actions of the global monetary organisations, which drives their policy options in relation to the developing countries. World Bank predictions were that millions would be moved out of poverty through trade liberalisation. More recent analysts have toned these figures down considerably, but still support the principle of free trade as a poverty reduction tool.

Recent critique of neoliberal economics has been led by the Nobel prize winning economist Joseph Stiglitz. Stiglitz does not deny the potential of trade to alleviate poverty, but he considers that the hasty and ill-judged application of market liberalisation by the IMF was in most cases destructive of the economies of the developing countries they were supposed to be helping. Other researchers have argued that the developed economies themselves did not achieve their current position through the application of free market policy. An historical analysis shows that in almost all cases industrial and technological development took place behind protectionist barriers (Ha-Joon Chang, 2007; Green, 2008). A further line of discussion shows that increased trade does not inherently work to reduce poverty. In fact the competitive advantage generally goes to the stronger economy, not the weaker. 
This chapter examines each of these arguments in more detail, before finishing with a review of a study of the impact of the WTO Doha Round negotiations on the economies of the African countries. The Doha Round has been tagged as a 'development round', with the intention of addressing some of the issues raised by the developing countries. The study by Jensen and Gibbon concludes that the Doha round agenda largely misses out on addressing the real trade issues for Africa.

For trade to work as a solution to the issues of global poverty a different approach is needed. The next chapter introduces the concept of pro-poor growth, and the conditions needed to ensure that the gains from growth are equitably distributed. Alternative approaches are looked at to find various strategies that can be implemented to ensure a pro-poor dimension to the way the global business is conducted.

\section{Neoliberal Economic Policy}

The post World War II period saw the formation of a number of organisations designed to enhance peaceful international cooperation, beginning with the United Nations. A big concern was to avoid the economic stagnation of the Great Depression of the 1930s, which had been a contributing factor to the war, and so the planning which set up the United Nations also included setting up the financial and economic institutions of the World Bank and the International Monetary Fund (IMF). The intention was to also have an International Trade Organisation, the ITO. These three institutions were to form the foundation for international economic stability and cooperation, and between them were to be responsible for preventing another global depression. Joseph Stiglitz, who was an Economic Advisor to President Bill Clinton and Chief Economist and senior vice-president of the World Bank says of the IMF's role in global economic policy that "The IMF was founded on the belief that there was a need for collective action at the global level for economic stability, just as the United Nations had been founded on the belief that there was a need for collective action at the global level for political stability” (Stiglitz, 2003, pp. 12, emphasis in original). 
In setting up these organisations there was a recognition that to work effectively the global economy needed guidance, regulation and the ability to stimulate the economies of countries that were not working well to ensure that they were able to come up to speed. In the initial period this included a belief that market forces did not automatically work effectively, and so needed regulation.

However, since the 1980s the prevalent economic philosophy in these global financial institutions has been the free-market or neoliberal economics. At the core of this theory is the belief that 'market forces' will naturally seek to work in the most efficient ways. That is, they will seek the best combination of raw materials and labour for production, to be able to sell to the consumer at the most competitive price. Unlimited competition will ensure that the market will settle at an equilibrium point between these three forces of raw materials, labour and a competitive sales price. According to the theory, this will work to the advantage of the poor countries, as cheaper labour and access to raw materials ensures that they will be the most competitive producers. The theory of "comparative advantage' says that any trade is better than no trade, and that if everyone concentrates on the one thing that they are best at, and sells this on the market then everyone will benefit ${ }^{6}$. For this to work the market has to be free of any constraint or regulation. If a country tries to protect uncompetitive production by any form of subsidy, or to restrict the flow of goods from outside by any form of tariff, then this will create inefficiencies that will ultimately work to the disadvantage of that country. A WTO publication explains that any protection of producers by a country will inevitably lead to "bloated, inefficient producers supplying consumers with outdated, unattractive products" (WTO, 2007, p. 14). Similarly, within this philosophy, any government run enterprise will by definition be less efficient than one in private ownership. Employees within a state owned enterprise (SOE) will feel secure in their positions, and so will not be prepared to take the hard market decisions that are needed for optimum efficiency. Government should not be involved in the market place. Basically the role of

\footnotetext{
${ }^{6}$ Duncan Foley calls this "Adam's Fallacy", from the origins of neoliberal theory in the work of Adam Smith. "Neither Smith nor any of his successors has been able to demonstrate rigorously and robustly how private selfishness turns into public altruism'. Quoted in (Servaas Storm, 2008a p. 336)
} 
government should be reduced to the minimum required for the maintenance of law and order.

With this as their core philosophy the three institutions of World Bank, IMF and World Trade Organisation (WTO) have worked to promote neoliberal market policies globally. The IMF and World Bank have done this through the terms and conditions that they have applied on countries coming to them for loan and development finance. The WTO has done it through the negotiation of global trade rules that participating countries are required to sign up to. The core agenda for all three has been around the areas of fiscal austerity by government agencies, privatisation of state owned enterprise, the deregulation of market controls, and the opening up of international trade and investment in goods and services, including banking and financial services. This push to economic globalisation has not been driven by technological innovation or other market or social forces, but by their particular policy paradigm. "In this paradigm, trade and financial liberalization is seen, along with other market-based institutional reforms such as privatization, legal and other regulatory systems, as the sine qua non of a successful integration into a globalizing world economy" (Nissanke \& Thorbecke, 2005 , p. 4). It is a philosophy that has been pursued with what some would see as a 'missionary' zeal. The claimed benefits of the policy have been immense, but a lot of studies question whether these benefits are really being achieved.

As an example of the expected effect of neoliberal policy on global poverty we can look at World Bank predictions of the number of people that would be lifted out of poverty by trade liberalisation. In 2002 World Bank estimates were that the removal of all trade barriers and subsidies would lift 320 million people above the \$2 per day poverty line by 2015 (the MDG goal). This was clearly the way forward, and the way to achieve the MDG targets. However by 2004 they reduced this to 95 million people. The reasons given include the incorporation of new data on the effects of trade reforms that have happened already, including such changes as the phasing out of preferential quotas and agreements, and new estimates of poverty numbers (Dominique van der Mensbrugghe, 2005). There is now a wide divergence among economists about the degree to which trade liberalisation will help the poor, and the expected benefits have declined rapidly in more recent 
studies. Antoine Bouët of the International Food Policy Research Institute analyses 16 assessments and shows that even the most positive predictions for the percentage increase in world welfare as a result of trade reforms are declining as more information becomes available. This is partly because some of the tariff restrictions are not as great as once thought, and so the benefits of removing them will not be so great. The study, while acknowledging that the benefits will not be as great as once predicted, still recommends trade reform as the way forward. Bouët admits that some developing countries are likely to be hurt by the reforms. “...liberalization may reduce some countries' terms of trade because soaring world prices of agricultural commodities would hurt net food importers (such as Bangladesh, China, Mexico, and countries in the Middle East and North Africa) or because preferential access to certain markets could be eroded (such as in Bangladesh, Mexico, Tunisia, and countries in Sub-Saharan Africa outside the Southern African Customs Union)" (Bouët, 2006, p. 2).

Many of the pro-liberalisation studies point to rising GDP figures without analysing the distribution of the increase or who has really benefited by the growth in trade ${ }^{7}$. A study by Utsav and Misra examines wage increases in India following the Indian IMF mandated structural reforms of the early 1990s. "A growing body of research indicates that trade liberalization by developing countries has raised their aggregate incomes" (Kumar Utsav \& Prachi Misra, 2008). They find that trade liberalisation benefits have reached the poor. This is because the impact of tariff reductions was higher in sectors employing greater numbers of unskilled workers, raising wages in the unskilled sectors and reducing the differential between skilled and unskilled workers. A study of the effects of agricultural trade reforms on poverty in Brazil examined the concern that most of the benefits would go to large scale commercial farmers rather than to any of the country's smallholder farmers, thus exacerbating poverty issues in Brazil (Azzoni, Brooks et al., 2007). The study undertook a detailed analysis of effects on different urban and rural communities, and concluded that while this will be true to a certain degree, the gains for employment of agricultural labour will offset this

\footnotetext{
${ }^{7}$ Kaushik Basu argues that rather than GDP growth, a better measure of real growth would be the percentage of income accruing to the poorest $20 \%$ of the population. This gives an indication of the distribution of growth, and of real pro-poor development (Kaushik Basu, 2006).
} 
such that there will be no net effect on inequality within Brazil ${ }^{8}$. However other studies show an increasing gap between rich and poor in the developing countries ${ }^{9}$. The Utsav and Misra study looked at the differential between different categories of workers, not at the overall differential between rich and poor in the country. The analysis of Indian economic growth in the period 1991-2007 by Storm and Naastepad shows that industrial and agricultural workers did not in fact benefit much from this growth, which has mostly been in the services sectors, and the benefit has been for the middle classes. In fact it could be argued that by increasing the opportunities for unskilled labour there is a danger of eroding the skills base to the ultimate disadvantage of the country (Servaas Storm \& Naastepad, 2007).

\section{The Critique of Neoliberalism}

The IMF/World Bank application of neoliberal economic policy has been widely criticised. One of the most influential of these critics has been Joseph Stiglitz. Stiglitz, who as an economist supports the principles of the free market, finds that the way they have been applied by the global financial institutions has been destructive and inappropriate. His book, Globalisation and its Discontents documents the destructive trends of widening global inequalities caused by the IMF application of open market policies. He attributes most of the damage not to the policies themselves, but to the way they were implemented. He accuses the IMF of "decisions ... made on the basis of what seemed a curious blend of ideology and bad economics, dogma that sometimes seemed to be thinly veiling special interests" (p. xiii), and the developed countries of blatant hypocrisy (Stiglitz, 2003). He lists the following as some of the problems of economic globalisation:

- The failure of advanced countries to open up their own markets to goods from the developing countries while insisting that those countries open up their

${ }^{8}$ It should be noted that Brazil, with a Gini coefficient of 59.3, is ranked amongst the worst 20 countries in the world for inequality between rich and poor (see http://library.thinkquest.org/05aug/00282/flash_map.swf ). The results of the study can equally be interpreted as proving that improved agricultural trade conditions will not improve the status of Brazil's poor relative to their fellow citizens.

9 Hans Rosling on the Gapminder website has very graphic presentations analysing some of the trends and demonstrating increased wealth differentials within many of the developing countries www.gapminder.org/downloads/presentations/human-development-trends-2005.html 
markets. This has particularly been true in continued subsidies on agriculture while insisting that developing countries remove subsidies on industrial goods.

- The opening of financial markets has seen speculative capital flows from the wealthy countries. This capital has generated enormous wealth for the speculators at the expense of the stability of the developing country's economy. These short term capital flows contribute to the increased vulnerability to external shocks for the recipient developing country. The costs of this instability have been disproportionately borne by the poor (p. 65-67).

- The opening up of trade in services has been mainly for services exported by the advanced countries. Developing countries have not had a proportionate share of the gains (p. 61). This is true despite the increased 'off-shoring' of services that Friedman gets so excited about when he sees the call-centres of Bangalore, India (Friedman, 2006).

- The strengthening of intellectual property rights reflected the interests and perspectives of producers rather than of users (especially in the area of pharmaceutical products - protection did not result in any significant increase in sales to developing world, because they could no longer afford the costs).

- Loans for failed projects, while recommended, designed, financed and implemented by Western advisors still have to be repaid by the poor people in the developing world who have not had any benefit from the project (p. 8) there has been no requirement of accountability on those designing and implementing the projects.

- The policy of privatisation has assumed that markets will rise to meet every need, failing to recognise that in many instances government activities are there precisely because the markets have failed to provide essential services (p. 55). In general markets have been notoriously weak in meeting the large scale capital investment for infrastructure needs. 
- Regional trade agreements have not worked to the advantage of the poor countries. Stiglitz claims that Sub-Saharan Africa has seen its income decline by an average of more than $2 \%$ as a result of regional trade agreements. ${ }^{10}$

- The IMF prescription was applied in a 'one-size-fits-all' way that took no cognisance of individual country differences and needs. It was also applied as a 'shock-therapy' prescription, where all the provisions of the philosophy had to be met as soon as possible, regardless of the readiness of the wider legal and social framework. This pattern left disastrous loopholes for the unscrupulous to exploit, at the expense of the poor.

- Globalization benefits have been less than claimed, while the price paid has been greater than acknowledged by advocates. The effects of this are seen in terms of environmental destruction, corrupted political processes, and a rate of change too rapid to allow for cultural adaptation, which has lead to social dissolution and massive unemployment. ${ }^{11}$

\section{The Neoliberal Free Market is NOT how developed countries achieved development}

Ha-Joon Chang is a Korean-born economist who has analysed the process of development both for the Western industrialised countries and for the newly developed economies like Japan, Korea, China and India (Ha-Joon Chang, 2007). $\mathrm{He}$ argues that the theory that a free-market economy was the reason for the industrial growth of the developed countries is a myth and a re-writing of history. He goes back to the beginnings of the industrial revolution in England, and traces the establishment of the British textile industry to market protection and import substitution industrialisation policies put in place by Henry VII in 1489. Prior to that time England had been a primary producer, exporting raw wool to Europe for

\footnotetext{
10 "It is crucial to be mindful of the geopolitical agenda which propels the EPAs [Economic Partnership Agreements]. These agreements are being punted at a time when European markets are shrinking, production costs are making it difficult for companies to make a significant profit from Northern consumers and three successive World Trade Organisation (WTO) ministerial meetings have gone badly for corporate interests" (Burnett \& Manji, 2007, p. 125) The regional trade agreements are being negotiated by the developed countries in the face of resistance by the developing world to WTO pressures, in a classic situation of 'divide and rule'.

${ }^{11}$ Other writers support this: "Thus, an objective reading of the vast research effort to date suggests that there is no strong, robust and uniform support for the theoretical argument that financial globalization per se delivers a higher rate of economic growth" (Prasad, Rogoff et al., 2003 p. 8)
} 
manufacture by the industrial producers of the 'Low Countries' (modern Belgium and Netherlands), and using these exports to finance their imports. Henry VII banned raw wool exports, banned the export of unfinished cloth, and researched the best areas of England in which to set up the new textile industry, which was carefully nurtured and protected until it was able to compete on an even footing with world markets. A similar pattern occurred for the development of other industries. Chang traces the same pattern through the development of the other 'traditional' industrial countries of Europe and the United States.

While the colonial era is pointed to as a period of low tariffs, it was not a period of free market as claimed by many. The colonial powers always regulated the production and economies of the colonies to meet the needs of the 'Home' country. Chang points to British attempts to keep the American colonies as agricultural producers, feeding the British industrial workers, and to the British navy action against Chinese attempts to ban the import of opium, which was a key link in British imperial trade. The colonial period was good for the growth of trade, but was not a good time for per capita income growth in Africa or Asia (HaJoon Chang, 2007, p. 25).

As a Korean, Chang begins his book looking at the development of Korea, as a spectacular example of a newly industrialised country. Contrary to statements by neoliberal economists, Korean development took place under the rule of a dictator, with high tariffs and a very regulated financial market, right through until their industries were strong enough to compete on the open market. The same was true for Japan, and can be seen in the current growth of China and India. Chang compares the growth rates of countries that have followed the liberalisation policy, and finds that inevitably growth is slower following implementation of the policy.

So what about the theory of 'comparative advantage'? Chang says that the theory is correct for countries who accept their current level of technology as given, but that it fails when a country wants to acquire more advanced technology. The absorption of new technology requires a period of protection from competition. Protection is costly, in exactly the way the neoliberal theorists claim, but that cost has to be paid to develop advanced industries. "Ricardo's theory is ... for those 
who accept the status quo but not for those who want to change it" (Chang $\mathrm{p}$ $47)^{12}$.

\section{Increased trade will NOT automatically help the poor...}

Another line of argument questions the basic premise of the free market, that trade will benefit the poor. As early as 1968 Kitamura was arguing that the basic mechanisms of trade worked in favour of wealthy countries, not of the poorer countries. '...international trade, if not assisted by the consciously guided transfer of factors of production, has no inherent tendency to equalize income and productivity levels. Indeed the trade mechanism works the other way around - in favour of the progressive countries and against stagnant ones, ${ }^{13}$. A number of factors work towards this. Global capital is attracted to countries with capital intensive industry and a skilled labour force, not to countries that are primarily agricultural. Export production in the developing countries, particularly the former colonies of the West, has been dominated by foreign ownership. Most of this production has been in either mining or plantation agriculture, and the profits from production have been repatriated to the West, rather than reinvested in other areas of the host country. The 'competitive advantage' of the developing countries has worked to drive down the value of their primary produce, while not affecting the value of industrial imports. A Washington Post report on labour rights in Guatemala illustrates this. The Central American Free Trade Agreement (CAFTA) included provisions for the improvement of workers' rights and conditions. The reporter found that in fact the free trade agreement had been weak in its effects on labour rights, and had facilitated the movement of production to countries with the cheapest labour costs, a downward spiral to the worst conditions of exploitation. "Managers in Guatemala said foreign firms demand adherence to labor standards but also demand lower prices, with constant threats to shift work to China if the Guatemalan firms don't go along" (Goodman, 2007). Another Washington Post article reports on the threat to thousands of factories in China as wages and conditions improve there. "'You shouldn't see China anymore as a sweatshop," said Ronald R. Haddock, a vice president at Booz Allen

\footnotetext{
${ }^{12}$ Duncan Green, Growth, Trade, Integration and Policy Space (Green, 2008) takes up Chang's arguments and produces further examples of growth situations that did not follow market liberalisation.

${ }^{13}$ H Kitamura, quoted in (Colman \& Nixson, 1978) page 81
} 
Hamilton in Shanghai. "The guys and gals with spreadsheets on where the next incremental investments should go are saying there are lower-cost destinations to set up manufacturing"' (Ariana Eunjung Cha, 2008). In other words, the push is coming from the investors, and is always to move to the bottom; as soon as conditions start to improve the investors will move on. The consensus of this line of argument is that increased trade only reinforces the dominance of the developed countries.

It is worth noting here the qualification in Kitamura's statement. He is saying that free trade, without any regulation or other consideration, will not inherently work to help the poor. However he is also indicating that there is the potential to devise systems that will make trade work for development. What is needed is a consciously pro-poor structure, designed to ensure that there is a significant and directed return for the lower deciles of the population. In a similar way Stiglitz is also calling for changes to the system if it is to really work for the poor. He writes "I believe that globalization - the removal of barriers to free trade and the closer integration of national economies - can be a force for good and that it has the potential to enrich everyone in the world, particularly the poor. But I also believe that if this is to be the case, the way globalization has been managed, including the international trade agreements that have played such a large role in removing those barriers and the policies that have been imposed on developing countries in the process of globalization, need to be radically rethought." (Stiglitz, 2003, pp. ix-x).

\section{The WTO and the Doha Round}

In view of the fundamental core belief of neo-liberalism in the power of the free market, the irony is that the wealthy countries themselves have never been prepared to fully commit their own economies to the theory. Going right back to the immediate post-World War II period when the global financial and trade organisations were being set up, the negotiations for the setting up of the International Trading Organisation (ITO - the original concept for what eventually became the WTO) Charter fell down when in 1950 the United States announced that it would not ratify the proposed Charter because of perceived threats to their primary producers. In a pattern which has been consistently 
repeated in the decades since then the biggest economies have regularly moved to protect their own perceived interests, despite supposedly supporting the open market theory. They have done this while working to impose neo-liberal policies on the weaker economies. Instead of the ITO, world trade rules were decided by the GATT (General Agreement on Trade and Tariffs) negotiations until the WTO was finally set up in 1995.

GATT and the WTO were set up with the intention that they would ensure that all countries had equal opportunities in trade, and that unfair tariffs and restrictions were abolished. At the end of sixty years of negotiations there is increasing realisation that the system has not succeeded in benefiting the poor countries. The truth has been that all too often GATT and the WTO have "functioned ... as a forum for the industrial countries to negotiate product-based tariff concessions", with WTO regulation being used to enforce compliance (DiCaprio \& Gallagher, 2006 p. 785). Some recognition of this led to the Doha round of trade negotiations being declared as a 'development round' tasked specifically to address the problems of the poor countries, although as we shall see later many have seen this as window-dressing which is too little, too late, and often directed at the wrong issues.

There has been considerable discussion about why the developing world countries have not benefited more from GATT and WTO rulings. At one level it is pointed out that the theoretical conditions of free trade have not been met, in that the industrialised countries have continued to maintain tariffs and quotas on agricultural produce from the developing world, and subsidies for their own primary producers, while requiring that tariffs and subsidies on industrial goods should be removed. There have been various estimates of the value to poor countries if these trading inequalities were removed. An Oxfam study estimated that developed country protectionism was costing the developing countries US\$700 billion in annual export earnings (Oxfam International, 2001). A study by the Center for Global Development looks at various ways of measuring the effects of tariffs and subsidies, and develops a set of estimates that weights the effects in relation to production levels (Roodman, 2005). This study finds that tariffs are far more significant in their effects than subsidies. Roodman also concludes that New 
Zealand has the lowest protections of the developed nations, and Japan the highest, because of Japan's high barriers to rice imports.

\section{Aid for Trade}

The alternative interpretation put forward is that the developing countries have lacked the basic capacities needed to enable them to take advantage of existing trade opportunities. The capacity gap may be in policies, institutions or infrastructure, but the challenge is to meet these situations, and build the needed capacity. The call is for development assistance to focus on building market capability in the developing countries, and for a proportion of global official development assistance (ODA) to be directed to this purpose. Called 'Aid for Trade', an OECD/WTO publication puts this at an average of US\$ 21 billion per year between 2002 and 2005. This was directed to building economic infrastructure, promoting economic productive capacity and increased understanding and implementation of global trade policies and regulations. For OECD countries this averaged $31 \%$ of their sector allocable ODA (ranging from $8 \%$ for Greek ODA to $62 \%$ for Japan; New Zealand was allocating $14 \%$ of ODA to trade related issues). The global financial institutions were giving this an even higher priority, with $50 \%$ of World Bank sector programmes being targeted at trade related projects. The report expects this to grow significantly in the coming years, reaching US\$ 30 billion by 2010 (OECD \& World Trade Organisation, 2007). The costs of becoming competitive in the global market are high. Tariff reductions mean a loss of revenue for governments, while administrative costs are high.

Aid for Trade is also used as a way of recognising that there are costs to a developing country in the process of trade liberalisation, costs that will be incurred before the expected benefits of liberalisation kick in. Aid for Trade is used to cover the cost to the developing country of market restructuring. There are complaints that promises of Aid for Trade financing are being used as an incentive for poor countries to sign up to potentially unfavourable regional trade agreements. A Commonwealth Secretariat study estimates that the cost of adjustments for the African, Caribbean and Pacific (ACP) nations of compliance with the trade liberalisation conditions contained in Economic Partnership 
Agreements (EPAs) with the EU could amount to 9.2 billion Euros (Oxfam, 2007, p. 9).

\section{Africa and the Doha Round}

With this discussion in mind it is worth looking at a study that has examined the implications of WTO and Doha Round issues for the countries of Africa. A recent issue of Development Policy Review looks at this in an article by Michael Friis Jensen and Peter Gibbon. As mentioned above, the Doha Round has recognised that there are special issues for developing countries, and in theory is looking at making special provisions for them. Jensen and Gibbon argue that the selection of issues to make a "development round" was more a public relations exercise to mollify those countries who believed that they had been short changed in the Uruguay round rather then a considered approach to dealing with the development problems created by the multilateral trading system.

"The current configuration of issues on the negotiating table in Geneva is not a promising entry point to the development of African economies. This is not because more trade would not generate higher growth in Africa, but because African trade is unlikely to be seriously stimulated by any likely settlement of the issues remaining on the table ... some of the probable outcomes of the Doha Round are likely to hurt rather than to help Africa's global integration ...the reality [is] that the Doha Round agenda and the objectives of the main negotiating parties in relation to it do not address Africa's trade problems" (Jensen \& Gibbon, 2007, pp. 5,6)

They proceed to examine some of these issues. The first and perhaps most controversial is agricultural policies. One of the highest remaining areas of trade tariffs for industrial countries is agriculture. While other trade protections have generally been greatly reduced, tariff and non-tariff protections on agriculture have been steadily maintained by the US, the EU, and other countries of the G10. These take several forms. The primary one of course is import duties levied on agricultural produce from the developing nations. Alongside this are subsidies to agricultural producers in the developed countries, which lower international prices, and enable surplus produce to be put on the international market at lower than cost prices. Both of these (import duties and subsidies) are very clearly counter to basic WTO policy, and are the reverse of the policies advocated by the industrial nations in regard to their own industrial product exports, and to developing nation subsidies on industrial production. 
In Jensen and Gibbon's analysis, WTO moves to deal with agricultural issues encounter a mixed reaction from African countries, because most African countries are net importers of basic food crops. They, and other developing countries who are net food importers, risk losing out if world food prices rise. The average consumer in these countries benefits from the lower prices of subsidised imports. The problem was recognised even before the setting up of the WTO. In 1994 the Uruguay Round identified 'Net Food Importing Developing Countries' (NFIDCs) as having special issues and being eligible for special treatment, but Jensen and Gibbons point out that this decision has never been implemented in any practical way. What has come out of it is a definition of a category of "Reform Crops" as the products most likely to be affected by OECD agricultural liberalisation (Jensen \& Gibbon, 2007, p. 9). Only 11 African countries are net exporters of these basic food items, and so in a position to benefit from a reduction in OECD tariffs.

While the average consumer benefits from the dumping of subsidised food items in the African market, the African farmer is hurt, and is forced to turn to planting export crops, which are then hit by developed country tariffs, and also in turn reduces the availability of local food crops and increases dependency on the subsidised imports. This is the vicious cycle which hits the less developed countries, building greater dependency, and ultimately putting them still further into debt.

Jensen and Gibbon do not get into discussion of this aspect, but rather move on to look at the erosion of existing African preferential trade agreements caused by WTO moves to standardise tariff liberalisation. Sub Saharan Africa nations have had a range of preferential access agreements which for some products have given them a significant margin over standard tariffs. They look at a number of studies around the degree to which these preferential arrangements have been utilised, and how effective they have been in building significant market diversification. They conclude that the schemes that were not well utilised were the ones where the margin of preference being offered was not enough to balance the costs of compliance and the hassles of dealing with regulatory obstacles. Margins of less than $5 \%$ over the standard tariff are not enough of an incentive. Where margins 
reached $10 \%$ there was significant uptake and good growth of exports. The neoliberal argument against preferential trade agreements is that "they encourage the growth of sectors that are globally non-competitive", and so are in the long term counter-productive. The study which Jensen and Gibbon do of African textile and clothing exports to the US indicates that preferential quota and tariff margins have not had this negative effect, but rather have been successful in stimulating export diversification.

\section{Regional Trade Agreements}

The Doha Round negotiations have stalled over the failure of the big industrial countries to reach agreement on the ending of agricultural subsidies. The large developing countries, Brazil, China and India, have been flexing their muscle and insisting on progress in areas they consider important before they will consider other issues. APEC ministers and others have had meetings to try and revive the Doha negotiations, but many see an increasing trend to the negotiation of regional trade agreements, as a way of bypassing the blocked Doha Round talks. The European Union has been negotiating Economic Partnership Agreements (EPAs) with African trade ministers. African leaders have expressed two concerns about this. Firstly they are undermining the solidarity of the ACPA (African, Caribbean and Pacific Alliance), and so weakening the bargaining power of the least developed nations. Secondly reciprocal free trade agreements between regions with unequal levels of development in fact damage the less developed economies. Some have seen the regional trade agreements as primarily designed to increase the spheres of influence of the wealthy nations ${ }^{14}$. Some fear that these EPAs could lead to losses of revenue of up to $30.5 \%$ for sub-Saharan Africa. The NGOs have been particularly strong in speaking out against the proliferation of regional trade agreements (Oxfam, 2006; Burnett \& Manji, 2007; Ecumenical News International, 2007; Oxfam, 2007, 2008).

\footnotetext{
14 “Since 2001 ... Bush has pursued a trade policy known as Competitive Liberalization. This policy envisages a series of mutually-reinforcing and sequential steps to ... place the United States at the centre of the world trading system. ... In sum ... the Bush Administration wanted ... to reassert its central position as the writer of rules for the world trading system". The policy of 'Competitive Liberalisation' is about establishing regional trade agreements. (Evenett \& Meier, 2008).
} 


\section{Conclusion}

It is clear from these two chapters on globalisation and the world markets that while there seem to be enormous opportunities for the reduction of poverty through the processes of economic growth, these are not happening in the ways predicted by the theories. There is a strong argument that what is needed are distinct pro-poor policies that will ensure an equitable distribution of the gains from global economic growth. This concept of pro-poor growth is the subject of the next chapter. 


\section{Chapter 4: Can Trade be Made Pro-Poor?}

Alternative approaches to trade as the solution to poverty are proposed by many Non-Government Organisations (NGOs). These include the Fair Trade movement and associated alternative trading organisations (ATOs). Fair Trade is promoted as a way of ensuring a larger return to the primary producer. This is done by promoting producer cooperatives to improve systems at the producer end, and by appealing to the social consciences of consumers in the developed world so that they will be prepared to pay a "social justice" premium on Fair Trade products. With this appeal to social justice, Fair Trade works to bring together the interests of both the producers and the consumers.

Fair Trade has tended to focus on primary producers, and agricultural products. Certainly in the liberalisation of global markets agricultural goods have been one of the areas where the developing countries have faced the greatest inequities. Developed countries, while pushing hard for tariff reductions on manufactured goods, have wanted to continue to protect their own agricultural producers. Fair Trade's focus on getting a better deal for farmers in the developing world has been a necessary counter. However Fair Trade can become something of a niche market. To truly tackle the problem of poverty requires an approach that moves the ethical base for Fair Trade beyond the niche into the mainstream of business. Economic globalisation has been built on the exploitation of inequality. How can all businesses introduce an ethical approach to the issues of equity? Is it possible to build a pro-poor dimension into the way that global business is conducted? This chapter will discuss definitions of pro-poor growth, the opportunities for investment in pro-poor business, and the role that small-to-medium enterprises (SMEs) can have in development.

In the preceding chapter we have seen that while trade has been promoted as the answer to global poverty, the reality has fallen far short of the mark. Global trading systems have been more inclined to work to the advantage of the wealthy and the exploitation of the poor. At the same time even critics of the system have also indicated that it can be made to work. Stiglitz, the economist, says that it is a matter of ensuring that the appropriate structural and legal framework is in place. He acknowledges that this will require a radical rethinking by global financial 
organisations, and a new approach to the legal and economic framework needed in developing countries. The NGOs like Oxfam point out the disparities in the system, but still advocate that these disparities can be balanced in ways that will bring equity for the poor ${ }^{15}$. Is it enough to deal with problems in the system, or does the system itself need to be modified to make it pro-poor? Can there be such a thing as pro-poor economic growth, built on pro-poor trade policies? What would be the necessary conditions for this to happen? There is considerable debate about this. While there are many who consider that it will be enough if the inconsistencies in the system are removed, and unequal trade restrictions removed, there are others who consider that even a perfectly balanced playing field is not enough. The lower capacities of the poor mean that even on a level playing field they will consistently slide backwards. Nissanke and Thorbecke argue that there is a complex balance of issues between poverty, growth and inequality. 'Pro-poor' must include positive steps in favour of the poor. Poverty reduction requires a combination of both growth and some form of pro-poor distribution of the gains from growth. They argue that "growth is considered propoor if it, in addition to reducing poverty, also decreases inequality" (Nissanke \& Thorbecke, 2005, pp. 12-13).

This is not a new concept, as is shown in the obituary of Sukhamoy Chakravarty written by Storm and Naastepad. They write that "In Chakravarty's view, marketled growth does not automatically imply or ensure development, which to him meant, in a fundamental sense, 'the capacity to expand the area of choice for vast numbers of people who live a constrained existence' due to mass poverty, malnutrition and unemployment". In fact for Chakravarty growth that does not consider issues of equity will ultimately be less effective than growth that gives priority to social equity and improving the conditions of the poor (Servaas Storm \& Naastepad, 2007, p. 1173). Chakravarty emphasised planning for inclusive growth, rather than uncontrolled, market-led, growth. Storm and Naastepad's analysis of Indian growth in the period 1991-2007 shows that much of the

\footnotetext{
${ }^{15}$ Several Oxfam reports support this. A 2005 Oxfam document urging changes to EU policy is mostly directed at issues in WTO and EU policy which are seen as having inequitable implications for developing countries. It affirms that "in the right circumstances, trade can be vital to poverty reduction" if the rich countries will stop pursuing their own short term interests against the interests of the poor countries (Fowler, 2001; Collins, Stuart et al., 2005, p. 19)
} 
apparently high rate of growth in this period has been based on unsustainable fiscal policy. Growth has been import intensive, focussed primarily on the services sector to the exclusion of both agriculture and industry, both of which have suffered. Growth has not created proportionate growth in employment opportunities or increase in domestic technological capability. While there has been spectacular growth of middle class incomes, both agricultural and industrial workers have seen increased poverty. Their conclusion is that "the greatly enhanced inequalities in the distribution of income, employment and wealth may eventually undermine the growth process as they increase the risk of social and political disruption" ( $p$ 1184). This conclusion is reinforced by the UNDP sponsored West Bengal Human Development Report analysis of the situation in the Indian state of West Bengal (Ghosh, 2004) ${ }^{16}$.

Growing inequality has been a feature of globalisation. Even where on a national level there has been a growth in such measures as GDP, there has also been widespread increase in inequality (Gilbert, 2007). It is this increased inequality that is seen by many as an issue of justice and fairness. Widening inequality disempowers the poor, and in turn accelerates the growth of disparities. There is a strong argument that attention to issues of fairness and justice for the poor can be a win-win scenario that will not sacrifice growth, but may even enhance it. Birdsall, De la Torre et al. (2008) argue that without attention to issues of fairness the process of integration of the Latin American countries into the global economy will increase economic insecurity and produce more losers than winners. They believe that there is a realistic win-win alternative that will not sacrifice overall growth because it is "not a matter of money but of the rules of the game and of political and civic leadership" (Birdsall, De la Torre et al., 2008, p. 28).

The report from the Allen Consulting Group in Australia Business for Poverty Relief: a business case for business action agrees, and proposes a set of what they call "Positive Business Practices" which are best practice standards able to be implemented by any company concerned with operating in ethical ways in developing countries (Figure 4:1). These consist of both ethical business practice, such as ensuring that they pay local taxes without the financial juggling that some

\footnotetext{
${ }^{16}$ See Appendix three, section on West Bengal
} 
TNCs are able to engage in, and ensuring that the company actively chooses options that will build pro-poor growth.

"These 'business as usual' activities do not necessarily involve any element of philanthropy; rather, they require businesses to be aware of the positive long-term value of enlightened practices, a country's development needs and to conduct their operations in a manner consistent with these" (p23); "the necessary steps need not be difficult, or expensive. Indeed, they often make sound business sense. (p44)"; "Through nothing other than by thinking constructively about, or in some cases reconfiguring, their core business activities, companies can supply affordable products and services to the poor, provide best practice working conditions for locals, and invest in the skills, infrastructure and technologies that will underpin future growth. The 'business of doing business' in developing markets will best and most sustainably overcome poverty in poor communities provided that companies adhere to enlightened practice in their supply chains." (The Allen Consulting Group, 2007, p. 33).

Figure 4:1 Pro-poor Business Practice

\section{Positive Business Practices}

- generating income and investment - through paying local wages, taxes, dividends, and royalties, making timely payment to local suppliers, and earning foreign exchange;

- creating jobs - recruiting locally, both within the company and along the supply chain, and facilitating positive organised labour relations;

- developing human resources - investing in training, skills development, health and safety in the workplace and along the supply chain;

- building local businesses - through supplier and distribution networks, especially with medium, small and micro-enterprises;

- spreading responsible international business standards and practices - in areas such as environment, health and safety management, human rights, ethics and quality;

- supporting technology development and transfer - investing in local research and development and introducing technologies and processes for cleaner and safer production systems; and

- establishing physical and institutional infrastructure - for example investing in plant and machinery, telecommunications and transport systems, and legal and financial frameworks and institutions. 
Karen Ellis of the British Overseas Development Institute, in an opinion piece published in April 2008 proposes a 'development impact assessment' for businesses, which could lead to the award of a 'Good for Development' product label similar to the Fairtrade labelling systems. The proposed development impact assessment covers similar issues to the 'Positive Business Practices' of the Allen Consulting group, but adds items like preferential use of local inputs, and reinvestment of earnings in the developing country. Ellis says of the 'Good for Development' product labelling idea "The best way to improve business development impact is to create mechanisms that reward businesses financially for increasing their contribution to development" (Ellis, 2008 p. 1) ${ }^{17}$.

How is this seen as being a win-win situation for business? The World Business Council for Sustainable Development (WBCSD) points out that most businesses are competing more and more fiercely for smaller and smaller markets, while the most obvious way to grow the size of world markets is to reduce poverty so that the poor are able to join mainstream markets. They talk about "Sustainable Livelihoods" business as "doing business with the poor in ways that benefit the poor and benefit the company", and go on to say: "WBCSD believe that globalization can be made more inclusive and that the leading global companies of the future will be those that do business in ways that address the world's major challenges, including poverty and inequity. Through its core operations, business can build capacity, grow markets and empower people to help them to move into formal economic activities" to resources to help companies understand development issues, and ways for business to link with development oriented organisations. Both the WBCSD and the Allen Consulting Group Report talk of best business practice as 'corporate citizenship' and as an essential part of a company's 'license to operate' in developing countries.

\footnotetext{
${ }^{17}$ Simon Maxwell, ODI Director, Stepping up the ladder: how business can help achieve the $M D G s$ sees four steps to engaging business in development issues. The first is traditional philanthropy, with corporate sponsorship of community causes; the second is in terms of CSR policies and good global citizenship; the third is intentional policies with development impact ('making business partners in development') as discussed in the Ellis paper; the fourth step is engaging business in creative ways with public policy issues (Maxwell, 2008).

${ }^{18}$ www.wbcsd.org link to publications. Accessed 16 May 2008
} 
"Business cannot solve poverty but poverty will not be solved without business. Business can design affordable products and penetrate new markets and it can seek out new sources of supply and service provision from low-income communities. This is both good business and good for development." www.wbcsd.org link to 'Development Overview, 19

The creation of employment opportunities is perhaps one of the first indicators of pro-poor economic policy. This is the theme of two books reviewed in the March 2008 issue of Development and Change. The first, reviewed by James Heintz, is Fighting Poverty: The Development-employment Link by Rizwanul Islam. "The core message ... is that employment is of paramount importance in any growth strategy that aims to reduce poverty and mitigate inequalities. Economic growth is necessary, but not sufficient, for achieving poverty reduction targets" (Heintz, 2008, p. 338). A pro-poor growth policy will improve employment opportunities and increase the returns to labour, as labour is the one production resource that is available to the poor. The second book backs this up with a study of the Indian situation. Development with Dignity: A Case for Full Employment by Amit Bhaduri is reviewed by Servaas Storm. Storm writes "While poverty is claimed to have fallen, per capita food consumption in India is down to the level where it was more than sixty years ago. No honest observer can avoid seeing that India's (liberal) economic policies, while delivering growth, do not lead to 'development with dignity' - if by this we mean increased productivity and decent employment for the masses and the eradication of poverty, illiteracy and malnourishment" (Servaas Storm, 2008b, p. 342). Bhaduri argues that redistribution by various forms of income transfer to the poor neither achieves growth, nor does it help the poor in any sustainable way. Both growth and sustainable help for the poor will be achieved by an integration of growth and employment objectives that target the under- or un-employed poor. In a country the size of India this cannot be built only on export demand, which is founded on labour market flexibility and low wage structures, but has to include growth of a domestic market.

\footnotetext{
${ }^{19}$ The full link for this quote (accessed 16 May 2007) is http://www.wbcsd.org/templates/TemplateWBCSD5/layout.asp?type=p\&MenuId=Mjg5\&doOp $\underline{\text { en }=1 \& \text { ClickMenu}=\text { LeftMenu }}$
} 


\section{The Alternative Trading Organisations (ATOs)}

In response to the perceived inequities of the global market systems there have been a number of attempts at building alternatives. These all have the aim of ensuring a higher return to the developing country producer, whether of primary food products, handcrafts, or some other more technological product. In general there are three ways that this return can be achieved. One is to assist with improved production techniques and processes (to improve worker productivity). This can be in the form of agricultural advice for primary producers, or of training opportunities for others in the production chain. The second is to find ways of shortening the commodity chain from producer to consumer by cutting out some of the intermediary processes, or by working to give the producer more control over these stages. This is generally done by the formation of cooperatives which can then take responsibility for more of the collection and export procedures. The third method of ensuring a better return is to appeal to consumers to be prepared to pay an 'ethical margin' on fair traded goods. Many consumers in the affluent countries, when given information on the exploitative conditions of third world producers, are prepared to pay a margin on the price of goods to ensure that the producer gets a better return.

The Trade Aid shops in New Zealand are one example of an ATO. Set up in the early 1970 s as a result of a New Zealand couple going to India to assist in the resettlement of Tibetan refugees, today Trade Aid has a chain of shops right through New Zealand selling a wide range of arts, crafts and food items.

The principles of 'Fair Trade' are:

- Creating opportunities for economically disadvantaged producers. They will look for people who are marginalised by the conventional trading system. This will usually be small scale producers in areas with limited access to commercial markets.

- Payment of a fair price. A fair price is agreed with the producers through dialogue, and is a price that not only covers the costs of production, but takes into account issues of social justice. This is combined with long-term purchasing agreements to give producers some guarantee of stability of 
prices and of sales volumes. The price will be at an agreed margin over that available through purely commercial transactions. Issues of price include ensuring that producers have access to and a full understanding of market information, so that pricing decisions can be transparent.

- Capacity building. They will look to helping producers to develop their skills and access to markets. The aim is to empower rather than to exploit the producers, and to equip them to also enter the mainstream markets and gain a fairer return from this.

- Some of the benefit from increased prices is expected to go into community development. This may be in the form of medical or educational services, or in other areas of community development.

- Environmentally sustainable. They look to have environmentally responsible methods of production and waste disposal.

- Giving a high regard for issues of human rights, such as gender equity, child labour, health and safety in work conditions, and the right to collective bargaining. Issues of gender equity are particularly important in many of the societies where their producers live. In the area of handcrafts women are often the key producers, and Fair Trade works to ensure that this is recognised, and that the women doing the work are empowered in the organisations they work in.

- Transparency and accountability between the organisation and their trading partners.

- Information campaigns and advice for consumers in the developed world, including lobbying governments and corporations for better trade conditions for the developing world. This advocacy role is an important one, as it extends the impact of fair trade far beyond the relatively small portion of market volume that it represents.

(Bird \& Hughes, 1997; Lyon, 2006; Trade Aid, n.d.) 
Some ATOs, like Trade Aid, cover the import and sale of a wide range of products. Others have specialised in particular products, like coffee. Some, again like Trade Aid, have set up their own chain of retail stores, others aim to sell Fair Trade products to the supermarket chains or individual retail outlets. Fair Trade certification is offered by Fairtrade Labelling Organisations International (FLO), which is a grouping of most of the organisations involved in promoting Fair Trade. They aim to guarantee standards, both in the quality of the goods delivered to the consumer, and also in the standards of interaction with the producers, and the return to them. There are several associations making up the FLO. IFAT, the International Fair Trade Association claims to have a global network of over 270 organisations in 60 countries, representing both the developed and the underdeveloped nations. Their claim is that IFAT's mission is to improve the livelihoods and well being of disadvantaged producers by linking and promoting Fair Trade Organizations, and speaking out for greater justice in world trade.

'IFAT members have the concept of 'fair trade' at the heart of their mission and at the core of what they do. They come in many shapes and sizes and represent the fair trade chain from product to sale. They are producer co-operatives and associations, export marketing companies, importers, retailers, national and regional fair trade networks, financial institutions and other support organizations, dedicated to the fair trade movement. IFAT members trade in a wide variety of fair trade goods, including giftware, household goods, furniture, garments, jewellery, food and beverages. They all adhere to IFAT's code of Practice, developed by the members themselves." 20

The Fair Trade ATOs are part of a wider, growing movement that is reacting against a variety of issues that are seen by developed world consumers as unjust, dangerous or environmentally unsustainable. They include issues like organic farming and environmental concerns alongside ethical issues of cruelty to animals used in research and the sweatshop labour conditions of global production. There are organizations like the Body Shop, which bring together a variety of these related issues as well as fair trade. This emphasis on ethical consumerism is seen as a small but growing portion of the market in some Western countries. The study by Bird and Hughes (1997) quotes a 1995 survey of British consumers which found that $23 \%$ of those surveyed were committed to buying ethically

\footnotetext{
${ }^{20}$ See the New Zealand Fair Trade Association website: www.fta.org.nz/IFAT?PHPSESSID=e1a5818184e92b0d809432f69cd4c8ba
} 
traded goods wherever possible, while a further $56 \%$ were classified as 'semiethical' (supported ethical trade in principle, but would not necessarily go out of their way to buy), leaving only $21 \%$ who either didn't care or didn't know. The same survey indicated that consumers committed to ethical products were prepared to pay premiums of between 10 and $18 \%$ above market rates for similar products.

More recent figures show that support for Fair Trade has continued to grow. Fairtrade sales in the UK reached GBP 490 million in 2007, an increase of $80 \%$ on the previous year (Susie Mesure \& Steve Bloomfield, 2008). This increase has come as supermarket chains and other corporate retailers have come on board and begun to include Fairtrade items as part of their regular stock. The growth has been so dramatic that cynics have started to question the reality of some of the claims. Certainly for the corporates this is a way to "paint themselves a greener hue', and portray themselves as having a concern for social and ethical issues, but there have been questions about how much of the Fairtrade markup actually goes back to the producers, and accusations that some of the chains have been profiteering on the brand ${ }^{21}$. The real victory for Fairtrade will be when the corporate retailers do not just agree to stock the products, but also buy into the principles of Fairtrade by reducing their margins to increase the proportion that the producers are able to receive. Mesure and Bloomfield quote Claire Melamed, head of trade and corporates at ActionAid, as saying: "Fairtrade is still essentially a niche product. The challenge is to get all trade conducted according to much fairer principles."

\section{Small to medium enterprise (SMEs) as an opportunity}

This point brings me to the second issue for pro-poor policy that I want to highlight, which is the opportunities for poverty reduction and economic growth in developing countries provided by small to medium enterprises (SMEs). Inevitably capital investment by the multi-national corporations is technology intensive, not labour intensive. Technology is capital intensive, and is intended to

${ }^{21}$ Carolyn Fisher writes of one perspective on Fairtrade as "the commodification of activism" (Fisher, 2007). 
increase the productivity output per employee, so that fewer employees are required for the same outputs. The use of technological processes also tends to require higher education levels, which again bypasses the poorest communities. SMEs, while individually small in size, in fact account for the majority of all global production. "According to the United Nations Industrial Development Organization (UNIDO), SMEs make up more than 90 percent of businesses worldwide and on average account for 50 percent of Gross Domestic Product (GDP) of all countries and for 60 percent of their employment" ${ }^{22}$. SMEs fill a valuable niche that has lower requirements for capital inputs and can provide employment opportunities that are not possible in the large-scale sector. A UNESCAP publication says

"[SMEs] are especially important in the less developed economies and economies in transition, where they produce the bulk of manufactured products, have high labour absorption and are mostly in the private sector, thus giving impetus to privatization." (United Nations Economic and Social Commission for Asia and the Pacific, nd, p. 31)

SMEs have an important role in global supply chains, generally being at the point of production for many multinational enterprises (MNE) who contract out the stages of their supply chains. They are often producing the bulk of the components or services that go into the final product for an MNE. "...most of the economic, environmental and social impacts of MNEs occur through their supply chain and a significant proportion occurs through SMEs in those chains" (Plugge \& Wiemer, 2008, p. 6). The UNESCAP report quoted above sees SMEs as the future focus for private sector development because of their potential to contribute to industrial growth. They see a valuable role in both government and private provision of Business Incubators and business development services (BDS) as ways of encouraging and supporting the growth of SMEs. "BDS ... assist in increasing the effectiveness and competitiveness of SMEs, thus increasing employment and contributing to poverty reduction in developing countries" (UNESCAP op.cit. p. 51). An ILO and World Bank sponsored report looks at

\footnotetext{
${ }^{22}$ Quoted in (Plugge \& Wiemer, 2008, p. 5). See also the World Business Council for Sustainable Development website www.wbcsd.org which quotes an even higher figure of $95 \%$ of private sector firms being SMEs. They say that SMEs "have a key role to play in poverty alleviation by promoting economic growth that is inclusive and reaches the majority of people".
} 
issues in the provision of BDS services for SMEs by donors like the World Bank (Tanburn, Trah et al., 2001).

SMEs then, even when they are a part of the multi-national supply chain, are at the front end of the opportunity to impact on poverty. They are in the best position to provide employment opportunities, and are able to operate in the communities that most need these opportunities. They are the key tool in building pro-poor business.

\section{Social Entrepreneurs - Agents of Change}

"Social entrepreneurs work at the bleeding edge of the market, where the risks are the greatest but the potential positive social impact is also enormous. These are men and women who seize the problems created by change as opportunities to transform societies" ${ }^{\prime 23}$.

SMEs have another role to play in the development of pro-poor business, in that they are a key venue for entrepreneurial actors. The economist Joseph Schumpeter (1883 - 1950) developed the concept of entrepreneurship, defining entrepreneurs as agents of innovation and technological change. The age of globalisation is one that puts a high value on change, and on finding new ways to do things. Entrepreneurs are people who find new ways of doing things, people who want to move things forward. SMEs have often been the places where their ideas can be tried out. This has been true in the scientific and business fields, but the concept has been extended to 'social entrepreneurs' as people who look to bring change to social systems and practices.

This carries through to the concept of "businesses that are formed to generate social value, not just to generate profits" ${ }^{\prime 2}$. These are the pro-poor businesses, where new ways of doing things can be put forward in contexts that will work for those on the margins. The Schwab Foundation is an example of an organisation set up to promote this concept of business enterprise that is committed to working for social change. They put forward the idea of 'social enterprises':

\footnotetext{
${ }^{23}$ Pamela Hartigan, Managing Director, Schwab Foundation for Social Entrepreneurship, quoted in (Carmichael \& Rice, 2006 p.2)

${ }^{24}$ See the website of the Social Enterprise Alliance, www.sealliance.org/about_leading.cfm\#businesses
} 
Most social enterprises are hybrid organisations. That is to say, they operate along business lines and may indeed aim to make a profit, but their primary goal is to promote social change. ... Both not-for-profit and forprofit hybrids apply innovative, transformational approaches to address government or market failures to provide goods, services and opportunities to excluded or marginalised sections of society.

For many social entrepreneurs, charity is essentially about philanthropy, whereas social enterprise is about empowering people who are socially disadvantaged to improve their financial, social and moral status and well being. These entrepreneurs are individuals who seize the initiative to tackle the problems affecting those who are socially disadvantaged.

(Carmichael \& Rice, 2006, pp. 1, 2)

The case studies in chapter six are all examples of this concept of social, entrepreneurial, enterprises. Chapter six describes these businesses, and then chapter seven looks at some of the issues they face, and the ways in which they can be seen as 'making business work for development'.

\section{Conclusion}

The premise of the ATOs is that the global trading system works against the needs of small producers. They aim to supply a balance to this, and to demonstrate to consumers in the developed world that an alternative is possible. They are here consciously tapping into consumer resistance to globalisation trends, with the appeal that it is possible to be a part of making a difference. The ATOs appeal to consumer anxieties about free trade and mega-corporate globalisation, and offer a counter to feelings of helplessness in the face of global trends with the opportunity to do something tangible and within the reach of every consumer. Fair Trade advertising also appeals to consumers who want to make definitive lifestyle and identity choices. The advertising presents consumers with information about the producers in order to emphasis the disparities and to promote the difference that can be made through the fair trade system (Lyon, 2006). While the percentage of fair traded product remains relatively small, the expectation is that by its existence fair trade will raise consumer awareness and provoke the larger players in the market into taking steps to move towards giving their producers a fairer return. 
Pro-poor business is not just possible. In the long term it makes good business sense. However it does require a change in perspective on the part of business management, away from short term profit gains to a long term perspective that can see the development of the community as building future market potential. This is a very different perspective to that of the developed world company moving its production off-shore to a developing country. Such a move does create employment opportunities in the developing country - even if the employment is in 'sweat-shop' conditions that many will be forced to choose as better than the option of unemployed poverty. The off-shore producer is aiming to exploit the low-wage conditions of one country in order to gain a competitive price advantage in the other, a situation geared to short term gain in ways that do not ultimately work to build the growth of either country. The vision of pro-poor business proposed here is entirely different dimension. This is looking to build a sustainable market, where the developing world is not simply a source of cheap labour, but rather a future customer, a market to be nurtured and helped to grow to the point where it can become a full partner in a globalised world. Poverty excludes people from full participation in the global marketplace, even while exploiting them. The aim of pro-poor business is to create the conditions for inclusion, in ways that will bring justice and opportunity for a fair portion of global resources.

The initiative for pro-poor business is often taken by social entrepreneurs. These are people who look for innovative ways to make the market work for the poor, people who want to see that the benefits of globalisation can indeed alleviate global poverty. 


\section{Chapter 5: Methodology}

This study examined businesses which had been begun by expatriates with entrepreneurial ability and a concern for poverty issues in Asia. I was aware of several instances from personal contact, and wanted to explore issues around their success or otherwise, and measures that could be used to evaluate them. The approach is based on a qualitative examination of a limited number of case studies, and uses these to identify and explore issues faced by this form of business venture in answering the question 'Can business work for development?'

The method used for the study was a postal/emailed questionnaire sent out to known organisations who were willing to participate. The questionnaire was then followed up with further emails, and $S k y p e^{25}$ or phone calls to explore and clarify additional points that came up.

This chapter will look at the selection of participants and the design of the questionnaire, followed by a brief analysis of the number of responses. The following chapter contains a detailed discussion of the companies that responded, and the issues that were discovered.

\section{Selection of Participants}

Three of the participating companies were already known to me through contact with the people involved. When the study began I invited them to participate and also asked for information about other companies working in similar areas. In addition as I talked about the proposal in various places I was told of other similar ventures. The final selection of the six companies that are included was based on the ability to use them to illustrate the wide range of issues and formats that can be involved.

The first issue in the selection was the variety of different types of business. The companies here are involved in four broad areas of business: primary agricultural production (coffee); production of items for export (scented candles, fashion

\footnotetext{
${ }^{25}$ Skype is a computer programme enabling telephone contact via the internet. Particularly for people with access to broadband internet service, these calls cost no more than what is already being paid for internet access. The programme is available as a free download from www.skype.com.
} 
accessories and garments); technology transfer (engineering services and soy milk production); and provision of services (English language teaching).

The second issue in selection of participants was the scale of enterprise that is involved. The companies selected are all the category known as SMEs - Small to Medium Enterprises. Within this category the selected companies cover a range of sizes from extremely small, barely more than what might be classed as microenterprise, through to an extensive business attracting capital input from multinational business concerns and from the International Finance Corporation (IFC).

A third issue is the degree of intentionality in directly targeting poverty issues. These businesses are all choosing to operate in the developing world, and see that as a contribution to the development of the host country. However some of them are being even more intentional in choosing specific communities of poverty or exploitation within which to operate.

Finally the choice of participants illustrates degrees of success (at the time of writing one of the case study companies is in the process of closing down, although they are still looking at the possibility of re-opening in some new format), and the need to be able to adapt with changing circumstances and a changing perception of the needs of the target community (during the course of the study one company has changed its approach to a producer cooperative format).

\section{The Questionnaire}

The questionnaire was designed to elicit information on three areas. The first of these is basic information about the structure and finances of the company. The second part looked at the vision and goals of the company, and asked for some evaluation of progress towards these goals. The final section of the questionnaire looked at development outcomes, and was looking to assess the perceived effectiveness of the business as a development tool. With the questionnaire, participants were sent an information sheet about the purposes of the study, and were required to sign a consent form relating to the use of the information given. This package of three documents is attached as Appendix 1. 


\section{Section I: Company Information}

As well as the basic information about the name, registration, business and history of the company, this section asked about the governance of the company. Who are the Directors, how are they appointed, and are they accountable to anyone else? Business governance can be a complicated issue. A small owner-operated business can be in the situation of having a single person as Board of Directors and CEO, with no accountability beyond making enough profit to keep in business. Larger businesses have responsibility to their funding sources, whether these are listed shareholders or parent agencies, and make reports accordingly. Business accountability to customers is usually limited to the market assumption that dissatisfied customers will go elsewhere. However the businesses in this study have an explicit social objective, and so it becomes a valid question to ask about their accountability in this sphere, as well as their accountability to their funding sources. I approached this question from various angles in each section of the questionnaire, to get different views. It is explored further in Section III, the development issues.

Section I also explored the company finances. Money is the 'bottom line' for most commercial enterprises. How do these companies fare when considered as commercial enterprises? What sort of capital investment has been involved? What sort of return do they manage? Profit is not their only motive, and perhaps not even their primary one, but if the business is to be sustainable the business activity must at least break even.

Finally in Section I was a question about people. Question 1.7.1 asked about who they were aiming to help when they set up the business. It is possibly a question that is more relevant to the Development Issues section, as it introduces the issue of motive, and also how the expected beneficiaries of the project were selected.

The rest of this question (1.7.2) related to the number of staff employed, and the wider community that is involved in the company, directly or indirectly.

\section{Section II: Company Vision, Goals, and Evaluation}

In management practice it is accepted that a successful organisation or project will have a clear vision statement setting out the over-arching intention behind the 
organisation. This needs to be clear enough to enable the organisation to set itself goals and targets that it wants to achieve, and to assist it in avoiding activities that are irrelevant to that founding vision. It also needs to be broad enough and flexible enough to cope with changing circumstances and complex issues.

What was the intention of the company when it was founded? What goals did they set themselves? Were any of these published in a format for fundraising or registration purposes? These are key questions that define parameters for evaluating the company. To what extent were poverty alleviation, human rights or other development related issues intentionally identified in the founding documents of these companies? Were these development issues seen as a core part of the vision of the company, or are they seen as a positive flow-on from a successful business venture, with the business itself being seen as the core vision? Do the companies use their development focus as a promotional tool?

The section went on to ask about barriers experienced in setting up and running the business. The International Finance Corporation (IFC) has a whole website (www.doingbusiness.org) devoted to assessing the ease of doing business in various countries around the world. They have regional and individual country reports assessing the regulatory environment and other issues for businesses in 178 countries. Countries are ranked on a number of scales like the requirements for setting up and registering a business, paying taxes, employment issues, enforcement of contracts, dealing with licenses, registration of property, and import/export procedures, and then are given an overall "Ease of Doing Business" evaluation. Apart from Thailand, which gets a very good ranking from the IFC, the rest of the countries in this study are all ranked as countries where it is not easy to do business. By comparison, New Zealand is ranked second in the world as one of the easiest places to do business; the United States is ranked third, and the United Kingdom is in sixth place (see Table 5:1). 
Table 5:1 IFC 'Ease of Doing Business' Rankings

\begin{tabular}{|l|l|}
\hline Country & Ranking \\
\hline Bangladesh & 107 \\
\hline Cambodia & 145 \\
\hline India & 120 \\
\hline Indonesia & 123 \\
\hline Kyrgyz Republic & 94 \\
\hline New Zealand & 2 \\
\hline Thailand & 15 \\
\hline Source: www.doingbusiness.org \\
\hline
\end{tabular}

Given this background, in the answers to this question we expected to hear about some of these issues, and the solutions that the case study companies have found for coping with these technical and regulatory requirements. The question also asks about issues of acceptance by the business and wider communities.

The literature review (see $\mathrm{p}$ 53) pointed out the value to small to medium enterprises of business incubators and business development services (BDS). Some countries have set up these facilities, but there have been questions about how readily accessible they are, particularly for businesses operating outside the capital city (Allal, 1999). Question 2.4 explores whether any of the case study businesses have had access to such services, and also whether they have been helped by membership of any trade organisations or through any links with Fair Trade organisations.

Finally Section II asked for their own evaluation of the company progress, and comment on future directions that they think are needed.

\section{Section III: Development Outcomes}

Here I was asking the questions that would be asked of a development project. They are not the questions that would normally be asked of a business. They do not relate to the commercial success of the enterprise, rather they aim to assess the effectiveness of the business as a tool for development.

The first and clearest development priority is very simply poverty alleviation. What do these companies see as their contribution to poverty alleviation? Is it just 
in the employment opportunities that they generate, or are the services that they offer also a part of their efforts at poverty alleviation? What training do they offer? Does this training make people more employable, more independent?

Question 3.2 looked at environmental issues. What sort of 'carbon footprint' is the company generating? What specific policies do they have regarding environmental issues?

Beyond the basic issue of extreme poverty are what have been called the 'crosscutting issues'. These are the issues that contribute to poverty - gender discrimination, human rights abuses, lack of education for children, and poor health conditions. These are explored in question 3.3.

In the past too many development projects have been done 'for' or 'to' the people of the developing countries without enough consultation with, or participation by, the proposed beneficiaries of the project. This has been proven to be an unsustainable approach, resulting in projects that have had little impact on the people they were supposed to be helping. The result is that development projects are now expected to give consideration to issues of participation by the beneficiaries in decision making processes, in the monitoring of the ongoing project and in terms of accountability for the results of the project. The proposed beneficiaries of a project should be involved from the start, in assessment of the need for the project, and planning the structure and directions of the project. In the final analysis those running a development project are required to be accountable to both the funders of the project and also to the intended beneficiaries.

This is not a normal requirement for a business. However for these businesses that have a dual purpose, is it something that they need to consider? Are any of them doing it to any degree? To what extent can a business venture involve the local community and its employees in the planning, operation and accountability processes? Where do issues of business confidentiality and sensitivity come in? These are the issues covered in questions 3.4 and 3.5. 


\section{Evaluation of the Questionnaire}

The nature of the research, where the questionnaire was followed up with email and other contact means that areas of potential weakness in the questionnaire were mostly picked up and covered by the ongoing conversation with participants. The questionnaire was a good tool for gaining basic information about the companies, and for getting the participants to start thinking about and analysing their work in development terms, and for identifying topics for the more interview style of the follow-up emails and discussions. If the study had been based only on the questionnaire there would have been a number of gaps. The use of a combination of research methods was important in order to get a fuller understanding of the issues faced by these companies.

The biggest gap in the information, and one which was also not explored in depth in the follow-up discussions, is in the financial information about the companies. The specific questions asked (Section 1.6) were too general, and did not elicit any significant detail. The result is that the financial information received is very general, and has not enabled any detailed analysis of the financial structures of the companies. The differences in the nature of business being conducted by the companies and the range of size of enterprise and countries involved does mean that comparisons of financial performance would be difficult and probably not very relevant to the issues under discussion. It would be hard to get a financial comparison that was truly comparing 'apples with apples' in this situation where the companies are operating in countries from Kyrgyzstan in the west to Cambodia in the East; ranging in size from under 10 employees to over 100 employees; and where the nature of business ranges from primary production to export trade to the provision of engineering services and English language teaching.

The second area that was not perhaps specific enough in the questionnaire, but which was picked up in the ongoing communication was in the area of initial help in setting up, and in business guidance and assistance. Although this was raised in Section 2.4, possibly more explanation was needed. None of the answers to this question were very clear, but in the course of further discussion it was clear for instance that three of the companies had been promoted or helped by 
Marketplacers International (MPIL), which is a company itself set up specifically to promote and provide resources for enterprises like those in the study. MPIL provides advice in the setting up and registration of companies, ongoing business advice and accounting services. While not promoting itself as a business incubator, or business development service (BDS) provider, this is in effect what MPIL does. The other businesses have all had similar assistance through various channels, none of which were clearly identified in their responses to Section 4.2 of the questionnaire.

The questionnaire did not explore the personal backgrounds of the participants. In the course of the study the entrepreneurial nature of these ventures became increasingly apparent, and the degree to which they depend on this entrepreneurial input. In the light of this some more background information about the motivation, training and experience of the participants would have added an interesting dimension to the study.

\section{Ethics}

The information sheet and consent form which were sent to participants with the questionnaire outlined the purposes of the research, gave contact information for the researcher and supervisor, and invited participants to specify any conditions that they wanted to put on the use of their information. This package that was sent to participants is included as Appendix 1.

While this study does not in any way probe the private lives of the participants, or require them to give any detail about their personal issues, it is a primary principle of ethical research that participants should be invited to give informed consent to their participation, with information about supervision in case of any complaints that they want to make, and also with the clearly stated freedom to opt out at any point if they are unhappy with the way things are proceeding.

While the information is not of a personal nature, there is the potential for some of the information offered by participants to be commercially sensitive. It is also important for some of these companies that they are present in their host countries as businesses, with business registration, and business visas for any expatriate staff. They are not NGOs, and do not want any information given in the course of 
this study to in any way imply that they are NGOs rather than businesses. For these reasons it was important that the confidentiality of all information should be guaranteed.

The final condition guaranteed in the consent process is the right of the participants to know what has been said about them. The consent form gives them the right to have this feedback, and the opportunity to correct anything that they see as factually incorrect. All of those who sent me material about their companies have been shown the description of the company that has been written for the thesis, and invited to comment on any factual errors or issues of interpretation. These comments have been incorporated into the final text.

The whole package of information sheet, consent form and questionnaire was submitted to the Victoria University of Wellington Human Ethics Committee, and was granted approval ${ }^{26}$.

\section{Responses}

Responses received from the case study companies are summarised in Table 5:2. These are the companies that have been include in the discussion in the following chapter. In addition to these six listed companies, I heard of, or was in contact with, several others who for various reasons were not able to be included. One company is still only in an initial investigative phase, and so did not feel that they were well enough established to contribute. Another company promised to consider my request, but never got back to me despite attempts at follow up contact. I am aware of a number of other companies that would have fitted the profile, but it was decided that the six companies considered here were sufficient for the purposes of this study.

\footnotetext{
${ }^{26}$ When the research was not completed by the original date of 30 December 2007, this approval was extended to 30 June 2008 by email from the Convenor of the Human Ethics Committee dated 24 February 2008.
} 
Table 5:2 Responses from Case Study Companies

\begin{tabular}{|l|l|l|l|}
\hline Company/Place & $\begin{array}{l}\text { Questionnaire } \\
\text { returned }\end{array}$ & $\begin{array}{l}\text { Additional } \\
\text { documents } \\
\text { provided }\end{array}$ & $\begin{array}{l}\text { Email/phonel } \\
\text { Skype } \\
\text { Conversations }\end{array}$ \\
\hline Dimensions, Dhaka, Bangladesh & Yes & Yes & Emails \\
\hline Freeset Bags, Kolkatta, India & Yes & Yes & Emails \\
\hline Aceh Coffee, Indonesia & Yes $^{\text {a }}$ & $\begin{array}{l}\text { Information } \\
\text { from their } \\
\text { website }\end{array}$ & 1 phone call \\
\hline Shofar Group, Naryn, Kyrgyzstan & Yes & Yes & Emails \\
\hline CWE, Chiang Mai, Thailand & No $^{b}$ & No & $\begin{array}{l}\text { Email \& } \\
\text { Skype }\end{array}$ \\
\hline $\begin{array}{l}\text { Hagar International, Phnom Penh, } \\
\text { Cambodia }\end{array}$ & No & $\begin{array}{l}\text { All documents } \\
\text { taken from } \\
\text { their website }\end{array}$ & No \\
\hline
\end{tabular}

Notes:

${ }^{a}$ When the draft of the discussion about the Aceh Coffee Company was sent for their final confirmation, the email was returned as "undeliverable" (23 June 2008). The website has also been removed. At the time of completing the thesis there was no further information available about what had happened to the company.

${ }^{\mathrm{b}}$ When the CWE Director looked at the questionnaire he decided that it did not really fit what they were doing. Although CWE fits the profile of an entrepreneurial company operating in Asia, he did not feel that development issues were a primary part of their vision, or that what they were doing was directed at 'poverty alleviation'. We talked about this by email and Skype, and he was happy for the company issues to be discussed as presented in the case study chapter.

${ }^{c}$ Hagar International did not respond to my email contacts. However they have a website with detailed information about the programmes of the company. Because of the size and scope of their operations they were considered to be worth including in the study just from their public domain information. As all information about the company was available in the public domain no consent was required under the ethics approval rules. 


\section{Chapter 6: Entrepreneurs in Asia - the Case Studies}

It is clear from the previous chapters that in an age of globalisation participation in the global economy is a necessary way forward for the developing countries, but also that this participation has to be on the right terms and conditions in order to be truly effective in helping either the country as a whole, or in reaching the poorest sectors of any country. Left to itself the global economy will be quite as exploitative of the poor as any regime set up by the powerful to exploit the powerless.

What are the issues for a pro-poor business? What obstacles do they face, and how can they be successful? The purpose of these case studies is to identify the conditions needed for this to happen, and to examine some of the positive and negative issues faced by businesses that have a pro-poor purpose. The small scale businesses of this study are ideally placed to selectively target the poor. They bring together the issues identified in chapter 4: they are started by entrepreneurs; they are in the SME size range; they are looking to create employment opportunities for specific communities; they are promoting the concepts of fair and ethical trade.

This chapter will describe each of the businesses, and identify the issues specific to that business. The next chapter will draw some comparisons and contrasts before identifying some of the key issues for the use of business ventures as a development tool. Note that Appendix 2 is a chart taken from the UNDP Human Development Report 2007/2008 which has comparative development statistics for each of the six countries in which these companies are operating. Appendix 3 has a further summary of basic information about each of the countries.

\section{Dimensions Limited - Dhaka, Bangladesh}

Dimensions was established in 1995 in Dhaka, Bangladesh. It was set up to carry out a range of light engineering activities as the founders looked to find a niche where their services would be most useful. The Memorandum of Association of the company were deliberately made broad enough to enable them to branch out 
into a range of associated activities as they found opportunities. These included import and export, consultancy and contracting. An early concept was gas conversion units for diesel generators. The Bangladesh electricity grid is very unreliable. Loadshedding and other outages are common, and so most factories have their own backup generator systems. Most of these are diesel, but Bangladesh has a good supply of natural gas. The founders of Dimensions had access to conversion units (sourced from NZ) that would enable the generators to be run on gas. The conversion would make the generators cheaper to run, more efficient, and also more environmentally friendly. Alongside this they offered servicing facilities for a variety of diesel engines.

The supply, installation and maintenance of backup power generation systems, both fixed and portable, continues to be a key service provided by Dimensions, although the gas conversion proposal was not one that gained any wide acceptance. They have generator sets available for hire, for events or other functions (they provided the backup power systems for the camera crews when the New Zealand cricket team visited Bangladesh).

However about the time the company was set up there were a number of big infrastructure projects happening in Bangladesh. These involved the import of heavy machinery using hydraulic control systems. There was a shortage of technicians able to maintain these, and in particular with the ability to supply and repair hydraulic hoses. The import, supply and maintenance of hydraulic hoses and fittings, including custom made fittings where required, became another key business area for the company.

In 2000 the founders of the company decided for various reasons that they needed to return to New Zealand. They sold the company to MarketPlacers International Limited (MPIL). MPIL is a $100 \%$ New Zealand owned group whose aim is to establish, support and encourage small scale business enterprises in Asia. They recruit entrepreneurs for ventures such as this, and they provide a variety of funding, investment and support services. 
As a company wholly owned by MPIL, the Board and the Managing Director of Dimensions are now appointed by, and responsible to the MPIL Board. The Dimensions Board is South Asia based.

The company currently has two expatriate staff and seventeen local employees. My contact in the company is Mr Jim Grieve, who is Director of Research and Development. As that title suggests, the company is looking to expand its operations, both by setting up branch offices in other parts of the country and looking for new opportunities.

The following are some of the issues that come out of their responses to the questionnaire:

Flexibility: The company set up documents were deliberately worded in a form that would allow for maximum flexibility. There was room to branch into just about anything and everything. At one point the company was looking at becoming a service garage for cars and light vehicles, but eventually decided that this would not be viable given the competition. The company constitution was flexible enough to allow for change ${ }^{27}$.

Relationships: Running a business in a foreign culture requires some specialist local input, and the maintenance of good relations with a variety of local officialdom. The first of these is legal advise in the establishment process. Local legal advice is necessary to ensure that all local requirements are met, without leaving hidden 'fishhooks'. Similarly a good tax lawyer is important. Grieve ${ }^{28}$ lists the following as important people to work with:

- The Board of Investment (for expatriate work permits)

- The Police Special Branch (for expatriate security clearances)

- The Home Ministry and the Visa Office (for expatriate visas)

- The VAT (taxation) office (for company taxes.)

- Our tax lawyer (for all company tax issues)

\footnotetext{
${ }^{27}$ Grieve, Case Study Questionnaire, 1.3
}

${ }^{28}$ Grieve, Case Study Questionnaire, 2.3.1 
"You must not offend government officials, because they often have the ability to use their power in whatever fashion takes their fancy without any justification at all. However, it does seem to me that there is vast scope in exactly that concept to be able to have good freedom for a business if you can get on-side with whomever. Depending on the nature of the relationship you are able to nurture your business efforts will be made hard or easy. ... These used to stress me until someone pointed out that this is just how things are here. Every year I am here I will have to sort another visa, some years it will be easy, some hard - so just be patient and accept that this is life." 29

Getting on-side with government officials does not have to mean under-the-table payments, but it does mean taking the time and the effort to build a relationship. In an Asian culture these relationships are more important than Western expatriates are generally prepared to acknowledge.

Grieve has less of a problem with outright corruption than with "the generally disorganised way that the effort is undertaken, ... with apathy, lack of caring, lack of interest in whether the job is done at all, let alone done right, poor communications between departments, constantly changing rules which nobody knows how to interpret, and this kind of thing" ${ }^{30}$.

This is important to note in a country known for a high level of corruption (Bangladesh regularly comes near the bottom of Transparency International's lists). One of Dimensions' aims is to demonstrate that it is possible to operate as a commercial entity without getting caught up in the endemic corruption of Bangladesh.

Business Priority: To achieve maximum effectiveness as a development tool, the project must be successful as a business. Grieve writes quite strongly about this:

"One of my pet agendas is to be seen as "business first" - making profit unashamedly, holding some of that profit for re-investment and growth, being seen to operate in an open, honest, and upright fashion that is visible to any outside observer. Then out of the surplus which is sure to come from this kind of operation we can be able to consider the needs of stake holders who are wider than just the immediate staff, families, clients and suppliers" 31 .

\footnotetext{
${ }^{29}$ Grieve, ibid

${ }^{30}$ Grieve, ibid

${ }^{31}$ Grieve op.cit. section 1.7.1
} 
In his evaluation of the success of the company, while acknowledging that the company "has come from nothing to being self sustaining in the marketplace", he still considers that it has "by and large failed to have the impact on the community that was initially hoped for",32.

"A company [is] in need of building up, just like a mal-nourished person if you feed them up and make them strong then they are better able to contribute to the community on an on-going basis than if the community continues to take from them while they are weak.

"I would like to see us develop more business muscle, a fatter bottom line, more stock holding, better trained staff, more and newer generators for the hire side of our operation. With these we would increase our cash flow and hopefully profit. From that increased profit we could consider far more ambitious development oriented activities than have been possible to date. $^{, 33}$

Modelling Good Practice: Dimensions considers this to be one of the key inputs that they can give to the country of Bangladesh. Grieve mentions this several times in his responses: "Vision - to be involved with a management team creating a vibrant growing business where people were held to be important. Where doing the right thing for the right reasons was held to be just as important as making money. To be able to show that business can be honest, clean, have a social conscience - and make a profit at the same time." 34

In response to the question on human rights, gender and equity issues Grieve writes that the company is limited in its ability to address such issues in the wider community, but that they work to demonstrate a different model of relationships within the company.

"Bengali culture is not egalitarian. They are all acutely aware of each others' ethnicity, status, gender, etc. In Dimensions we are constantly being accused of giving status where we should not. [For example by] addressing the lowest technician in our workshop as an equal I am lifting him up. Outsiders look at this and wonder (I have been both asked about this, and criticised for it) .... The wisdom of this kind of policy has been questioned several times in our office, and as we seek to work out the why's \& wherefore's in an on-going basis I trust that we may see some

\footnotetext{
${ }^{32}$ ibid section 2.5

33 ibid Section 2.5

34 ibid Section 2.1
} 
culture change over time - I would view that as a development outcome also." 35

Environmental Issues: Bangladesh, as with other developing countries trying to promote industrial production, faces enormous environmental issues. There is a cultural issue here related to a sense of corporate responsibility. Bangladesh homes are kept immaculately clean - the rubbish is thrown into the street for someone else to deal with. In addition, for a poor country, there is a reluctance to spend money on anything which does not have a clear value-added return to sales prices. As an engineering concern, Dimensions is clearly in a place where energy use, carbon output and waste disposal are important issues. Their policy is "to try and be socially and environmentally aware. If given a choice we will choose (even at cost) the more responsible way." $" 36$

In support of this they encouraged one of their employees who proposed a recycling programme for used lubricating oil. Unfortunately they discovered that his concept of recycling was to filter out large particles by pouring the oil through a cloth, then mixing kerosene in to make it look fresher. This of course reduced its lubricating properties! They had to put a stop to this project ${ }^{37}$. They are looking for ways to set up recycling of glycol based engine coolant (for which there are currently no facilities in Bangladesh).

Development Outcomes: Grieve acknowledges that specific development outcomes for Dimensions are hard to quantify. Seventeen people are employed, and gaining on-the-job experience and some level of training input. Other small neighbouring firms get some spin off of work contracted out. It is very small scale. They aim to donate ten percent of annual profits to local charities.

In terms of Human Rights, they have given employment opportunities to people from poorer communities and minority groups who might otherwise have found it harder to get employment. They acknowledge that given the wider cultural context it is likely to be some time before they see a female applicant for a job in the mechanical workshop, but they do have a Garo woman in the position of

\footnotetext{
${ }^{35}$ ibid Section 3.3

${ }^{36}$ ibid Section 3.2.2

${ }^{37}$ Grieve, personal communication
} 
office manager. The Garo people are a minority tribal ethnic group from the north of the country.

They have a policy of sponsoring their employees in wider training opportunities, not just areas relevant to the company operation. They see this as important for personal development, and also for giving the staff greater options in the future, beyond just within the company. As part of this they are building up a fund to be used for areas related to the future economic development and security of their employees $^{38}$.

As referred to above, they see a significant part of their role in modelling an ethical, sustainable business. This is a development input, but one that is impossible to measure in terms of outputs.

They see what they are doing as a contribution to infrastructure development. They enable and encourage the use of electrical power by a range of medium size enterprises, which are the real development for Bangladesh. ${ }^{39}$

Customer Base: a significant proportion of Dimensions customer base is other expatriate organisations, such as embassies or other foreign owned/managed concerns. These are people who, when they are looking for engineering skills, find it easier to deal with another expatriate who understands their issues, and who knows how to work with the local market. They have started a branch office in Saidpur, in the north of the country. This is also serving an expatriate based market, with two foreign run hospitals and two multinational NGOs as their primary customers. I do not see this as in any way detracting from what Dimensions are doing, but it is another aspect of the particular market niche that they are filling.

Financial Investment: In the original company setup there was an allotment of 300 shares valued at BD Taka 1000 each. In addition the original two owners of the company brought in a lot of tools and equipment that they put into the company as non-financial investments. When MPIL bought the company they

\footnotetext{
${ }^{38}$ email from John Osborne, a New Zealand accountant who was involved in the original setting up of the company, and is now MPIL representative on the Board, 20 June 2008

39 ibid Section 3.1.4
} 
injected a further US\$15,000 as part of the buy-out of the original owners. "'Sweat capital' was important. For the initial 5+ years no expatriate salary was drawn from the company - so that in effect was a regular hidden investment of approx Tk350000 per year" ${ }^{40}$. In recent years the company has contributed significantly to expatriate costs, although there continues to be some subsidy here.

"The company (after 11 years) is in a good financial position. Cash flow is relatively secure - though with the present down turn in the economy and recent historical expense pay outs, we are having to curb immediate development, while we build some more reserves. We could do with an injection of cash for future development. Ideally this should be as much as Taka 1,000,000 [NZ\$20,000 approx] ... that development is going to happen [although] it may be delayed and so we may lose some competitive edge. We have never borrowed money. Perhaps we have to look at that alternative $^{41}$.

\section{Conclusion}

Bangladesh is not an easy country in which to do business. The IFC "Ease of doing Business" study ranks it $107^{\text {th }}$ out of 178 countries surveyed. It is a country with a reputation for high levels of corruption, regularly coming near the bottom of the Transparency International surveys. It is also a country with a high level of political instability. At the same time they have made a lot of progress economically in the last decade. This has been helped by a high level of involvement in the garments manufacture business for the US and European markets.

Dimensions have succeeded in finding a particular niche market. They have established themselves well in this niche, and, subject to conditions in Bangladesh, look set to continue. It has been hard work. Grieve says "it has all been struggle, struggle, struggle, right from the start" ${ }^{\circ}$, and he is concerned that the original founders of a venture like this carry the vision in ways that it takes time for others to pick up. He thinks that in the transfer of ownership there have been opportunities that have been missed, and agrees with Osborne about the need for a boost with further capital input. He says

\footnotetext{
${ }^{40}$ Osborne, personal email

${ }^{41}$ Osborne, personal email

${ }^{42}$ Grieve, email 5 June 2008.
} 
Shoe-string is OK if that is all you've got ... but dream big, and hold on to it. Remember to constantly be developing the strategy for "what next". You will be able to replace string with a lace, and then maybe even afford a whole pair of shoes. After you're done with mere survival and achieved survival with style, comes the opportunity to share the style - and that's called development too. Shoe-string is part of NZ'ers "ethos", but I think it's desperately important not to treat shoe-string as "all"43.

\section{Freeset Bags/Triplenine Software Private Ltd - Kolkata, India}

When I returned from Bangladesh at the end of 1999 I met a young couple heading to Kolkata (Calcutta) to set up a business. Kerry and Annie Hilton had visited Kolkata before, and were excited by the concept of using business as a medium for doing something to help the poor. They did not know what sort of business it would be, or what part of the city they would look at. They were going to find a place to live, and then investigate opportunities that would fit their purpose.

They found a place to live, and realising that they were in the edges of one of Kolkata's red-light zones, began researching the sex trade in the city, and so to focusing on business opportunities that would offer an alternative to women trapped in the trade. The answer was the manufacture of jute bags for export. The bags come in a variety of shapes and sizes, from wine-bottle holders to student bags big enough to hold notes and books, from small handbags to large shopping bags. The jute is dyed and/or screen printed with colours and designs aimed at the developed-world market. From small beginnings in September 2001, the business has taken off, so that one of their biggest problems is keeping up with orders (see Figure 6:1).

${ }^{43}$ Grieve, email 3 June 2008 
Figure 6:1 Freeset Bags Timeline

\begin{tabular}{|lll|}
\hline Year & Progress & $\begin{array}{l}\text { Annual } \\
\text { Turnover }\end{array}$ \\
2001 & September - begin production with 20 women & \\
2002 & $\begin{array}{l}\text { January - begin fulltime production } \\
\text { April - purchase Triplenine Software }\end{array}$ & $2002 / 03$ \\
& & Rs 1,327,000 \\
& August - 10 new trainees, Freeset Trust & \\
& established & $2003 / 04$ \\
2004 & November - purchased current building & Rs 2,861,000 \\
& & $2004 / 05$ \\
2005 & & Rs 2,561,000 \\
2006 & Start medical insurance and retirement schemes & $2005 / 06$ \\
& for staff & Rs 6,624,000 \\
2006 & Set up screen printing processes & $2006 / 07$ \\
& & Rs 9,600,000 \\
2007 & 113 people employed, looking at purchasing a & $2007 / 08$ \\
& second building & Rs 14,400,000 \\
Exchange rate (June 2008): NZ\$1=Rs32.30 (Indian Rupees) \\
\hline
\end{tabular}

Once the target community was found and the product selected and researched, the next thing was to set up a trading company. To speed up the process they purchased an existing company that had been set up, but which had never traded. This shell company had the necessary registration and permits to enable it to operate in all the areas that they needed. The only real problem that they have had with this arrangement is that the Government of India will not allow them to change the company name - Triplenine Software - even though they are not doing anything with software! At the time of purchase in 2001, the rules for foreign ownership of Indian companies were such that the company was purchased in the name of a group of Indian partners. These people have supported the vision of Freeset Bags, but have remained sleeping partners, not involved in the day to day running of the company. The Hiltons went to Kolkata with the support of Marketplacers International Limited (MPIL), who have assisted with a range of support services. The regulations around foreign ownership have since changed, and with further capital investment needed MPIL are looking to change the legal shareholding arrangements ${ }^{44}$.

\footnotetext{
${ }^{44}$ Osborne writes "MPIL is looking at changing the legal shareholding - [including] foreign ownership, ... and MPIL will continue to look at a shareholding that is closer to the community. We don't think that the women will have direct shareholding in the near future, but some kind
} 
The product line is called Freeset Bags, in line with their vision statement, which is "In business to set people free". Their premises are situated in the largest redlight area of the city, and the aim is to offer an alternative income source to women trapped in prostitution and their daughters. Beginning with 20 women in September 2001, they now employ 113 women, and are constantly looking for ways to expand. They purchased the building that they use as their factory in November 2004. They are looking for opportunities to start work in another redlight area and to purchase another building.

Capital investment has come through funding raised by MPIL. This has included purchase of the shell company to get business operations started, and the later purchase of a building for the factory and office premises. Some of this has been in the form of loan funds, which will be repaid over a longer term.

The main employees of Freeset are women. They do employ a few men for specific tasks, but the target community for the business is women in the sex trade, or whose mothers are or have been in the trade. The women do not have to have any skill or ability, just the desire to get out of the trade. They are given a three month training period, during which time they are assessed and matched to tasks in the production processes. If a woman is not able to pick up sewing machine skills, then she is moved to other areas of the production process, such as finishing work like cutting off loose threads or attaching labels. Ongoing training includes literacy classes, as well as "simple maths, budgeting advice, savings plans, health and diet advice" 45 . As the business has grown and developed they have included a superannuation savings scheme, and a health insurance scheme for the women. Plans and fund raising activities are also underway for the establishment of a community health clinic.

Sonagacchi is reputed to be the oldest and the largest red light district in Kolkata, with an estimated 10,000 women working the sex trade. The district has featured in a number of media reports, and in the work of various NGOs. Of particular note was perhaps the film Born into Brothels, the story of the children of the district.

of shareholding that keeps the company "in trust" for the women is what we would be feeling after" email 20/6/08.

${ }^{45}$ Hilton, Case Study Questionnaire, Section 3.1.2 
Written and directed by Zana Briski and Ross Kauffman, it is the story of how as a photographer Briski went into the district to take photos of the prostitutes, but ended up giving cameras to the children and getting them to take photos of their lives $^{46}$. In India the biggest threat of HIV/AIDS comes through the high incidence of prostitution. Various NGO groups have worked with the prostitute communities to raise the awareness of AIDS, but with limited success. Media stories have featured the work of Smarajit Jana in establishing a prostitutes' collective as a way of building the use of condoms (Madhusree Mukerjee, 2006). The collective has claimed a high rate of success in this, but other reports have indicated that in fact the success rate is much lower (Grant, 2004; Vater, 2004).

Examples of the women's stories are seen in Figure 6.2, which is taken from a Freeset Bags publicity brochure. Another is the story of Mina which is told in the documentary Calcutta Hilton, the story of Freeset and the Hiltons made by John Sinclair and shown in NZ on TV2 in 2005. This is available for general distribution on a DVD which also includes extra footage not included in the TV programme (Sinclair, 2005). Originally from Bangladesh, Mina was caught up in the Bangladesh independence war in 1971. Mina and her family fled the fighting and ended up in a refugee camp across the border in India. Mina was at that time a young teenager. In the camp she was befriended by a woman who promised that she could organise a job for Mina if they went to Kolkata. When they got there, the 'job' was in the sex trade. Mina was trapped, not knowing anyone else in the city and with no way to flee. She was kept in a room and sold as a virgin to a man who forced her to "stand in the line" for customers in the red light district. Once in the trade, Mina was too shamed by what had happened to ever try to get away and return to her family. Mina was one of the first group of women to start working at Freeset. In time she even gained the courage to contact her family in Bangladesh, and with the help of Freeset staff, to go back and visit them. She is now a strong advocate of Freeset, and is encouraging them to visit another of the red-light areas of Kolkata with a view to starting work there.

\footnotetext{
${ }^{46}$ See http://www.imdb.com/title/tt0388789/ for a review of the film, and http://kids-withcameras.org/ for the continuing story of Briski's contact with the children. http://www.aliciapatterson.org/APF2003/Briski/Briski.html has photos and story of some of the women.
} 
Mina's story is typical of many in the sex trade in Indian cities, as is shown in the study by Padam Simkhada of Nepali girls trafficked into Indian brothels. In this study $54.8 \%$ of the girls had been lured by false job offers, either for factory work or as housemaids. On arrival they find they had been sold to a brothel owner, and are told that they now have to work to repay their 'debt' to the owner (Padam Simkhada, 2008). In Tom Vater's report he quotes Indrani Sinha, director of Sanlaap, another organization working with sex workers, saying "Most women are coerced into this trade. ... We hear of women being trafficked into Calcutta's red light districts every day" (Vater, 2004).

When asked for his evaluation of the success of the company, Hilton writes: "When there are up to nine thousand women trapped in the sex trade within a mile of where we are located we have to say we are happy to have come this far but certainly not happy with the fact that thousands are still in the trade. Our first priority in business is to bring freedom for women and their children" 47 .

Design and Marketing: The market for Freeset Bags is intended to be in the developed world - America, Europe and Australasia. In order to reach this market it is important to have designs that will sell to these customers. Freeset Bags have recruited design and marketing personnel from New Zealand. These are people who have gone as volunteers to work in Kolkata for short term contracts. The marketing people have also done trips to Europe and America to promote the products. They are members of Fair Trade USA, but their aim is to not just sell through Fair Trade specialty shops, but to try and reach the mainstream market. They have a website, and are working to establish online sales also.

Figure $6: 2$ is from a publicity brochure. This publicity material is intended to build awareness of the exploitation involved in the sex trade in places like Sonagacchi, and to tell more of the stories of the women that they are working with. This is used as an advocacy tool, and is made to be one of the selling points for the bags.

${ }^{47}$ ibid Section 2.5 


\section{Sonagacchi}

Sonali stands in a doorway... waiting. The smile on her face? Just part of the job. Stolen from her village she was then dragged, wide-eyed and innocent, to the back streets of Calcutta where she was sold into prostitution by a stranger. The first customer drugged and then raped her. She was just thirteen.

Bashanti takes her place in line each day thanks to her family. She was sold into the trade by her mother, sacrificed to provide food for the family to eat.

Shoulder to shoulder the women stand, as far as the eye can see. Scanning this everyday spectacle - as if shopping in a supermarket - is a steady stream of men. Twenty thousand every day, for one purpose - sex.

There is nothing glamorous about this place. Sonali and Bashanti are among the six thousand women who work in Sonagacchi, the oldest and largest of Calcutta's many sex districts. Some women are paid as little as US25 cents per customer just enough to buy a simple meal.

Indian society shuns these women. They are branded "outcasts" for life. They didn't choose prostitution - it chose them.

Bring up the subject of prostitution and most people will usually think of sex, exploitation, or maybe AIDS. But really prostitution is about money - it's about BUSINESS.

Freeset publicity brochure

Environmental Issues: The bags are made with jute, which is a natural fibre. They are members of the local jute industry. They are using water based dyes for their screen printing, as these are more environmentally friendly. Being based in the centre of a mega-city such as Kolkata they do not have access to any waste disposal facilities other than those provided by the city. One of their more recent projects is a plan to set up a water filtration unit that will provide safe drinking water not just for the staff, but also for the surrounding community.

Participation: While Freeset Bags are working to free women from the sex trade, they are not aiming to physically remove them from the red-light district. The factory is in the district, and the women continue to live in the area. They are looking to build an alternative community right there in the district. They organise community activities, and through things like the drinking water project and the community health clinic they set out to serve the wider community. In terms of community activity as distinct from the business processes, "There is a strong leadership team of women who play a significant role in the running of the 
community" 48 . In terms of the business activities, they are working to develop management personnel. This had a setback when a woman who had played a significant role in helping them to get established left to set up her own company. Hilton sees that growing business leadership will take time, and that "to remain healthy and grow, at this stage foreign leadership is still very very important" ${ }^{\text {"49 }}$. Company decision making includes "a team of elected women from the staff".

Given the district that they are working in, consultation with wider community leadership is more problematic! There was some consultation around the purchase of the building, and Hilton says "The doors are open for community leaders should they wish to comment. We are listening and need to listen. Historically their response is more motivated by greed and corruption." ${ }^{50}$ As they are in business to challenge the sex industry, they expect to come up against opposition from some influential people, but so far this has been less than expected. The wider community does not have input into the business decisions of the company.

Freeset Bags are happy to work with other businesses with similar goals, and in particular to assist local businesses with finding export markets for their goods. They also cooperate with NGOs working among the prostitute community. They will assist women from the community to get into drug and alcohol rehabilitation programmes where appropriate.

Viability: At this stage in the development of the company expatriate salaries are not being paid by the company. Expatriate involvement continues to be essential for product design and marketing for the western markets that they are targeting, and also in managing production processes and flow. This remains a subsidy in the company operation. The expatriates involved in the company are either volunteers funding themselves, or else are being funded through regular donations from family and supporters in New Zealand. Hilton says of this "Not paying foreigners is also a choice. Nobody can say we foreigners are benefiting from the

\footnotetext{
48 ibid Section 3.2.3

${ }^{49}$ op.cit.

${ }^{50}$ Section 3.5
} 
business monetarily. I plan to continue this whether the company can afford it or not. $^{51,}$

The Freeset Trust: Alongside the business Freeset Bags have set up a Trust. Initially this was set up when they decided that for the ongoing security of the business they needed to own their own premises. They did not have enough funds in India to buy the building, and currency regulations meant that as a company they were not going to be allowed to bring in the extra capital. The Trust was set up to be able to accept overseas funds for the purchase of property. Having an independent Trust has a number of other advantages. The company rents the building from the Trust, at market rates. The Trust then uses this income to fund a variety of welfare projects for the women and for the wider community. These include:

- Literacy training amongst the Freeset women.

- Child care (crèche), initially for the children of staff, but plans to widen the access to this for others in the community.

- Health care (soon to be a clinic for the community - not just Freeset).

- Community crisis aid (funding and help for needs within the surrounding community).

- Alcohol / drug addiction assistance.

There are plans for these services to be extended in various areas, including setting up a filtered water facility to provide safe drinking water for the wider community, and for some form of educational facilities.

The Trust has four Trustees who are all Indian nationals. There are no expatriates on the Trust. Hilton says the Trust "exists for women who are trapped in the sex trade, for them and their children". It provides security for the capital investment

\footnotetext{
${ }^{51}$ Hilton, personal email 22/5/08. Osborne writes that, while they would not be able to pay western standard 'fat' expatriate salaries, the company would be capable of paying at least one, if not two expatriates an amount that would be a good living allowance in India. “...if you look at fat expat salaries then perhaps your statement is right, but if you are pro-poor then non-fat expat salaries are the order of the day - and these could be paid" (Osborne email 20/6/08).
} 
involved in property ownership, as it is separated from the company and will remain should anything happen to the company. They are currently looking at purchasing two further properties. One of these would enable the factory in Sonagacchi ${ }^{52}$ to extend its production, and the other would open a new facility in another red light zone in the city ${ }^{53}$.

\section{The Aceh Coffee Company / Indonesian Specialty Coffee Cooperative Development (ISCCD)}

The Gayo mountain district of Aceh is the source of around 60\% of Sumatra's Arabica coffee. This significant coffee growing region was the centre for a separatist movement that fought a long guerrilla war with Indonesian government troops. The conflict forced many farming families off their land, and restricted coffee production. A report to the UNDP sponsored Indonesian Coffee Industry Forum in September 2005 estimated that nearly a quarter of the coffee plantations in Central Aceh had been rendered unproductive by the conflict, in an area where $80-85 \%$ of the population are dependent on the coffee industry (UNDP, 2005). This report also highlighted the lack of cooperation and mutual understanding between those involved in the market processes - growers, collectors and traders. They pointed to the need to rebuild the market, with emphasis on sustainable livelihoods for the farmers, processes to ensure the quality of the product, and promotion of the product in the international market. The Aceh Coffee Forum was set up to start dealing with these issues (Aceh Coffee Forum, 2006).

However the devastation of the coastal regions by the December 2004 tsunami eventually led to a peace settlement with the Aceh separatists. Representatives of the Indonesian Government and the Gerakan Aceh Merdeka independence movement signed a comprehensive peace agreement in Helsinki, Finland in August 2005 (Fricke, 2005). This settlement, as well as facilitating reconstruction in the tsunami affected coastal regions, also opened the way for a rebuilding and rehabilitation of the coffee growing regions. The peace settlement was

\footnotetext{
${ }^{52}$ Sonagacchi (or Sonagachi) translates as "Golden Tree"

${ }^{53}$ Hilton, personal email
} 
immediately followed up by the creation of the Sustain Sumatra Campaign in September 2005. This was part of the efforts of a coalition of American, European and Indonesian private sector partners aimed at facilitating the rebuilding process. With a variety of high level political and business support, the Campaign had objectives of "Trade After Aid" - rebuilding small and medium enterprise (SME) through access to credit, a commitment to purchase products from Aceh and Sumatra, and an advertising campaign to promote the "Sustain Sumatra" brand internationally.

It was in this environment that the Aceh Coffee Company ${ }^{54}$ was set up. Towards the end of 2005 they acquired a coffee washing station and associated four hectare property built by the Dutch government as part of a development project in 1983, but abandoned in the early 1990s because of the conflict, and they began the process of rebuilding this as a significant link in the coffee growing chain. In February 2006 the UNDP and the Aceh Development Planning Board (BAPPEDA) sponsored the formation of an Aceh Coffee Forum for all stakeholders in the Aceh coffee industry. In April of that year the Indonesian Specialty Coffee Association was established, with the Aceh Coffee Company as one of the foundation members. By the end of the year the Gayo Mountain Cooperative was formed to focus specifically on the needs of the 2,000 small scale village farmers spread through the district. This was claimed to be the first democratically run coffee growers cooperative in Aceh, and was supported by the Aceh Coffee Company. There are in fact other coffee cooperatives in the Gayo Mountain area. One such is the PPKGO (Gayo Organic Coffee Farmers Association) which was founded in 1997. They are Fair Trade and Organic certified, and exporting particularly to the USA (TransFair USA, 2005).

The global coffee market is quite problematic for growers. Global coffee prices have been subject to wild fluctuations, with resulting issues for small holder farmers reliant on this crop for their income. A study by Dang Thanh $\mathrm{Ha}$ and

\footnotetext{
${ }^{54}$ I first heard about the Aceh Coffee Company at a Hospice Fundraising Dinner where I was seated next to Penny Hawkins of NZAID. We discussed my thesis concept and she told me about the Aceh Coffee Company.
} 
Shively looked at the effects of price fluctuations on coffee growers in Vietnam, and discusses the need for income diversification in order to cushion the effects of price fluctuations. Too rapid an expansion of crop area results in increased production which contributes to price reductions as seen in the 1990 s with the growth of competition between the Vietnam and Colombian markets. This study also notes concern about the expansion of the area under coffee cultivation leading to substantial forest destruction in the Vietnam highlands (Dang Thanh Ha \& Shively, 2007). In the highly competitive coffee market one of the marketing tools that is used is promotion of geographic point of origin as a defining point of quality and flavour. For this to work growers, processors and marketers have to be careful to ensure the quality of the product (Neilson, 2007).

This is an opportunity that is picked up by the Aceh Coffee Company. Their website (www.acehcoffee.com ${ }^{55}$ ) says that "Aceh Coffee is the first company to set up shop at the farm gate in Sumatra and to work directly with the farmers to process and export the very best fairtrade, organic and conventional Sumatran Arabica. We will guarantee origin with direct passage from the washing station to our global partners", and that "Part of our role is also to support, manage and implement public and private sector programmes for the Gayo Mountain Cooperative". One objective of the company was to assist the cooperative to "become a model for other communities". They also had an objective that eventually ownership of the company would pass to the cooperative.

This process seems to have moved faster than anticipated. By August 2007 when McNeice returned my questionnaire he wrote: "you can see that we have moved away from a trading company which in these parts put zero back. [The] ISCCD project develops the co-op, promotes the co-op which will include one day it's own warehouse in California so the co-op reaps the full benefits of the supply chain... This is relationship coffee taken to the fullest. Transparency between roaster/importer and farmer. The UNDP will have the MOU with the co-op

\footnotetext{
${ }^{55}$ Note that at the time of completion of this thesis (June 2008) the website has been removed. The url now points to a marker site with sales links to other sites. Emails are returned "undeliverable".
} 
drafted next month [this will] support the co-op with good governance, transparency and accountability."

At this point the returned questionnaire is no longer reporting on the Aceh Coffee Company, but on the ISCCD (Indonesian Specialty Coffee Cooperative Development). This has a board elected through a UNDP supported democratic process, reporting to a membership of 2000 farmers. These farmers are from the central highlands of Aceh, needing rehabilitation of their farms from the 30 year period of civil conflict. The Co-op directly employs 165 staff, of whom 150 are women. They expect this to grow in the next three years to 450 women. They are members of the Specialty Coffee Association of America, Europe and Indonesia. They are working to Fairtrade and Organic certification, and plan in the future to add Carbon Neutral certification to this. They will be setting up training programmes for the farmers, supported by the Coffee Quality Institute of America and the Roasters Guild. These will see an increase in yields, and, through quality improvement, an increase in premiums paid over and above the standard market rates.

Setting up and registration issues at local and national government levels have been facilitated by IFC and UNDP involvement. Financial support has included a two year funding grant from USAID. An email from McNeice (14/10/07) says "We are looking at growing our project (ISCCD, Indonesian Specialty Coffee Cooperative Development) to a second origin ${ }^{57}$. The model we will apply is based on what we are doing in Aceh but have zero investment or ownership and I understand NZAID and Oxfam NZ are working in livelihood projects in the new proposed origin."

One has to feel that the scope of the venture has changed from being a business like the others in the study, to something that looks much more like a traditional development project. The standard development questions are answered more readily than the business questions (they have not given me any information on capital investment or company turnover). Poverty alleviation goals are clearly included, as well as the cross-cutting issues of gender, environment and

\footnotetext{
${ }^{56}$ Robert McNeice, email correspondence

${ }^{57}$ i.e. production region, using 'point of origin' as one of the selling points as discussed above.
} 
community participation. Accountability is in two directions - to the UNDP, as well as to the co-op members.

This is not to say that it is not a good project. It looks like an excellent project, and one that will have good returns in sustainability and the economic viability of the community. The company model has morphed into a cooperative model shaped to meet the needs of the target communities and of market promotion. All the issues that face coffee growers are issues that make the cooperative format probably the most helpful for the growers. As discussed in chapter 4, this is an issue that is seen particularly by the Fairtrade organisations who see cooperatives as the best way to give more control and more return to the primary producers.

\section{Shofar Group Limited - Naryn, Kyrgyzstan}

The Shofar Group Ltd are registered in Kyrgyzstan as a small scale manufacturing and service provider. The founding Director, Chris Binder, is a chemical engineer by training, with experience in product development and brand management in a multinational company. He visited Kyrgyzstan in 2003 and worked briefly with a micro-credit agency in Bishkek. He returned in 2004, and spent some time investigating opportunities and learning the Kyrgyz language, before setting up the company in June 2006. The aim is to help people in some of the poorest areas of rural Kyrgyzstan, and so the company is based in Naryn, a town which is the administrative centre for one of the poorest regions of the country. See Appendix 3 for a summary of country statistics on Kyrgyzstan, the Naryn Oblast (province), and the town.

In addition to responding to my questionnaire Binder sent me a copy of his original business plan, and a pdf formatted company brochure. He has also emailed responses to further questions on issues that I asked for clarification.

The business plan calls for the setting up of small business units using intermediate technology solutions and non-capital intensive processes for the provision of simple goods and services. The aim of these units is to create employment and personal development opportunities in regions of high 
unemployment. The hope is that this will stimulate the economy in these regions and will model successful business practices that will spread to other users. The company brochure says "we strongly believe that long-term success will come from combining world-class product development and production management methods with in-depth knowledge of the local culture. From small beginnings, our aim is to grow the business to the size of a medium-scale enterprise, generating employment directly for the organisation's employees and indirectly for local suppliers $" 58$.

At this stage only one such unit has been established. This unit is manufacturing high quality scented candles both for the local market and for export. From a September 2006 start, they are now employing six local staff, and for a startup capital investment of US\$14,300 achieved a turnover of US\$8,300 for the 2007 year. This has been a good start, but Binder's evaluation of the company is that it will need to grow significantly in the next two years if it is to become financially sustainable. This will not be easy, as they have found building national level sales distribution difficult, with a high resistance to the introduction of new products. They have experienced difficulty setting up export systems due to complex procedural requirements and high levels of corruption ${ }^{59}$.

Setting up and running a company in Kyrgyzstan, as in most countries, requires good legal and accounting services. "Taxation laws are complex and multiple filings must be made to several separate government organisations each quarter. This requires the use of a competent accountant ${ }^{\prime 60}$. As mentioned in the previous paragraph they have found issues with high levels of corruption that making running a business difficult.

The business plan stated that "Consistent with the local culture, we will seek to develop good relationships with individuals/communities before starting any business activities in a place. We will only start a business unit after obtaining the agreement of key stake-holders and relevant community leaders... However, we

\footnotetext{
${ }^{58}$ Living Fragrance Candles, Shofar Group company brochure, pdf file included in personal communication from $\mathrm{C}$ Binder

${ }^{59}$ This despite the IFC 'Ease of Doing Business' survey giving Kyrgyzstan a better ranking than some of the other countries in this study. See chapter 5, Table 5:1.

${ }^{60}$ Binder, Case Study Questionnaire, Section 2.3.1
} 
strongly believe that developing strong relationships within the community is fundamental to the long-term sustainability of each business unit." 61 Binder acknowledges that he did not fully follow through with this consultation process before setting up the candle making business. Naryn is a township of around 40,000 people, where Binder did not feel that there was a particularly strong sense of community, and so he did not in the end set up any community consultation process. He says that if he was doing something in a smaller, village level community he would consider the consultation process to be a more important part of gaining acceptance. In the event he considers that the business has been well received by the community, who are glad to see something happening. The region has a very negative image with the rest of the country, and the fact that the company is producing a quality product has had a positive effect for their self esteem.

Legal advice in setting up the company was against having any governing board. It was not required, and in the Kyrgyzstan environment would have introduced unnecessary complications for a small limited company. Their intention is ultimately to create a local advisory board, although this would still not have any legal governance role.

Binder is very clear that to be fully effective they must succeed on a commercial level. "This is a commercial organisation and as such must be run as a profitable business" was one of his key operating principles in the business plan. A follow on from this is that, while priority in employment will be given to those who do not have access to other employment options, "Employees will only be taken on if they have the necessary skills for the job. Furthermore, if they consistently fail to meet the necessary standards of diligence, quality and honesty, then their contract of employment will be terminated" ${ }^{\prime 2}$. They are a business, not a charity, and everyone must pull their weight to make the business succeed. Employees are given position specific training, related to the role that they are being asked to full. For example the manager has been given training in relevant computer skills.

\footnotetext{
${ }^{61}$ Binder, Shofar Group Development Project, Kyrgyzstan April 2006 document included in personal communication.

${ }^{62}$ Binder, April 2006 Business Plan document
} 
On environmental issues, Binder points out that with the candle making business most scrap materials are recycled back into the product. The local power supply is hydroelectric. However the remote location of the region does mean a higher carbon footprint for transport issues.

With regard to gender and equity issues, the current employees are evenly balanced between male and female. As stated above, they do aim to discriminate in favour of those who have no other employment options. They do encourage staff to be involved in discussion and feedback both on new product ideas and also on work processes.

One of the key aims of the company is to model good business practice for others. With this in mind they are intentional in cooperation with other businesses and organisations, and open to sharing their experience in developing best practice processes in the local environment. They offer technical assistance and consultancy services for local businesses.

It is relevant here to look at what other projects exist in the province. One Village, a British organisation promoting Fair Trade and ethnic handcraft sales commissioned a report by Roy Smith on export prospects for the traditional Kyrgyz sheep's wool felt rugs (Scott, 2001). In the traditional nomadic Kyrgyz culture these were used in making the coverings and internal decoration for their yurts, the tent structures that they lived in. The wool was felted and decorated through one of two processes, known as ala-kyiz or shyrdak. These produce two different styles, which have been developed for potential export as rugs. Smith reports on a cooperative group of producers known as Altyn Kol (which translates as "Golden Hands") in the Naryn Oblast. This Cooperative was set up with help from Helvetas, a Swiss development NGO, who have assisted them with training programmes, setting up quality control systems, and building market access both in Bishkek, the Kyrgyzstan capital, and internationally. There are now over 300 women members of the cooperative.

Export promotion has been handled through a national organisation called Kyrgyz Style, and two international NGOs, Helvetas and Aid to Artisans, a US organisation promoting handcrafts. The costs of these rugs is high compare to 
other handcraft rug products sold in the UK. As Binder also reported, export procedures are complex and costly. Export licenses are required from both the Ministry of Commerce and the Ministry of Culture, with considerable costs at each stage. As Kyrgyzstan is a landlocked country, and overland transport through neighbouring countries is unreliable, air freight has to be used, adding enormously to costs (and to the environmental issues). Even with the help of sympathetic, socially proactive organisations such as those involved in the support of Fair Trade operations, the cost mark-up at each stage of the export handling process adds up to a significant amount ${ }^{63}$.

Shyrdak rugs are a rural product. They are produced by rural women to supplement their nomadic sheep-grazing lifestyle. They are in no way in competition with Binder's operation in the city of Naryn, but both groups face many of the same issues. Scott has a section of his report discussing the quality control processes followed by the Altyn Kol group. Binder also mentions the need for stringent quality control in his candle making business. Entry to the export market means that quality control must always have a high priority. For both the cooperative and the candle making, the underdeveloped nature of Naryn province and the mountainous country mean that they face difficulties in transport both to local markets in the rest of the country, and to international markets. Regions without easy market access and un-competitive transport costs will find it harder to build export markets (Gries \& Naude, 2008). However organisations with a poverty alleviation target must go where the greatest poverty is to be found, even if this is a disadvantage to their operations in economic terms.

\section{Cornerstone Workplace English (CWE) - Chiang Mai, Thailand}

CWE is another company with links to MPIL. This one operates in Chiang Mai, Thailand. Their aim is to provide workplace English language classes for the staff of companies in the tourist or export business areas. When approached with my questionnaire they declined to fill it in on the basis that their objectives are not

\footnotetext{
${ }^{63}$ Binder reports on an April 2008 meeting in the UK with One Village personnel and being told by them that exports from Altyn Kol are not working out because of difficulties with the export processes.
} 
particularly targeted at poverty reduction. They were also having some concerns about the long term viability of the venture. We had some email correspondence and a Skype discussion about their business and its objectives, and they agreed to this being quoted as part of this study. I have chosen to still include them in the study because they represent an enterprise working into a different sector of the economy. The first sector is the primary agricultural producers, here represented by the coffee growers of the Gayo Highlands of Aceh; the second sector is industry, represented by Freeset Bags and the Shofar Group; the third sector is technology transfer, represented by Dimensions; the fourth sector, which I have chosen CWE to represent, is services. In the modern global economy the services sector is regarded as being increasingly important. I am aware of other companies providing English language teaching, or other services sector skills. A measure of a developed economy is the proportion of the workforce that is employed in the services sector, however in the terms of the 'pro-poor' objective which is the focus of this thesis, the services sector cannot have such an immediate poverty reduction effect. It is also economically a tougher area in which to work, as shown by the issues faced by CWE.

The stated vision of CWE is to "Serve the Thai business community and to work with Chiang Mai into the business future" ${ }^{24}$. They provide English language classes that are specifically focussed on workplace English, and are tailored to the specific needs of the business where the students are employed. While some students pay their own way, most have been sponsored by their employers. The majority are middle class, and have a university degree, or are in some position of responsibility in their place of employment. There are other English language courses available in Chiang Mai. The point of advantage that CWE has to offer is that their staff are all native English speakers - expatriates who are trained ESOL teachers.

Following personal contacts of the founder of CWE, and as a way of coping with the complexities of Thai Government requirements for foreign owned companies, the company, while funded and run by MPIL, is legally $100 \%$ owned by a Thai national, a businessman with a number of other business interests around the city.

$\overline{{ }^{64} \text { Neil Perry, personal communication }}$ 
These include a language school for foreigners wanting to learn Thai, a property development, and a local fitness centre, all under the Cornerstone Group ${ }^{65}$. There are significant legal issues for a foreign or partly foreign owned business working in Thailand. These are easier if the majority ownership is Thai, but there are still large issues around visas and work permits for expatriate staff. As an English language teaching institution, they have to satisfy the Education Department in terms of syllabus, and the advantages of having native English speakers on the staff; the Labour Department in terms of employment issues; and then the Immigration Department. These compliance issues have been a major factor in the ongoing viability of the company.

The company was set up and operating well before the tsunami. However they did benefit in the post-tsunami period when there was a move by tourists away from the coastal areas and to some of the inland features. Hotels and restaurants in Chiang Mai in particular experienced something of a boom, and so were eager to see their staff improve their English language skills. Currently however the business climate in Chiang Mai is experiencing a mild recession. The tourist surge has ebbed as memories of the tsunami fade, and visitors return to the coastal attractions. In addition the current period of political uncertainty in Thailand has had a negative impact on business investment. "Our business really depends on other businesses having the financial resources to invest in training of their staff. Of course when times are difficult the first thing that goes is the training of staff..."66. There is now less demand for that level of English language input.

In addition, while Chiang Mai is a significant city in the Thai economy, most export business is still handled through Bangkok, and so there is not the same need for Chiang Mai based staff in export related businesses to have English

\footnotetext{
${ }^{65}$ See www.cornerstone.co.th

${ }^{66}$ Neil Perry, personal communication (Skype). John Osborne, an MPIL Director, adds "Language schools are certainly a 'development' thing. They are far harder to make viable than a manufacturing concern - because you are selling intellectual service, not product. That is, you are selling an intangible. You are concentrating on the local market. [CWE] have aimed at commercial enterprises, rather than individuals. So the 'owners' need to be convinced that it is worth their while investing in their staff - that is they see the possibility of improving their profit bottom line. A language school aimed at individuals has a better chance of survival - but it has definite competition - and because teaching is an intangible quality has to be proved by demonstration and over time - so initially people will go for the lower price and only then find out about quality or lack of" (personal email communication).
} 
language skills. It is very much something that is seen as an advantage in good times, but that in a period of downturn can be cut from company budgets. CWE management are starting to realise that the business may not be viable in Chiang Mai, although it could still be viable if it moved its base of operations to Bangkok.

In summary, CWE is a development oriented business in as much as they are working to build the capacity of Thai businesses to compete in the global market. Within Thailand they are not particularly pro-poor. Their customers are middle class professionals.

In addition to the fact of being in the area of service provision, CWE is an interesting case study because Thailand is one of the developing economies that has done well in the recent period. Thailand is a country that has been through a period of restructuring, and has largely followed the WTO/IMF prescriptions for restructuring the legal environment for business. Thailand is now rated by the International Finance Corporation website www.doingbusiness.org as fifteenth in the world for ease of doing business, which puts it well up with the OECD countries. Globalisation, neoliberal economic policy and WTO/IMF/World Bank pressure, as discussed in preceding chapters, has seen an enormous reduction in the barriers to foreign ownership and activity in the developing countries. The legal environment for foreign owned firms, and the whole area of cost of compliance, both in financial terms and in terms of time and effort required has been simplified. However, as CWE has found, there are still barriers, and often barriers which hit SMEs rather than larger scale enterprise. Big business has the muscle to ensure that the barriers are lowered for them, while SMEs are seen by government officials as less important or even something of a nuisance.

Viability is an issue for all businesses, anywhere. Every business has to find the niche market that it can target most effectively. For CWE, their niche has been eroded by two issues beyond their control - the economic downturn and national level political issues. The latest news I have from them is that the company in its present form will be closed in July 2008. They are still hoping to find some way of operating in the area of English language services, but are not sure what form this will take. To recover viability they are faced with having to rethink the whole concept of the business. 


\section{Hagar International - Phnom Penh, Cambodia}

Hagar International is a Swiss based development organisation with a vision for exploited, abused, trafficked, destitute and rejected women and children in Cambodia, and their rehabilitation through a variety of social, educational and economic programmes. The website ${ }^{67}$ talks about the 'Hagar Model' as being Recovery - safe accommodation, health and nutrition programmes; Risk Reduction - access to basic skills of numeracy, literacy and life skills; Reintegration - vocational skills training followed by on the job support and counselling; Resilience - covering micro-enterprise investment and support, but also what they call 'Social Enterprise Development', which is investment in the sort of business enterprises which are the focus of this thesis.

They have three separate businesses under this heading of Social Enterprise Development. These are Hagar Catering and Facilities Management, providing catering services to hotels, factories and other organisations in Phnom Penh; HO-T! Apparel and Accessories manufacturing clothing and craft items for export; and Hagar Soya, Cambodia's only large scale soy milk producing factory, with the capacity to produce up to 12,000 litres of soy milk per day, and also producing a range of other nutritious snack food items.

Pierre Tami, the founder of Hagar visited Cambodia in 1990. He tells the story of hearing the wailing of a mother whose six month old baby had died of malaria. Within two weeks Tami himself almost died of the same disease. These two events led Tami and his wife to commit themselves to the task of doing something for the women and children of Cambodia (Hagar International, 2005). Hagar was founded in 1994 as a programme to help vulnerable and at risk women and children. The programme began with 'Hagar Shelter', providing a place with safe accommodation, basic health care and life-skills training. Tami is an entrepreneur. It was quickly apparent that it was not enough to provide safe accommodation, even with health and nutrition assistance. Rehabilitation had to be a total package which included reintegration into the community, and access to employment. The

\footnotetext{
${ }^{67}$ www.hagarinternational.org. They did not reply to my email with the Case Study Questionnaire, so the information in this section is all taken from their website, and documents that are available through the website. The Hagar model is also described on page 8 of the pdf brochure for HO-T! Apparel and Accessories
} 
business enterprises were born from this need. The initial businesses were cooking and crafts. Cooking skills were taught in the shelter, and then the women were encouraged to cook food for sale in the local markets as the beginning to setting up micro-credit enterprises to earn income to support themselves. In a similar way the women were being taught sewing skills, and this grew into the manufacture of craft items for sale.

Hagar Crafts was set up to market these items. In 2001 Hagar Crafts was formed into Hagar Design and registered as a limited company to produce apparel and fashion accessories for the international market. In 2004 they won a Good Design award from the Japan Industrial Design Promotion Organisation for their handbag and accessories lines. They aim to model state-of-the-art production facilities; to meet Fair Trade standards in the treatment of their producers; and to provide top quality products and customer services. The name was changed to HO-T! Apparel and Accessories (HO-T! stands for 'Hagar On-time!') in 2005, as part of a corporate branding exercise. Sales grew from US\$111,000 in 2003, to US\$157,000 in 2005 (see Table 6:1). Of this US\$97,000 was in export sales to America, Australia, Japan, Mexico and Switzerland (Hagar International, 2005, p. 23). They were employing 90 staff, of whom 72 were women. 59 of the women had come through from the Shelter programme.

The success of the catering business has been a similar story. As well as providing catering services to hotels (their contracts include two international 5-star hotels in Phnom Penh) and factories, they have their own restaurant and won the contract to provide catering for the American Embassy. Their sales figures took a dramatic turn in 2005, with new marketing, new contracts and an expansion in the number of staff employed (Table 6:2). This trend continued in the 2006 Annual Report, where staff had almost doubled again, from 72 to 140 people, and the number of meals provided gone up from 370,000 to 600,000 . In the 2005 year they were able to become the first of the Hagar companies to return a financial dividend to the wider Hagar social projects.

Hagar Soya Limited is the most ambitious of the business ventures. Like the other two businesses, the soy milk project began as a cottage industry giving work to women in the sheltered accommodation. In this form they grew to having a 
capacity of 500 litres per day for a product with a very short shelf life that depended on a local distribution. The company sought help from the Mekong Private Sector Development Facility (MPDF), an initiative of the International Finance Corporation (IFC), which is itself linked to the World Bank ${ }^{68}$. With MPDF assistance, and with US\$450,000 directly from the IFC, they were able to finance a US\$1.3 million factory, with a capacity of 12,000 litres per day. In 2004 they received an ISO 9001-2000 certificate for their standards in manufacturing UHT soya milk and beverages. They continue to have technical assistance through MPDF and the Swiss Agency for Development and Cooperation ${ }^{69}$. In 2006 the Soya Milk project had a staff of 88 workers, of whom nearly half had come through the social projects. One of their goals is to develop nutritional products for use by other NGOs and development projects running health and nutrition programmes in Cambodia. In June 2007 the Nestlé company donated a vacated dairy factory in Phnom Penh to Hagar. This will enable them to expand the Soya operations, and will also provide facilities for the other Hagar operations ${ }^{70}$.

Table 6:1 Hagar Sales

\begin{tabular}{|l|r|c|c|}
\hline \multicolumn{4}{|l|}{ Hagar Social Enterprise Sales Statistics (US\$) } \\
\hline & $\mathbf{2 0 0 3}$ & $\mathbf{2 0 0 4}$ & $\mathbf{2 0 0 5}$ \\
\hline Hagar Catering (HCFM) & $\$ 71,265$ & $\$ 84,643$ & $\$ 353,463$ \\
\hline $\begin{array}{l}\text { Hagar Design Ltd (HO-T! Apparel and } \\
\text { Accessories) }\end{array}$ & $\$ 111,510$ & $\$ 113,348$ & $\$ 157,048$ \\
\hline Hagar Soya Company Ltd & & & \\
\hline \multicolumn{1}{|c|}{ Sales Totals } & $\$ 6,000$ & $\$ 127,600$ & $\$ 203,999$ \\
\hline
\end{tabular}

Source: Hagar International Annual Report 2005

The Hagar companies have received international recognition, including from the "Grassroots Business Initiative" (GBI) of the International Finance Corporation (IFC). They are members of the International Fair Trade Association, and have won a number of awards for quality and design. The vision of the companies is that they will 'employ and empower disadvantaged women and their families by helping them achieve financial self-sustainability' and that ' $100 \%$ of the profits

\footnotetext{
${ }^{68}$ See www.ifc.org/mpdf. "MPDF is an advisory services program covering Lao PDR, Vietnam and Cambodia. IFC MPDF's donors are Australia, Canada, the European Union, Finland, IFC, Ireland, Japan, New Zealand, the Netherlands, Norway, Sweden, and Switzerland".

${ }^{69}$ www.hagarinternational.org pdf brochure on Hagar Soya Company Limited

${ }^{70}$ www.hagarinternational.org pdf brochure on Hagar Commercial Center Refurbishment Project
} 
will go into improving the working environments and social and economic status of [their] employees or are given back to support Hagar's various social programmes' (Hagar International, 2006) Between them, in 2006, the three companies were employing 161 women who had come through the social projects.

Table 6:2 Hagar Beneficiaries

\begin{tabular}{|l|l|l|l|}
\hline \multicolumn{3}{|l|}{ Background of beneficiaries of Hagar's Social Action Projects } \\
\hline $\begin{array}{l}\text { Women's Residential } \\
\text { Shelter }\end{array}$ & $\%$ & $\begin{array}{l}\text { Children's Hostels and } \\
\text { Foster Care }\end{array}$ & $\%$ \\
\hline Domestic Violence & $31 \%$ & Abandoned or Orphaned & $53 \%$ \\
\hline Extreme Poverty & $27 \%$ & $\begin{array}{l}\text { Sexual abuse or } \\
\text { Trafficking }\end{array}$ & $30 \%$ \\
\cline { 1 - 3 } Trafficked & $12 \%$ & $\begin{array}{l}\text { Physical or mental } \\
\text { disability }\end{array}$ & $17 \%$ \\
\cline { 1 - 3 } Rape & $24 \%$ & Total 220 boys and girls (2006) \\
\cline { 1 - 2 } Street Women & $6 \%$ & $\begin{array}{l}\text { Source: Hagar International Annual } \\
\text { Report 2006 }\end{array}$ \\
\cline { 1 - 2 } $\begin{array}{l}\text { Total 127 women and their } \\
\text { children (2006) }\end{array}$ & \multicolumn{2}{|l}{} \\
\hline
\end{tabular}

The focus point for Hagar is not the success of these three business enterprises, but the social programmes that they are designed to be a part of and to support. The social projects are extensive, and certainly bigger than anything that could be supported just by the business enterprises, even as successful as these have been. In 2006 donation income for the social projects totalled US\$2.2 million. This came from a variety of sources including Swiss and United States government funds, Foundations, Trusts and religious organisations. The social projects are in fact the core of what Hagar is about: "We are passionate about the recovery and restoration of exploited, destitute and rejected women and children into life in all its fullness" (www.hagarinternational.org Vision Statement). Table 6:2 shows the backgrounds of the women and children who are taken into the programmes. The businesses are a tool in one part of this process. The annual reports reflect these priorities, with the businesses taking six pages out of a forty page report (2005), and three of sixteen pages in the 2006 report.

The first step in the Hagar programme for these women and children is the residential shelters. These are places of safety from violence, places where health 
and nutrition needs are dealt with first, and then where ongoing needs can be assessed. The women and children from these residential programmes are then processed through into other ongoing support programmes. These include a variety of education and vocational training programmes to suit their capability, followed by assistance in reintegration into the community and ongoing counselling services. Reintegration includes assistance with employment opportunities, and suitable housing. Employment opportunities include opportunities in the three Hagar businesses, but also help with other opportunities including micro-credit facilities for starting up their own businesses. Figure 6:3 has the story of one Hagar woman.

Figure 6:3 Hagar Story

\section{Abandoned while pregnant, Thanna finds financial independence}

Thanna (not her real name) was 8 years old when she was raped by her step father. She didn't dare tell anyone about what happened as he threatened to hurt her if she did. When she was 16 years old he raped her again. Scared and confused, Thanna ran away and went to live with a neighbour. A friend then offered to take her to Phnom Penh where she lived with an aunt. During this time she married and became pregnant. She was only two months pregnant when she found out her husband had a mistress. While she was still pregnant her husband abandoned her.

With no support and unable to return to her family, Thanna found she had no one to turn to. After she had the baby she heard about Hagar Shelter from a moto taxi driver. When she arrived at Hagar Shelter she was able to live with other women from similar backgrounds. She was able to undertake literacy classes, counselling and then vocational training in sewing. Once she completed her training she was offered a job at Hagar Design. Today, life is full of hope for Thanna. She is able to support herself as she has enough money to pay the rent, buy food and look after her baby.

Source: Hagar International, Annual Report 2005 p23

Hagar also believe that education and good health facilities are key to reducing the risk of women and children being exposed to abuse. To this end they are building a programme to support Cambodia's provincial school system through improved teacher salaries and provision of educational resources. They are looking to provide soy milk supplements to school children. They have undertaken an extensive water filter project which in 2006 assisted in the construction of 3,857 community water filter systems.

Hagar International is now looking to expand its operations beyond Cambodia. The vision of Hagar has been successful in ways that they are now looking to replicate in other countries where the status of women is an issue. 
"Hagar International has selected Afghanistan, India, Nepal and Vietnam as target countries for Hagar replication due to the status of women, the issue of vulnerability, and the economic situation. Through strategic partnerships with government bodies, foundations and private sectors, Hagar International will implement social programmes that create income generating enterprises and job opportunities for women in these targeted countries. With the long term ambition of ensuring that the individual needs of vulnerable women and children are met and through economic empowerment, women can live healthy and full lives." (Hagar International, 2006, p. 15)

\section{Conclusion}

This chapter has described the individual case study participants. On the surface the six companies are very different to each other, and encounter very different issues in their operation. They are working in different countries, at different stages in development. Thailand, Indonesia and Kyrgyzstan score above average for developing countries in the UNDP Human Development Index ${ }^{71}$, India, Cambodia and Bangladesh are all below this average. The six countries are also all very different in their politics and in their economies. The companies have been deliberately chosen because they are working in very diverse fields of enterprise, and have had varying levels of success. Two of the companies have closed down in the course of the study. One of these is looking to restart in a different format, the other has merged into existing cooperative growers organisations. Most of the companies are very small scale, but one has a budget running into the millions of dollars.

The threads that bring them together are firstly the involvement of expatriate personnel in the founding and running of the company, and secondly in the deliberate choice of context and intention to be pro-poor. While this chapter has been descriptive, the next chapter sets out to analyse the issues for the companies from this pro-poor perspective.

\footnotetext{
${ }^{71}$ See Appendix 2.
} 


\section{Chapter 7: The Case Studies - Analysis of Issues}

This study has not been a quantitative survey of the commercial achievements of SME business in Asia. Rather these specific companies have been chosen to illustrate some of the opportunities and the issues for what is a very specific form of pro-poor business. These are all businesses initiated and run by expatriate entrepreneurs with a desire to make a difference in a developing country. They are all looking to a business model as a pattern for sustainable development. The previous chapter described the companies that they have established, and the level of progress that they have achieved. The aim of this chapter is to draw out some significant issues for the concept of "Making Business Work for Development".

As described in chapter four, one of the issues in the choice of the case studies was to illustrate the full range of different types of business. These were categorised into four areas: primary agricultural production (Aceh Coffee Company); technology transfer (Dimensions, providing engineering services for new technology in backup power generation and hydraulic hose systems; and Hagar Soya Company, bringing in the technology for UHT soy milk production); adapting indigenous technologies and resources for the export market (Freeset, using a local product, jute, and low technology production methods and Shofar, aiming to use intermediate technology in production of a traditional item to an export quality); and services ( $C W E$, providing English language skills for the staff of local businesses; and Hagar Catering and Facilities Management, providing catering skills and services for businesses in Phnom Penh). Within the SME size range which is the focus of this study, these four areas are representative of almost the full range of the globalised commercial market. Issues related to each of these areas have featured in WTO trade negotiations at all levels.

\section{Choice of niche opportunity}

From the above it is clear that there are opportunities in almost any area of business activity. However some of these will have less of a direct and visible impact on poverty issues. The highest immediate impact is from the businesses that offer the highest number of employment opportunities. This should not be 
taken to mean that other businesses cannot also have a valuable pro-poor role. Businesses in the services sector will not generally employ big numbers of people, but the functioning of the business does facilitate the functioning of other businesses that bring employment to a community. This is the sort of role that a firm like Dimensions sees for itself, in the provision of technology and support services.

For each of these businesses it has been important to find the right opportunities in each of the local situations where they operate. This involves flexibility, and the ability to change to meet the real opportunities as they come up. It also involves spending time in the community to discover what the needs are.

\section{Business Priority}

Most of the respondents to my questionnaire were in agreement that for the aim of using business as a development tool to be achieved, the business side of things has to be given a level of priority. The business has to work and has to be successful on a commercial level. Grieve writes very strongly about this, coming back to it several times in his answers. "'Business first' - making profit unashamedly... then out of the surplus which is sure to come from this kind of operation we can ... consider the needs" (Section 1.7.1). He wants to see an increased cash flow in the company generating healthier profits that can then be used for development-oriented activities (Section 2.5). To the question of whether they used any volunteers, his reply is very straight: "No - remember, it's a business. ... We seek for sustainability without non-paid workers." (Section 1.7.2). Binder is also very clear about this in his business plan. "This is a commercial organisation and as such must be run as a profitable business" ${ }^{, 72}$. Shofar Group employees must have the necessary skills for the job, and if they consistently fail to pull their weight they will have their employment contracts terminated.

The exception to this is Aceh Coffee, who have over the time of the study deliberately moved away from the business model for their project. Their

\footnotetext{
${ }^{72}$ Binder, Shofar Group Business Plan
} 
comment is "a trading company ... in these parts put[s] zero back"73. Their alternative is a co-operative model, with the aim of giving a higher return to the producers. I think that this has to be seen as a factor primarily of their target of working with the primary producers. In this situation a company inserted in the processing chain becomes one more 'middle-man' between grower and consumer, adding extra layers of cost which can perhaps be avoided by the formation of a cooperative to handle more of the chain to the benefit of the growers. The aim of the ISCCD project is to give the growers themselves control of the supply chain right through to the warehouse level in the consumer country. This is one of the key points recognised in the Fairtrade model discussed in chapter 3.

A position in between these two is taken by Freeset Bags and the Hagar Project. For both of these the business is important as a tool, but is not the whole of the project. For Freeset Bags, putting in place a Trust to work alongside the business has enabled them to go beyond the purely business functions of the company and to have a medium for the provision of welfare services for the wider community where they live. The Trust has served more than one function for them. It has assisted the business, by being the medium for bringing in foreign capital for the purchase of the building. Ownership of the building is with the Trust, and the company pays rent to the Trust for the use of the building. This gives the Trust a source of income, which is used to fund a variety of activities such as literacy training for Freeset workers, a crèche facility for children of the staff, health care (their plan is that this will become a clinic for the wider community, not just their staff workers), community crisis aid (funding and help for needs within the surrounding community), and alcohol/drug addiction assistance. Their plans for the future include setting up a filtered water facility that will provide pure drinking water for the surrounding community also, and possibly the setting up of some sort of schooling facility for children living in the district who are currently unable to get to any of the government education facilities.

So far the Freeset Trust has only been able to access foreign funding for the capital purchase of the building. They are hoping to extend the registration of the

${ }^{73}$ Aceh Coffee, personal email 
Trust to a category that would enable them to bring in funds for some of the other activities.

Sustainability is an issue for all of these businesses. None of these enterprises has yet reached the point where they are truly covering all their costs in the full sense of a commercial operation. This would have to include the full costs of any expatriate staff, and the other costs that a New Zealand firm would have to meet, such as costs of capital, or the payment of a dividend to shareholders. Of the case study ventures, Hagar, CWE and Dimensions have probably come the closest to this level of sustainability. While for the first five or six years of operation Dimensions did not pay any expatriate salaries, they are now in the position where they are paying these, and also some items like Director's fees. In the $2006-2007$ year around Bangladesh Taka 600,000 (approximately NZ\$12,000) was paid out in expatriate costs.

There is some discussion about what is an appropriate level of expatriate payments for a company working in Asia and calling itself 'pro-poor'. Expatriate salaries paid by multinational companies and organisations like the United Nations working in Asia are high - often even by Western standards, and usually also include various hardship allowances. Such salaries are totally out of proportion to the salaries of the nationals of the country that they are working in. The companies in this study consider such salaries inappropriate for the 'pro-poor' vision that they have, and also an impossible extra burden on the company in its development phases. As mentioned in the discussion on Freeset Bags, Osborne considers that the company could pay up to two expatriate salaries at a rate that would be sufficient to live comfortably in India - but these would not be salaries at Western rates ${ }^{74}$. An issue that they have is that some Asian countries require expatriate salaries to be at a certain rate before they will issue work permits and visas (Bangladesh and Thailand both have this requirement. The minimum expatriate salaries that have to be paid are double what Dimensions and CWE would consider necessary for living in those countries).

\footnotetext{
${ }^{74}$ Osborne asks "are we talking about equitable salaries or salaries that would be expected in the home country?” (emails 22/6/08)
} 
As discussed in the case studies, Hilton would prefer not to pay any expatriate costs from Freeset Bags company income. However they are paying market rental on the building which is owned by their Trust. This rental money is then being used to fund their welfare programmes. If they did not own the building, and were paying this rental to an outside owner, then they would not have any funds for these other programmes. They argue that the over-riding goal of the project is not to make a profit. They are "In business to set people free"75, and this is the priority. Having a sustainable business is a tool towards this goal, but the business does not have to be supporting the total project. If the total project requires a continued input of external funding, then that is acceptable.

\section{Social Investment}

Freeset's capital for setting up the company, and then later for purchase of the building was raised in New Zealand. This fundraising has been marketed as investment opportunities for socially concerned investors in New Zealand ${ }^{76}$. This concept of 'social investment' has been important for all the companies in the study in raising capital for their enterprises. This is investment marketed in the developed countries as an investment which will have no financial return, or only a low rate of interest payment, but which will give a 'social dividend' in poverty alleviation. Social investment is different from socially responsible investment (SRI), which is the application of defined ethical standards by investors to the companies in which they will invest (see table $7: 1)^{77}$, although at times the two may overlap. There are varying degrees of social investment being offered by different organisations. At one end what is being asked for is in effect a donation, but with the understanding that because the donated funds will become part of the operating capital of a company, they will be used to generate a profit that goes to helping poverty alleviation in some way. This is seen as using funds in a way that is more sustainable than a normal charity donation. This is the sort of investment being invited by Freeset Bags. It has an appeal particularly to business oriented people who want to see their money being used in ways that generate more money. Other social investment organisations offer the opportunity to invest funds

\footnotetext{
${ }^{75}$ Hilton, Case Study Questionnaire, Section 2.2

${ }^{76}$ See www.marketplacers.co.nz/profile/investment.asp

${ }^{77}$ For an example of Socially Responsible Investments see www.socialinvest.org/
} 
for a set period, with a guarantee of a refund at the end of the period. Some will even offer some level of interest payment for the period of the investment, although this will be at lower than commercial rates.

An example of the latter is www.microplace.com/, who offer interest rates of between $0 \%$ and $3 \%$ for funds that will be used by microcredit organisations in a wide range of countries and organisations around the world. Fast Company reporter Cheryl Dahle writes of the concept of venture funding in not-for-profit projects as an idea gaining acceptance in fundraising circles, bringing business funding methods to the area of social projects (Dahle, 2006). The article is looking at it from the point of view of funding for educational institutions and other notfor-profits in the US, but the idea of business style investments in pro-poor projects with the expectation of low or no financial return is one which has gained a degree of recognition in various ways.

Figure 7:1 Social Investment Vs Ethical Investment

\section{The difference between social investment and ethical or socially responsible investment}

Social investments may generate a financial return, but the main objective in making them is to help specified beneficiaries. Social investment is primarily, if not exclusively, concerned with furthering these objectives, rather than any financial return to the investor. It is not the same thing as ethical, or socially responsible investment. Ethical, or socially responsible, investment is investment in the ordinary, financial sense, but recognising ethical objections to investment in certain areas such as armaments or the gambling industry.

Adapted from www.charity-commission.gov.uk/supportingcharities/casi.asp

It is interesting to contrast the scale of the projects and to compare "return on investment" in terms of capital involved, number of people employed and product sales generated between Hagar as the largest of the case study projects, and Shofar as the smallest. While all the Hagar companies started small, they have in recent years had some large scale capital investment. The biggest of these investments has been in the soy milk factory, which cost them US\$1.3 million in 2003, and 
since then they were gifted the Nestlé factory in 2007. By comparison Shofar had a start-up capital investment of US\$14,300. Hagar employed 161 women across the three companies (of the target community of disadvantaged women - the total number of employees in the companies is double this) and generated combined sales of US\$715,000, or sales of approximately US\$4,500 per employee. Shofar employed 6 people from their community, with sales of US\$8,300 or US\$1,400 per employee.

\section{The Development Outcomes}

Section 3 of the Case Study Questionnaire was aimed at development outcomes. These development outcomes are discussed in the Introduction. There were several issues that I was looking for here. At the most basic level was the question of poverty alleviation. How successful were these ventures at the fundamental issue of poverty alleviation? Next was the issue of capacity building. Are these businesses training and equipping people in their communities? Finally there were what NZAID calls the 'cross-cutting issues' of development: human rights, gender equity, environmental issues, and individual and community empowerment.

So how do my case study companies come out on these issues? Both $C W E$ and Dimensions freely admit that they cannot point to any particular gains in the area of direct poverty alleviation. Neither of them are big employers. Beyond the fact that they are working in developing world countries, they are not particularly targeting the lower deciles of the population in those countries. Both of these companies are working much more at the level of capacity building. CWE has been building the ability of Chiang Mai based companies to operate in the global market, where English is the primary medium of communication. Dimensions is working at an infrastructure level, equipping other local organisations to better cope with the vagaries of the Bangladesh infrastructure. In the course of this they are introducing some items of technology, and giving training to their staff in the specialist areas that they are working in.

In terms of the 'cross-cutting' issues also both of these companies have fairly limited input. Both would consider that they model good practice in relation to 
human rights and gender equity issues in their company practices, but beyond this they do not specifically target these issues in the wider community in any way. Dimensions are working in a field where environmental issues are more immediately to the front, and here their policy is that they will 'do the right thing' in their own practice, even if it is going to cost more. They will also actively encouraging recycling practices.

In terms of number of people potentially impacted by the project, Aceh Coffee/ISCCD and the combined Hagar concerns have the biggest scope. Aceh Coffee/ISCCD are going to directly employ 165 people growing to 450 over the next three years, with potential benefits for over 2000 coffee growers. At the time of responding to the questionnaire they were still in setting up stages, and so could not supply any figures for actual returns to the growers. However the potential in terms of employment opportunities and through increased yields and improved market prices for the crop is considerable. It will need another study in a few years' time to confirm whether this potential is realised.

Aceh Coffee/ISCCD will also score well on the 'cross-cutting' issues. The Gayo Highlands region is ethnically diverse, with a high proportion of minority groups, including Gayo, Padang and Batak, as well as the majority Javanese and Acehnese people. (TransFair USA, 2005). Development of the project will depend on promoting and supporting the peace process that began after the tsunami. This process is under threat, with reported incidents of renewed violence (AP Report, 2008). They are aiming to have a high proportion of women employed in the factory production. On environmental issues they are working to get organic and carbon neutral certifications. The cooperative focus that they have moved to is one that inherently gives a high profile to issues of community empowerment. Again, another study in a few years' time will be needed to confirm whether this potential has been realised.

The Hagar business ventures employed a combined total of 161 women from their target community (disadvantaged/abused Cambodian women) in 2006, and this is set to grow considerably with the expansion plans that they have. However the Hagar impact goes far beyond just the business ventures. The full Hagar project combines business and a wide range of more "traditional" development 
projects. Business ventures are considered to be one tool in a range of programmes designed to have a very holistic approach to the needs of disadvantaged and abused women and children. The three businesses are expected to be successful as businesses. They are also expected to specifically improve the conditions of their employees, and ultimately to make a financial dividend for the wider social projects. They are not expected to fund the wider programme, and as we have seen, donation funding for the development activities is bigger even than the turnover of the businesses.

In order to compare development outcomes between Hagar and the other case studies we have to limit the discussion to the development outcomes of the three businesses. The other programmes for shelter, rehabilitation, education, vocational training and prevention are all significant development programmes in their own right, and worth study and assessment. The overall impact of the total Hagar project is something that reaches to thousands of people, not just the 161 employed in the businesses. However that is beyond the scope of this thesis, which is looking specifically at the outcomes of business ventures.

Considered separately, each of the Hagar businesses is a significant achievement. To take disadvantaged, poorly educated and abused women, and to give them the skills and the confidence to work in an international standard catering operation, serving the guests at a five star international hotel, is impressive. The challenges of running a food product factory in a country like Cambodia, maintaining standards and output, are huge, without adding the commitment to taking on staff that no one else would employ, and giving them a secure environment, where they can learn and participate. They certainly score high for capacity building. They score high also on the 'cross-cutting' issues of human rights and gender, where they are specifically targeting the issue of gender abuse and discrimination.

Hagar's published material does not deal with the issue of the environmental impacts of any of the companies, nor does it touch on any issues of participatory involvement in decision making by women of the target community. The women are clearly empowered to make their own decisions and to change their own lives, but there is no mention of participation in company or project decision making. 
For development outcomes Freeset Bags is a very appealing project with proven results in all three areas of poverty alleviation, capacity building and the 'crosscutting' issues. They have now been running for seven years. The number of women employed has grown steadily. They are concerned at the most basic level with the human rights of women trapped and enslaved by the sex trade. In parallel with the business of bag production they are working to build up a set of community services which will empower and build the community. In this area they are picking up something of the Hagar model. Hilton acknowledges this, and sees the Hagar project as one of his inspirations for what he is doing ${ }^{78}$. The jute bags which are the core of the business part of the project are 'environmentally friendly', being made with natural jute fibre, using very low technology processes in the manufacture.

The Living Fragrance Candles project of the Shofar Group is the smallest project in the case studies. In immediate poverty alleviation terms, only six people are employed, so the effect is minute. The significance of the project is in bringing a manufacturing business to a poor and under-developed region that has a very negative image in the country, and modelling a successful small scale business for the community ${ }^{79}$. The proof of this concept will come in a few years' time, because, as Binder acknowledges, the business needs to grow significantly in the next couple of years to reach sustainability. The Binders' choice of region, town and product have all been strategic from this capacity building perspective. In line with the size and scope of the business their environmental footprint is small. Within the business they practice gender equality.

Any sense of community empowerment from this project has to come from their concept that they are modelling a viable business process that others in the community can learn from and put into practice for themselves. In an environment where a certain level of corruption is seen as normal and even necessary for success, they are aiming to demonstrate that the alternative is possible. In a region that is seen as a neglected backwater of the national economy they are aiming to prove that successful business startups are possible, and that economic progress

\footnotetext{
${ }^{78}$ Hilton, personal email communication

${ }^{79}$ Binder, Case Study Questionnaire, Sections 3.1.3; 3.1 .4
} 
for the region is attainable. Whatever the success of the project as a business, the ability of the community to learn from this example and the replicate it in their own businesses will be a measure of the success of the project in 'development' terms.

\section{Modelling Best Practice}

The concept that they are "modelling best practice" is common to all the businesses in the study, and is something that deserves some discussion. It is an idea that has measures of both truth and danger. How is "best practice" defined, and who has defined it? Inappropriately applied it will come to many Asians as yet another form of colonialism - white people coming and saying "we know what is best for you"! To what degree is "best practice" in New Zealand also best practice in Asia, let alone in the specific situations of Dhaka, Calcutta or Naryn?

Standards of "Best Practice" are a feature of the era of globalisation. The study of Geography refers to the practice of "benchmarking", where countries and organisations are ranked against standardised measures of comparison. Standardisation of practices makes comparison easier. An accountant can pick up a set of accounts from any company and very quickly have a good idea of the financial condition of the company or organisation. In the commercial world an underlying concept of "best practice" is to maximise profit, something which clearly has a different priority level for the case study businesses.

The case study organisations use of the term "best practice" is referring more to issues such as standards of ethical behaviour, and maintenance of the quality standards that are needed for taking part in the global market. They are thinking too of issues such as human rights and social justice. For them best practice includes modelling equity in the treatment of employees, and the hiring of staff who might not get a chance elsewhere.

"Best practice" is also a matter of establishing systems that will work efficiently. While systems efficiency is a concept that comes from industrial society, it is not one that is necessarily high on the priority list in an agricultural society. Businesses that are focussed on working with people who are less educated or disadvantaged in some way, need to model efficient systems. In this sense "best 
practice" is accumulated experience of the things that can go wrong for a business, and the ways that have been found by experience and practice to protect against these. Good accounting systems are there for the protection of both the company and the employee. They are there to protect against malpractice, and to assist in creating transparency.

There does have to be a recognition of cultural differences, and the influence that these may have on what can be defined as best practice. Grieve talks about the importance of building good relationships with local officialdom. In a Western context this would not be considered necessary. In Western terms officials are there to do a job, and should do that regardless of any personal relationship with the applicant. Anything else has overtones of undue use of influence or corrupt practice. Asian society is more relationship oriented, and to fail to take note of this is considered rude and insulting.

\section{Accountability}

"Above all, for humanitarianism to live up to its principles and great possibilities, it must be based on respect for the rights of, empathy with not pity of, and on overarching human solidarity with those who are vulnerable." 80

An important question for all of these projects needs to be the issue of accountability. A New Zealand business, unless it is a small enterprise totally owned by a single person or family, will have layers of accountability and reporting. At the very least there will be some level of reporting and accountability to the shareholders who have put up the funds for the enterprise. In the development world accountability is considered an even more important issue. A development project requires a stakeholder analysis that looks at both the funders and the beneficiaries of a project, and considers accountability issues in both directions. The question was asked specifically in the questionnaire (Section $3.5)$, and received a variety of answers.

${ }^{80}$ (Omara-Otunnu, 2007) Professor Amii Omara-Otunnu, UNESCO Chair in Human Rights, Executive-Director of the UConn-ANC Partnership and Professor of History at the University of Connecticut, Storrs., in an article about the reported kidnapping of children for adoption by a French NGO in Chad. http://blackstarnews.com/ 
Most of the case studies saw the question of accountability much more in terms of the business model rather than the development model. That is, they accepted the need for accountability to boards and investors, and gave less attention to ways of being accountable to the beneficiaries (employees and local communities). In development practice this is a serious issue. As referred to in Chapter 5, the experience of development practitioners is that projects undertaken without adequate consultation with, participation by, and accountability to, the proposed beneficiaries are significantly less effective and less sustainable. Contemporary development practice puts a high priority on participatory involvement and accountability. In the melding of the business and development models this is an area which deserves more attention.

It needs to be emphasised here that this is also a weakness in the way that this study has been conducted. The distance approach of the questionnaire and followup emails and discussions has limited consultation to the managers of each business. A more thorough approach would have involved visiting each of the businesses and conducting interviews with the employees and the surrounding communities to determine the actual level of participation and involvement perceived by them. 


\section{Chapter 8: Conclusion}

This thesis has set out to examine the question of whether business can be made to work for development. Proponents of neoliberal economic globalisation claim that economic growth is by definition good for the poor, and that the opening of global markets gives unprecedented opportunities for poverty reduction. The literature study shows that such claims are much exaggerated, and that the global market does not automatically work to benefit the poor. The thesis examines the claims and the problems with them, before investigating the concept of 'pro-poor business'. What is needed to structure business to have a positive bias in favour of the poor? There are some basic and fairly simple steps which all business could adopt to assist in poverty alleviation. The thesis then looks at the case studies of six businesses that have in various ways gone even further to make themselves actively pro-poor.

\section{The opportunities of globalisation}

In chapter two I began the discussion on globalisation by looking at Thomas Friedman's theory of how globalisation is 'flattening' the world by opening up new opportunities for participation in the global economy (Friedman, 2006). Globalisation is described as qualitatively different to previous eras of international trade and economic relationships (Gereffi, 1999; Larner \& Le Heron, 2002). Globalisation crosses traditional international political, economic and cultural boundaries with new levels of integration and cross-boundary processes. The globalisation described by Friedman is particularly based on the revolution in information technology (IT). Information in digitised form can be instantly transferred anywhere in the world either for the processing of data or for communication about production orders. Thus India can supply data processing services for the banking systems of America and New Zealand; Taiwan, Thailand and Indonesia can each produce parts for computers that are assembled in Malaysia for customers from Europe, America and Australia who place their orders through call centres in India. The permutations and combinations are endless, and pay little heed to political boundaries. The argument is that this creates opportunities for participation in the global chains of commodity production, and in the global provision of services, which can be taken up by 
anyone anywhere in the world. The theory goes on to suggest that in fact the poor countries have the advantage in this global market precisely because of the low wages that they can pay their workers. Even highly skilled engineers or computer programmers in India are paid a lot less than people doing the exact equivalent work in the developed countries. They can then win the contracts, do the work and benefit from the transaction, bringing new wealth for themselves and for their countries.

Proponents of this economic globalisation point to the new wealth shown in the mega-cities of Asia. Twelve Asian cities now have populations of over ten million people. These cities show the signs of wealth, with multi-storied office blocks housing the local corporate offices of all the same global corporations as are found in any developed world city. Shopping complexes sell the same goods, and the streets are jammed with the same brands of cars. Their airports cater daily for thousands of international passengers. These cities seem to be alive with energy and progress, and at least on the surface there are few signs of poverty. Globalisation is clearly working for them, and is equally obviously the solution to poverty. All that is needed is to find the centres of poverty and bring them into this global market.

\section{Neoliberal economic policies}

Chapter three looks at the conditions required to enable the developing countries to take advantage of the global opportunities. The IMF, the World Bank and the WTO are the institutions tasked with the responsibility of global economic stability and growth. They are responsible for advising the poor countries on what is needed to set up the right environment for growth. Since the 1980s the guiding principles for these institutions have been the theories of neoliberal economics. Proponents of globalisation find the 'free-market' principles very compatible with their ideals. Globalisation, with its new levels of integration of processes, production and services across political boundaries, is facilitated when this process of integration is carried right through to the legislative and compliance regimes of all the countries that are involved. Putting these two things globalisation and neoliberal economics - together has brought in an era of the 
standardisation of global trade legislation, with the reduction of tariffs and the removal of national barriers and national market protections.

The debate continues to be fierce, but the evidence is increasingly clear that unfettered, unregulated globalisation does not of itself alleviate poverty, and in many cases can contribute to a worsening situation (Stiglitz, 2003). Many countries that have implemented neoliberal policy have seen a decrease in their rate of GDP growth. In countries that have had an increase in GDP growth this has not been evenly distributed, resulting in widening disparity between rich and poor. Countries that have established their own industries on a sound footing first, and have then entered the global market are the ones that have succeeded best (Ha-Joon Chang, 2007). For some who have been able to seize the opportunities globalisation has created enormous wealth. However those below the poverty line are not in a position to benefit from these opportunities. They do not have the education or the economic resources to enter the market. For them globalisation has been yet one more form of neo-colonial exploitation.

For these people to experience the benefits of globalisation there have to be propoor policies in place that will protect their interests, and that will facilitate their entry into the market (Birdsall et al., 2008). Certainly the humanitarian arguments for this are strong. Justice demands a more equitable distribution of global resources. A global economy ought to take care of those at the fringes, and ensure that they are not being abused by systems over which they have no control. However the arguments for implementing pro-poor policy are not just purely humanitarian. There is a strong market argument that by excluding the poor from participation the market is placing serious limits on its own potential for growth. Leaving aside for the moment discussions about sustainability issues, if the poor who are currently living at the subsistence level of 'a dollar a day' (the current slogan defining absolute poverty) can be brought into the market as producers and consumers then there is potential for considerable market growth (The Allen Consulting Group, 2007; Servaas Storm, 2008b).

Too often neoliberal economic globalisation, when it has looked at the poverty issues of developing countries has seen the poor only as potential producers, not as potential consumers. The poor are cheap labour to be exploited for the 
production of goods which are consumed by the rich. How many of the sweatshop workers in Asia will ever be able to afford to buy any of the items they are producing? Real, equitable growth will bring these workers into the equation as both producers and consumers.

\section{Pro-poor business}

This leads to the basic question of this thesis. What is needed to make the global market work for the poor? The market does not automatically work for the poor, but it is possible to have conditions that will enable it to happen. These conditions do not need to be anti-competitive, or anti-market. The alternative trading organisations (ATOs) have been advocates for pro-poor business, and have carved out for themselves a significant niche market based on trying to give the primary producer an ethical return. What is needed is to take those principles and move them into acceptance by mainstream business operators? Chapter four has begun the task of looking at what makes a pro-poor business, one that will work to the advantage of the poor. At the core of these is an ethical stance about what makes good business.

One of the issues that becomes clear is the particular opportunity for positive, propoor action by small to medium sized enterprise (SMEs). They are at the production end of the commodity chain. They have the local and community knowledge to enable them to engage with the needs of the poor, and to build employment opportunity at this level. In order to do this they do need the support and understanding of larger enterprises further up the chain. Too often they are under pressure to keep wages low, with the threat that otherwise production will be moved elsewhere. In fact at this level when wage structures are kept so low a significant increase in wages will have a minimal effect on the final sales cost of the product.

Related to this is the opportunity for entrepreneurial action. The SME is acknowledged as the venue that gives the most freedom and the most incentive for entrepreneurial activity. Entrepreneurs with a pro-poor bias are the people who are able to find and create opportunities for businesses that will have a real impact on poverty. 


\section{The Case Studies}

This is the context for the case study enterprises examined in the thesis. The case studies have looked at six SME companies set up in six Asian countries by Western entrepreneurs with varying degrees of pro-poor intentionality. They are all working in very different countries, with different conditions and different styles of business. The study looks at the issues that each faces, the degree to which they are able to target specific needs, and the development outcomes that they are able to achieve. The discussion of the case studies identifies some common priorities and issues for the case study businesses.

For some of these businesses 'pro-poor' is interpreted in its widest sense of contributing to the infrastructure or skills development of a developing country. So Dimensions, providing engineering services in Bangladesh see this as facilitating other businesses as part of the overall development of infrastructure in the country and $C W E$ saw building English language skills as part of helping Thai businesses to compete in the global economy. The other four businesses are being more proactive about targeting some more specific community or area of need, such as the Gayo Mountain coffee growers of Aceh; the prostitute communities of Kolkatta or abused women and children in Phnom Penh.

For some the business is the only objective of the project. The business is there to function as a business, and by its presence it will help the community. For them the business is the priority. They believe that an effective business will be of most use to the community, and so that, rather than any social action programmes, is the focus of their efforts. Others see the business as one prong of a multi-faceted project aimed at meeting the poverty needs of a community, and so they are providing a variety of community services alongside the business. The business contributes financially and in other ways to these services.

All of the businesses have found it to be important to be flexible enough to be able to learn and adapt to the needs of the situation as they have progressed. For the Aceh Coffee Company this has been a complete change to a cooperative format of operation. $C W E$ has closed down in its present format, but is looking to find another format that will be better suited to the situation in Thailand. Freeset is looking to move into new products made from new materials, so alongside the 
existing range of jute bags they are looking at making screen printed cotton $t$ shirts. Dimensions has been open to a variety of engineering based options.

One of the things that all these businesses have in common is that they believe that they are in a position to model 'best practice' conditions that other businesses will be able to adopt and use. In their choice of products or services, in their standards of workplace and employment conditions, and in the standards of the goods or services that they produce they are providing models for both the global market operators and for local businesses. For the global market operators they are modelling opportunities for positive interactions with poverty issues. For local businesses in the communities they have chosen to work in they are demonstrating the opportunities that exist in the wider global scene, and the standards that are needed in order to enter this market.

A significant area of analysis for the case studies is development outcomes. The question asked here is, if they were a development project rather than a business, how would they be assessed? The development questions asked are:

- Poverty alleviation: how effective have they been in poverty alleviation for the communities where they work? The simplest measure is employment generation. How many jobs have been created - directly or indirectly? Three of the case studies are employing significant numbers of people. Two of the case studies see their impact as being more in the facilitation of others, rather than in direct numbers of employees. The smallest unit, Shofar, agree that the candle making venture needs to grow significantly in order to become sustainable, but they also believe in the creation of a number of separate units rather than a single large conglomerate. They are still in the early stages, but this is their vision of the way forward.

- Capacity building: what training opportunities are they giving their staff? In seeing themselves as modelling opportunities for others, in what ways are they cooperating with other businesses to build wider capacity? All of the companies give their staff on-the-job training, with skills that will in the long term be transferable to other employment. Hagar's business ventures all came out of the training programmes that they were offering 
for the women coming through their shelter programmes. Shofar are very clear in their intention to network with other local businesses, sharing experiences and offering technical assistance and consultancy services.

- Human rights and gender equity: all of the companies in the study set out to model good human rights observance in their own business practice. Hagar and Freeset are both more intentional in specifically targeting human rights and gender issues by their choice of target community. Hagar is focussed on abused and destitute women and children, while Freeset has focussed on alternative income generation for women forced into prostitution.

- Environment: environmental issues are not a primary focus for any of these ventures, however they would all see the modelling of good environmental practices in their own work as a part of their input for the wider community. They seek to demonstrate by their own practice that it is possible for a commercially viable business to also have good environmental awareness.

- Individual and community empowerment: these people all see the very nature of the business venture as empowering. Individual employees are empowered by gaining employment, and learning employable skills. Communities of poverty are empowered by the presence of a viable business venture that they can see is intended to be for their benefit rather than one that is there to exploit their poverty.

- The study does raise the question of accountability. The business model of accountability is to boards and investors rather than to employees and local communities. A development model requires a stakeholder analysis that looks wider than this, and considers funders and beneficiaries, managers, employees and the wider community within which the project is functioning, and who stand to benefit from its operation. This is an area where participation by the community is not straightforward, and would need some careful consideration. Clearly the owners and managers of the 
brothels of Sonagacchi will have a different perspective on consultation about the operations of Freeset!

Global corporations, financial and trade organisations unite to affirm the benefits of globalisation. Globalisation will bring the end of poverty, and there will be a new era of prosperity for all. But they can hardly be counted as unbiased participants. Unless and until the corporations can start operating beyond the exclusive self interest of their shareholders, the benefits of globalisation will not touch the 'vast craters' of poverty. Unless and until the global organisations target issues of poverty their policies provide only for the wealthy and the powerful. Too much of globalisation has been based on the exploitation of inequality, aiming only to maximise short term gain. What is needed is a vision of the greater potential that could be generated by a more equitable distribution of gains.

There are indeed new opportunities resulting from globalisation. The case studies of this thesis demonstrate that business can take advantage of those opportunities and enable the poor to become participants in the global economy. Pro-poor business is not just possible, in the long term it makes good business sense. Propoor business does offer sustainable gains in poverty reduction, and is a valid development tool. 


\section{Appendix 1: The Questionnaire, Consent Form and Information Sheet}

\section{Questionnaire:}

Thank you for agreeing to take part in this study. Please answer the following questions in the way that you think will best represent the activities of your company. Use this electronic file, inserting extra lines as needed after every question. If there is useful information in other documents, please attach these, and put a note by the question indicating where the information is.

- Please ask me to clarify anything that you are not sure about.

- Please return the completed questionnaire to me by email.

My contact details:

Email: paul.thompson@paradise.net.nz

Skype name: bideshi

Phone: +64 49736777 or mobile +64 211317861

Postal Address: 46 Hathaway Ave, Karori, Wellington, New Zealand

\section{Section I: Background information on your company}

1.1. What is the registered Trading Name of the company?

1.2. Where is it registered?

1.3. What is the nature of the business that the company is set up for?

1.4. Where are your operations based (City \& Country)?

1.5. The Governance structure of the company - who are you accountable to?

1.5.1. Do you have a Board of Directors? How are they appointed, how often do they meet, and where are they based?

1.5.2. Who do you make reports to, and how often?

1.6. Financial Issues

1.6.1. What capital investment has been put into the company, both at start-up and since then?

1.6.2. What non-financial inputs have been required in setting up and running the company?

1.6.3. Can you give me figures for the annual turnover of the company since the start? 


\subsection{People}

1.7.1. When the company was set up, was there a specific group of people that you were aiming to help? If so, who are they and how were they selected?

1.7.2. How many people are involved in the company now?

- How many Staff?

- Any volunteers?

- How many people benefit from the operation of the company?

1.8. Brief history - date of establishment, etc

\section{Section II: Vision, Goals and Evaluation of the Company}

2.1. What was your vision in setting up this company? What were you hoping to achieve? What goals did you set yourself?

2.2. Do you have any published Mission or Vision statements? Where have these been used, and what response has there been? If possible please send me copies of these.

2.3. What barriers/obstacles have you experienced in setting up and running the Company?

2.3.1. Government level - how easy has it been to register the company in the country that you are operating in, and to set up the administrative functions like taxation, working with the local/city authorities, etc.?

2.3.2. What has been the Community acceptance of the company? Have there been groups which have opposed the company's work?

\subsubsection{Trading/business level}

2.4. What assistance have you had in setting up the company and getting established?

2.4.1. Have you been helped by any Business Incubation or Business Development Services? What training have they been able to give you? What follow up guidance/help?

\subsubsection{Are you a member of any relevant trade associations?}


2.4.3. Have you had any contact with or help from Fair Trade or other similar support groups?

2.5. What is your evaluation of the success of the company so far, and how would you like to see it develop?

\section{Section III: Development Outcomes}

In this section I want you to try to look at the company from a development perspective. This is not the same as asking about the success of the company as a business. Rather it is asking what the company achieving in things like poverty alleviation, and what is it doing to help the development of the host community / country? The following questions are what would be asked of a development project, but we want to see how your company would compare on these issues.

3.1. Poverty alleviation - what is your company doing for the poor?

3.1.1. How many people are employed, and how are they chosen?

3.1.2. What training do you provide?

3.1.3. In what ways does the company programme improve access for the community to improved knowledge and technology?

3.1.4. Can you point to any returns to the community beyond just the number of people who are employed?

3.2. Environmental and Sustainability issues

3.2.1. What is the environmental impact of your company activities in terms of use of renewable resources, energy use, carbon output, and the disposal of waste products?

3.2.2. Does your company have any activities or policies that work to improve the environment conditions of the community?

3.2.3. What would happen to the company and to your employees if because of accident, illness or other reason you had to leave the country? Would the company have to close down? If not, what contingency plans do you have for it to continue?

3.3. Development projects are expected to have a positive discrimination in favour of the least privileged in the community. Does the company have policies on Human Rights issues, gender equality in employment, and other issues of equity in the local community? To what extent is the 
company able to address any of these issues in the wider community from which your employees are drawn?

3.4. Issues of Partnership and Participation

3.4.1. To what extent are you building partnerships with other local businesses or organisations which will build their values and capability? Do you see any of your locally recruited staff being able to become partners in the business?

3.4.2. To what extent have you, or do you, consult with local community leaders / people before making decisions about the directions and activities of the company?

3.4.3. What opportunities for input on company decision making do your staff have?

3.5. Accountability and Monitoring

What accountability do you have to any of the following, and do any of them have the right to monitor and comment on the impacts of the company activity?

- New Zealand based board members or investors?

- Local community leaders?

- Members of the community that you are trying to help?

- Any other individual(s) or groups?

I appreciate the work that you are doing, and the fact that this survey will have taken time and effort. THANK YOU! 


\section{CONSENT TO PARTICIPATION IN RESEARCH}

\section{Title of project: Making Business Work for Development: Issues for Small to Medium Enterprises}

\section{Researcher: Paul Thompson}

\section{Supervisor: Professor John Overton}

I have received an information sheet about this research project. I have had an opportunity to ask questions and have them answered to my satisfaction. I understand that I may withdraw myself from this project without having to give reasons, and that if I do so any information that I have given will not be used.

- I understand that I may identify specified items of the information given by me as background to my situation which I wish to have kept confidential to the researcher and the supervisor, or which, if used must be in a form that is not attributable to me. These will be marked on the returned questionnaire, or requested in the course of any telephone interview.

- I understand that any telephone interviews will be recorded, and that I may ask for a copy of the recording if I have any questions about material used.

- I understand that I will have an opportunity to review all information about me or my company before publication.

- I understand that the data I provide will not be used for any other purpose or released to others without my written consent.

- I understand that all information provided by me in the course of this study will be kept in a secure location; will only be seen by the researcher and supervisor; and will be destroyed within 3 years of completion of the study.

Please tick the following items if you agree to them:

You may identify me by name in the thesis.

You may identify my company by name in the thesis.

$\square$ I have attached conditions to the use of my information (please attach with the consent form).

$\square$ Subject to any items that I request confidentiality for as specified above, you have my permission to attribute my statements to me.

I would like to receive a summary of the results of this research when it is completed. agree to take part in this research

Signature: Date:

Address:

Email: 


\section{Fil Enterprises}

\section{Paul Thompson}

Thank you for agreeing to be a part of this study. The purpose of this thesis is to examine ways in which business ventures can be used to promote development in the Least Developed Countries (LDCs). An NZAID brochure says "The potential gains from trade far outweigh the gains from international aid". They quote an Oxfam study showing that a $1 \%$ increase in world export share for each developing region could potentially reduce poverty by $12 \%$. There are obvious conditions to this, and experience has shown that in many cases trade liberalization has not been pro-development. The aim of this research is to look at business ventures such as yours, and to examine the advantages and disadvantages in development terms. I hope that coming from the study we will be able to identify some of the conditions necessary to 'make business work for development'.

To introduce myself briefly: I was born in a missionary family. My parents worked in Egypt and then in Eritrea. I returned to New Zealand as a teenager and completed secondary school at Tawa College in Wellington, before going on to a degree in Psychology from Victoria University. I then went to Carey Baptist College in Auckland and completed a BD degree. At the end of the 1970s my wife Adrienne and I went to Bangladesh with the tranzsend team. In Bangladesh we were involved with a variety of church and development programmes. Through the 1990s I was Team Leader for the tranzsend team in Bangladesh. Back in New Zealand I am a member of the tranzsend Council, a member of the board of RMS Refugee Resettlement, and working part time for the Churches Agency on Social Issues (CASI) as a researcher while studying to complete the MDevStudies degree from VUW.

This research is being done for the thesis component of a Masters in Development Studies (MDevStudies) from Victoria University of Wellington (VUW). The information gathered from these questionnaires and follow up interviews and discussions with you will be written up as part of the thesis. On completion a copy of the thesis will be deposited with the University Library. The questionnaire and procedures for this study have been subject to the approval of the Human Ethics procedures of the University. You may at any point indicate any information that you would prefer not to see published (or if published, to be in a form that is not attributable to you or your organization). You also have the right to correct any information about your venture that is used in the thesis. I will send you a draft version of all information that I intend to use, to give you the opportunity to ensure that factual information is correct. All material supplied by you and not used in the thesis will be kept confidential and under secure storage, and will be destroyed within 3 years of completion of the thesis.

Should you decide at any stage to withdraw from the project any information already given by you will not be used in the thesis.

My supervisor for this thesis is Professor John Overton. If you have any questions about the project, or any concerns about the ways in which information could be used you may contact him. His email address is john.overton@vuw.ac.nz, or he may be contacted through the University: Prof John Overton, Director, Graduate Programme in Development Studies, VUW, PO Box 600, Wellington, New Zealand.

My contact details are: email: paul.thompson@paradise.net.nz; Postal address: 46 Hathaway Ave, Karori, Wellington, New Zealand; Phone: +64 49736777 or +64 211317861 (mobile); Skype Name: bideshi 


\section{Appendix 2: Comparative Country Statistics}

\begin{tabular}{|c|c|c|c|c|c|c|c|c|c|c|c|c|c|c|c|c|}
\hline \multicolumn{17}{|c|}{ Human Development Report $2007 / 2008$} \\
\hline Indicators & & $\begin{array}{l}\text { All developing } \\
\text { countries }\end{array}$ & & OECD & & Thailand & & Indonesia & & Kyrgyzstan & India & & Cambodia & & Bangladesh & \\
\hline Population (millions, est.) & 2007 & & & & & 65.068 & & 234.693 & & 5.214 & $1,129.86$ & & 13.995 & & 150.448 & \\
\hline Area (thousand sq. Km) & & & & & & 514.00 & & $1,919.44$ & & 198.5 & $3,287.59$ & & 181.04 & & 144.00 & \\
\hline Human development index & 2005 & 0.691 & & 0.916 & & 0.781 & & 0.728 & & 0.696 & 0.619 & & 0.598 & & 0.547 & \\
\hline $\begin{array}{l}\text { Life expectancy at birth, annual } \\
\text { estimates (years) }\end{array}$ & $2005 a$ & 66.1 & & 78.3 & & 69.6 & & 69.7 & & 65.6 & 63.7 & & 58 & & 63.1 & \\
\hline $\begin{array}{l}\text { Adult literacy rate (\% aged } 15 \\
\text { and older) }\end{array}$ & $\begin{array}{l}1995- \\
2005 b\end{array}$ & 76.6 & & .. & & 92.6 & & 90.4 & & 98.7 & 61 & & 73.6 & & 47.5 & \\
\hline $\begin{array}{l}\text { Combined gross enrolment ratio } \\
\text { for primary, secondary and } \\
\text { tertiary education }(\%)\end{array}$ & 2005 & 64.1 & & 88.6 & & 71.2 & $f$ & 68.2 & $f$ & 77.7 & 63.8 & $f$ & 60 & $f$ & 56 & $g$ \\
\hline GDP per capita (PPP US\$) & 2005 & 5,282 & & 29,197 & & 8,677 & & 3,843 & & 1,927 & 3,452 & $\mathrm{~h}$ & 2,727 & $\mathrm{~h}$ & 2,053 & \\
\hline Life expectancy index & & 0.685 & & 0.888 & & 0.743 & & 0.745 & & 0.676 & 0.645 & & 0.55 & & 0.635 & \\
\hline Education index & & 0.725 & & 0.912 & & 0.855 & & 0.83 & & 0.917 & 0.62 & & 0.691 & & 0.503 & \\
\hline GDP index & & 0.662 & & 0.947 & & 0.745 & & 0.609 & & 0.494 & 0.591 & & 0.552 & & 0.504 & \\
\hline Imports of goods and services & 1990 & 24 & & 18 & & 42 & & 24 & & 50 & 9 & & 13 & & 14 & \\
\hline (\% of GDP) & 2005 & 40 & & 23 & $\mathrm{i}$ & 75 & & 29 & & 58 & 24 & & 74 & & 23 & \\
\hline Exports of goods and services & 1990 & 25 & & 17 & & 34 & & 25 & & 29 & 7 & & 6 & & 6 & \\
\hline (\% of GDP) & 2005 & 44 & & 22 & $\mathrm{i}$ & 74 & & 34 & & 39 & 21 & & 65 & & 17 & \\
\hline Primary exports (\% of & $1990 c$ & 40 & & 21 & & 36 & & 65 & & .. & 28 & & .. & & 22 & j \\
\hline merchandise exports) & 2005 & 28 & & 18 & & 22 & & 53 & & 35 & 29 & & 3 & i & 10 & $\mathrm{i}$ \\
\hline Manufactured exports (\% of & 1990 & 59 & & 77 & & 63 & & 35 & & .. & 70 & & .. & & 77 & \\
\hline merchandise exports) & 2005 & 71 & & 79 & & 77 & & 47 & & 27 & 70 & & 97 & i & 90 & $\mathrm{i}$ \\
\hline High-technology exports (\% of & 1990 & 10.4 & k & 18.1 & & 20.7 & & 1.2 & & .. & 2.4 & & .. & & 0.1 & \\
\hline manufactured exports) & 2005 & 28.3 & & 18.2 & & 26.6 & & 16.3 & & 2.2 & 4.9 & $\mathrm{i}$ & 0.2 & $\mathrm{i}$ & $()$. & $\mathrm{i}$ \\
\hline Terms of trade $(2000=100)$ d,e & $\begin{array}{l}2004- \\
2005\end{array}$ &.. & &.. & & 93 & & 104 & &.. & 76 & &.. & & 88 & \\
\hline $\begin{array}{l}\text { Electricity consumption per } \\
\text { capita (kilowatt-hours) }\end{array}$ & 2004 & 1,221 & & 8,795 & & 2,020 & 1 & 476 & I & 2,320 & 618 & & 10 & I & 154 & \\
\hline Unemployment (\%) (note o) & 2004 & & & 6.7 & & 1.7 & & 9.7 & $g$ & 18 & 7.2 & g & 2.5 & & 4.3 & $p$ \\
\hline Population below poverty line $\%$ & 2004 & & & & & 13.6 & & 27.1 & & 41 & 28.6 & & 35 & & 49.8 & \\
\hline Gini Index (1989 - 2004) & $\mathrm{M}$ & & & 33 & $\mathrm{n}$ & 42 & & 34.3 & & 30.3 & 36.8 & & 41.7 & & 33.4 & \\
\hline
\end{tabular}


Making Business Work for Development

\section{Notes:}

a. The HDI rank is determined using HDI values to the sixth decimal point.

b. Data refer to national literacy estimates from censuses or surveys conducted between 1995 and 2005, unless otherwise specified. Due to differences in methodology and timeliness of underlying data, comparisons across countries and over time should be made with caution. For more details, see http://www.uis.unesco.org/.

c. Primary exports include exports of agricultural raw materials, food, fuels, ores and metals as defined in the Standard International Trade Classification.

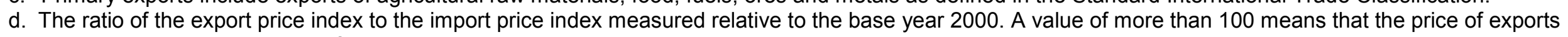
has risen relative to the price of imports.

e. Data refer to the most recent year available during the period specified, unless otherwise noted.

f. National or UNESCO Institute for Statistics estimate.

g. Data refer to a year other than that specified.

h. World Bank estimate based on regression.

i. Data refer to an earlier year than that specified; from 2000 onwards.

j. One or more of the components of primary exports are missing.

k. Data refer to the closest available year between 1988 and 1992.

I. Data are estimates produced by the UN Statistics Division.

m. Gini Index source: World Bank 2007. World Development Indicators 2007. Higher numbers indicate greater inequality

n. For OECD, Gini Index is the average of 15 of the 30 OECD members for 2000 data. www.imf.org/external/pubs/ft/scr/2008/cr0823.pdf

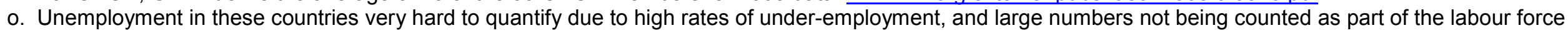

p. Bangladesh figure taken from www.un-bd.org/bgd/index.html

Source: http://hdrstats.undp.org/buildtables/ accessed 1/4/08 


\section{Appendix 3: Country Information}

\section{Bangladesh}

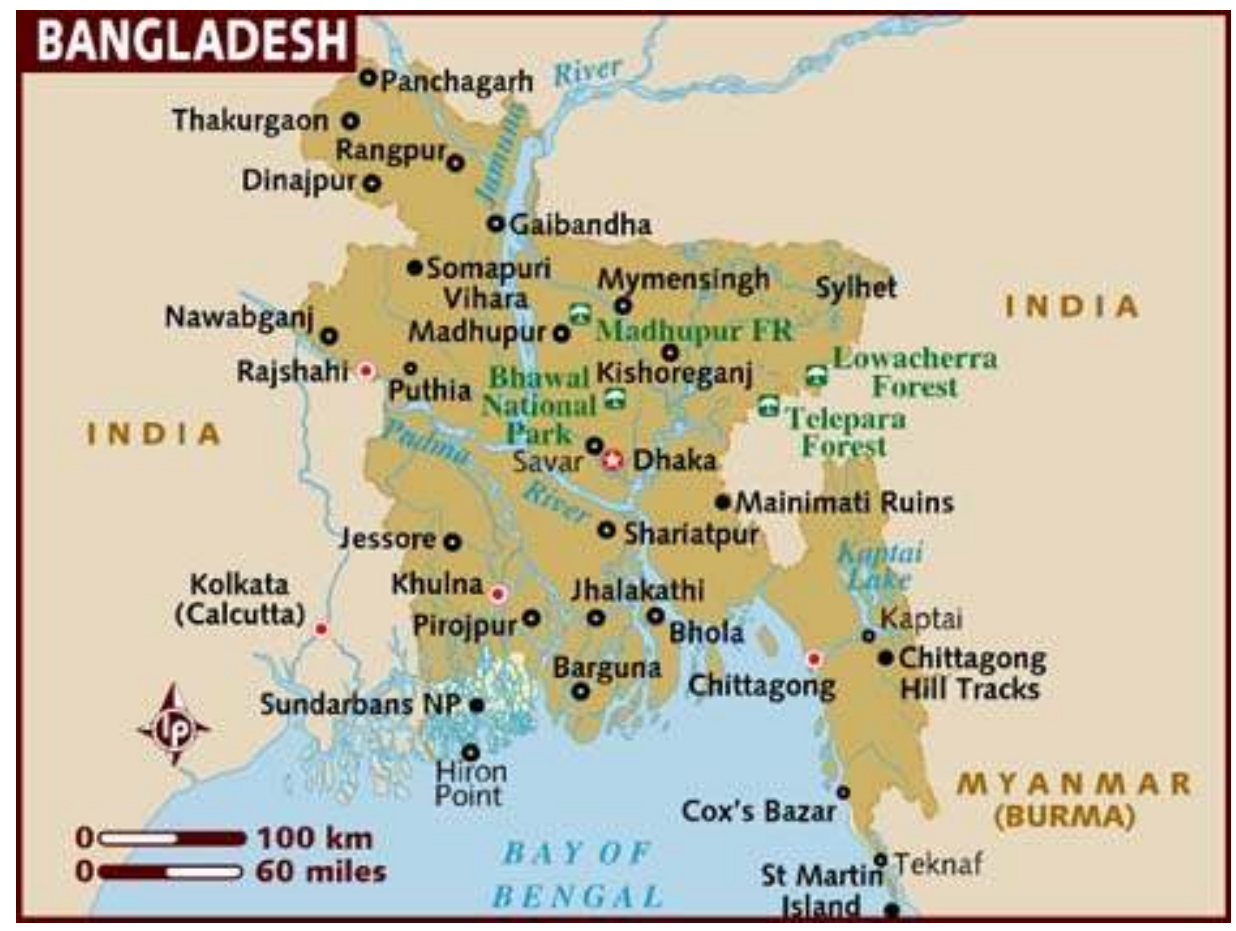

Map Source: Lonely Planet.com

Bangladesh was the eastern half of the state of Bengal in British India. The departure of the British and the partition of India on religious grounds in 1947 saw East Bengal, which had a majority Muslim population, become East Pakistan. East and West Pakistan were a strange anomaly among nations - one nation divided in two by a subcontinent. The only things the two halves had in common were religion and government, and they could never agree on the government. They were different in language, culture and economic foundation. The differences were such that in 1971 East Pakistan broke away and become Bangladesh. That start has been reflected in continued political instability.

Geographically Bangladesh is the lower delta area for three rivers that bring considerable amounts of water into the country. The Ganges and the Brahmaputra rivers between them drain both the southern and the northern slopes of a large portion of the Himalayan range, including the whole of Nepal. The third river, the Meghna, is the shortest of the three, but is draining one of the highest rainfall areas in the world. 
The regular flooding which is a feature of Bangladesh, while bringing disruption and hardship, also ensures the continued high fertility of the land.

\section{Country Data}

\begin{tabular}{|c|c|}
\hline People & \\
\hline Ethnic Groups & Bengali $98 \%$, tribal groups and other $2 \%$ \\
\hline Religions & Muslim $87 \%$, Hindu 12\%, Other 1\% \\
\hline \multicolumn{2}{|l|}{ Economy } \\
\hline GDP composition by Sector & $\begin{array}{l}\text { agriculture: } 20.5 \%, \\
\text { industry: } 26.7 \%, \\
\text { services: } 52.8 \% \text { (2004 est.) }\end{array}$ \\
\hline Labour force by occupation & $\begin{array}{l}\text { Agriculture: } 63 \% \\
\text { industry: } 11 \%, \\
\text { services: } 26 \%\end{array}$ \\
\hline Export destinations & $\begin{array}{l}\text { US } 22.4 \% \text {, Germany } 14.5 \% \text {, UK } 11.2 \% \text {, France } 6.9 \% \text {, } \\
\text { Italy } 4 \% \text { (2004 est) }\end{array}$ \\
\hline Import sources & $\begin{array}{l}\text { India } 15.1 \% \text {, China } 12.5 \% \text {, Singapore } 7.5 \% \text {, Kuwait } \\
5.5 \% \text {, Japan } 5.3 \% \text {, Hong Kong } 4.5 \% \text { (2004 est) }\end{array}$ \\
\hline
\end{tabular}

\section{Cambodia}

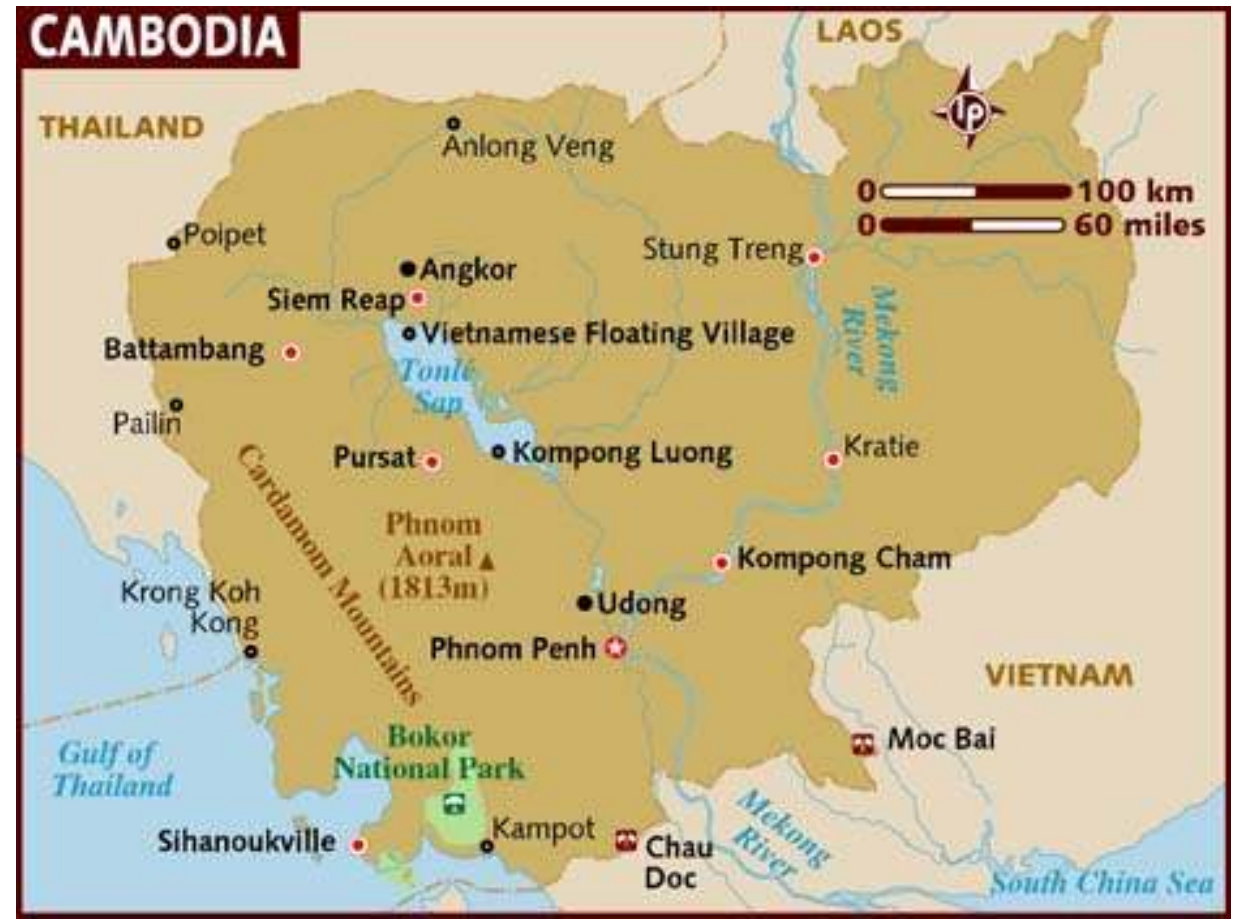

Map source: Lonely Planet.com 
Country Data

\begin{tabular}{|c|c|}
\hline People & \\
\hline Ethnic Groups & Khmer $90 \%$, Vietnamese $5 \%$, Chinese $1 \%$, other $4 \%$ \\
\hline Religions & Theravada Buddhist $95 \%$, other $5 \%$ \\
\hline \multicolumn{2}{|l|}{ Economy } \\
\hline GDP composition by Sector & $\begin{array}{l}\text { agriculture: } 31 \% \\
\text { industry: } 26 \% \\
\text { services: } 43 \% \text { (2007 est.) }\end{array}$ \\
\hline Labour force by occupation & $\begin{array}{l}\text { agriculture: } 75 \% \\
\text { industry: NA\% } \\
\text { services: NA\% (2004 est.) }\end{array}$ \\
\hline Export destinations & $\begin{array}{l}\text { US } 53.3 \% \text {, Hong Kong } 15.2 \% \text {, Germany } 6.6 \% \text {, UK } \\
4.3 \%(2006)\end{array}$ \\
\hline Import sources & $\begin{array}{l}\text { Hong Kong } 18.1 \% \text {, China } 17.5 \% \text {, Thailand } 13.9 \% \text {, } \\
\text { Taiwan } 12.7 \% \text {, Vietnam } 9 \% \text {, Singapore } 5.3 \% \text {, South } \\
\text { Korea } 4.9 \% \text {, Japan } 4.3 \%(2006)\end{array}$ \\
\hline
\end{tabular}

\section{Women in Cambodia}

- One in 36 women die in childbirth.

- $19 \%$ of women use contraception.

- About 14,000 sex workers in Cambodia have been tricked or forced into the business.

- $66 \%$ of pregnant women have anaemia.

- 1 in 4 women in Cambodia are victims of domestic violence.

- $41 \%$ of adult women are illiterate.

- $70 \%$ of the population does not have access to safe water.

- 20 out of 123 elected Parliamentarians are women.

\section{Children in Cambodia}

- 110 out of every 1,000 babies die at birth.

- 140 out of every 1,000 children die before the age of five.

- 2.3 million children aged 5 to 17 work $-37,000$ of them work away from home.

- As many as one third of sex workers in Cambodia are under the age of 18.

- At least 3,000 girls from Southern Vietnam, in 1998, were trafficked to Cambodia for prostitution - more than $15 \%$ were under the age of 15 .

- Hundreds of Cambodians are deported from Thailand every month - half are children. Many are re-trafficked back to Thailand and the cycle is repeated. 


\section{West Bengal, India}

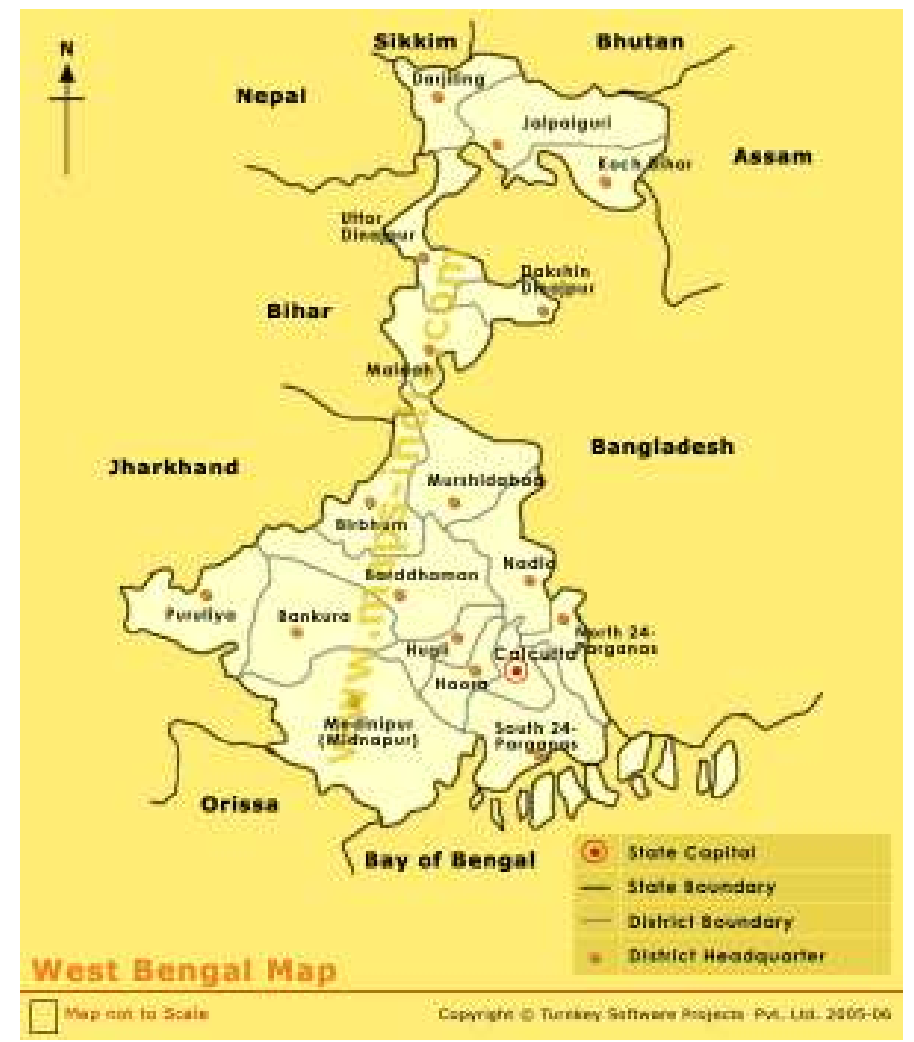

Map: www.maps-india.com/west-bengal/

In the British colonial period, what is now West Bengal was part of the wider state of Bengal. In the early part of the colonial period, Calcutta/Kolkata was the capital of the British Indian Empire. With the departure of the British, Bengal was divided in half on religious grounds, with the eastern half becoming what is now Bangladesh. Apart from the issue of religion, Bangladesh and West Bengal have a lot in common. They have a culture that (apart from the religious influences) has much in common, and a common language. The geography of both is shaped by the fact that they are both part of the delta region of the Ganges and the Brahmaputra rivers. They are also both among the most densely populated regions in the world. West Bengal is the most densely populated state of the Indian Federation, with $2.7 \%$ of the land area, but $7.8 \%$ of the population, for an average population density of 904 people per square kilometre in 2001.

The state government of West Bengal is the world's longest running democratically elected communist government, having been in power since 1977. Despite being under a communist government, West Bengal took an active part in the economic 
reforms of the 1990s. On a state level these have made a big difference. The State is now a net food and electricity exporter. Industry has been modernised, and they are getting into IT services. In economic terms they have been one of the fastest growing states in India, with an annual growth rate of around 7\% through the 1990s.

However despite these macro level improvements, there has been less change in terms of poverty issues. The UNDP sponsored West Bengal Human Development Report 2004 (Ghosh, 2004) comments that the period was marked by very low rates of employment generation. Rural employment grew at less than $0.6 \%$ per annum, which was only one third of the population growth rate. Urban employment growth averaged $2.3 \%$ per annum, which was less than in pre-reform periods. Per capita food consumption has declined, and declining expenditure on public services has affected the services available to the poor. Industrial modernisation has in fact reduced employment options in the factories. While, as mentioned above, reforms in the agricultural sector have made the state a net food exporter, returns on agricultural produce have declined, while the costs of agricultural inputs has gone up (Ghosh, 2004, pp. $6-8)$.

Country Data

\begin{tabular}{|c|c|c|}
\hline & India & West Bengal $^{\text {a }}$ \\
\hline \multicolumn{3}{|l|}{ People } \\
\hline Population & $1,129,860,000(2007)$ & $82,000,000(2001)$ \\
\hline Ethnic Groups & $\begin{array}{l}\text { Indo-Aryan } 72 \% \text {, Dravidian } \\
25 \% \text {, Mongoloid and other } \\
3 \%\end{array}$ & $\begin{array}{l}\text { Bengali; Scheduled caste } \\
28.6 \% \text {, tribal } 5.8 \%\end{array}$ \\
\hline Religions & $\begin{array}{l}\text { Hindu } 80.5 \% \text {, Muslim } 13.4 \% \text {, } \\
\text { Christian } 2.3 \% \text {, Sikh } 1.9 \% \text {, } \\
\text { other } 1.8 \% \text {, unspecified } 0.1 \%\end{array}$ & $\begin{array}{l}\text { Majority Hindu; } \\
\text { Muslim } 28.6 \%\end{array}$ \\
\hline \multicolumn{3}{|l|}{ Economy } \\
\hline GDP & PPP US\$ 3,452 & $\begin{array}{l}\text { State DP (2001) Indian Rs } \\
16,072 \text { per capita }{ }^{b}(=U S \$ 375 \\
\text { a, current exchange rates) } \\
\end{array}$ \\
\hline Below Poverty line & $28.6 \%(2004)$ & $31.85 \%(1999 / 2000)$ \\
\hline $\begin{array}{l}\text { GDP composition } \\
\text { by Sector }\end{array}$ & $\begin{array}{l}\text { agriculture: } 16.6 \% \\
\text { industry: } 28.4 \% \\
\text { services: } 55 \% \text { (2007 est.) }\end{array}$ & \\
\hline $\begin{array}{l}\text { Labour force by } \\
\text { occupation }\end{array}$ & $\begin{array}{l}\text { agriculture: } 60 \% \\
\text { industry: } 12 \% \\
\text { services: } 28 \%(2003)\end{array}$ & \\
\hline
\end{tabular}

Notes:

a Taken from West Bengal Human Development Report 2004 (Ghosh, 2004)

b (Ghosh, 2004, p. 5)

c This is not calculated in PPP rates. 


\section{Indonesia and the Province/Special Region of Aceh}

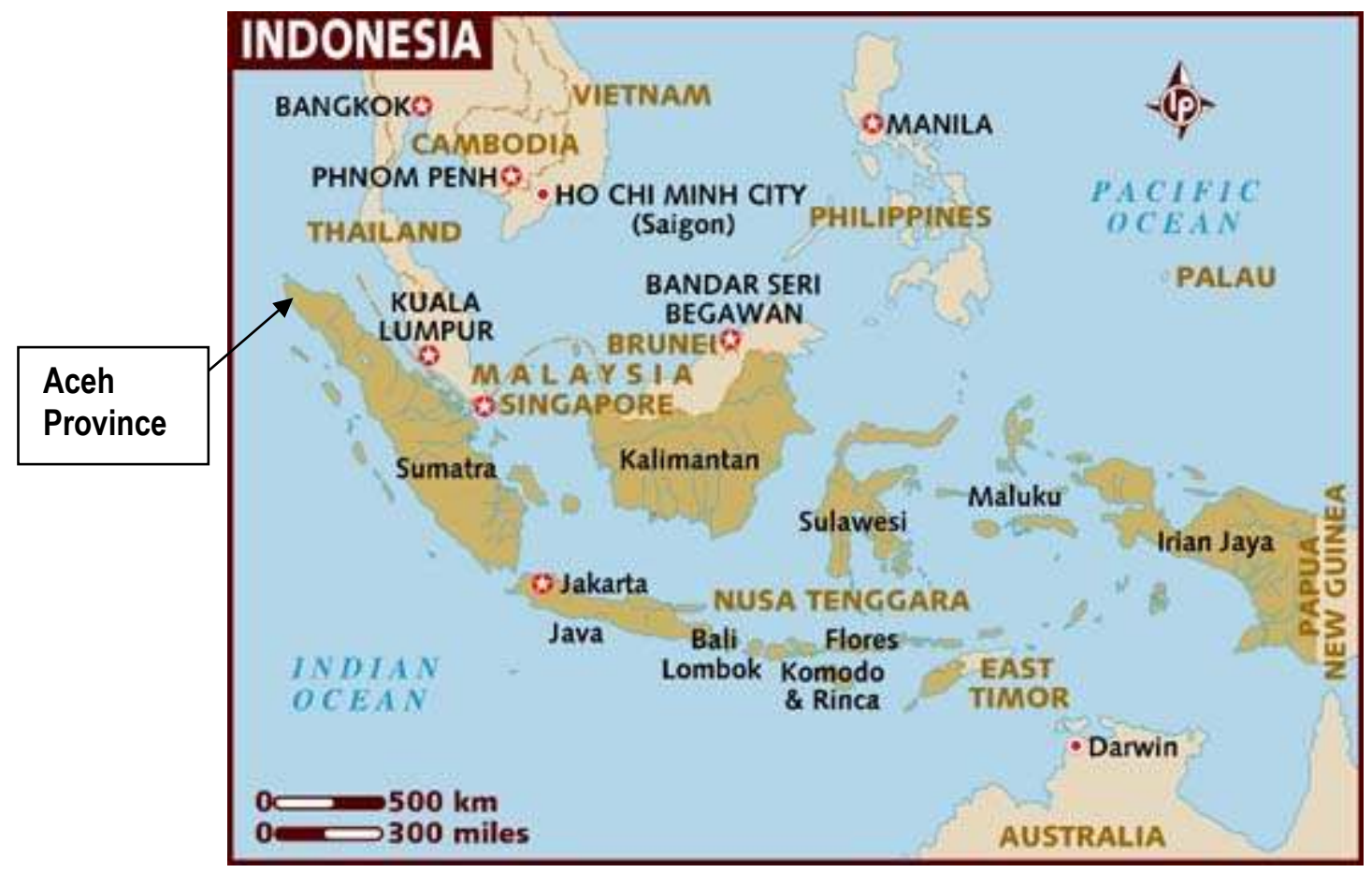

Map Source: Lonely Planet.com

Indonesia is a country composed of some 6000 inhabited islands and another around 11,500 uninhabited islands. These islands occupy the strategic sea lanes between the Pacific Ocean and East Asian countries and India, West Asia, and Africa. This is a shipping route with a history of thousands of years, which continues to be significant as otherwise east-west shipping has to circle around Australia. Indonesians come from many different ethnic groups, and this has at times caused tensions and civil war.

\section{Country Data}

\begin{tabular}{|l|l|}
\hline People & \\
\hline Ethnic Groups & $\begin{array}{l}\text { Javanese 40.6\%, Sundanese 15\%, Madurese 3.3\%, } \\
\text { Minangkabau 2.7\%, Betawi 2.4\%, Bugis 2.4\%, } \\
\text { Banten 2\%, Banjar 1.7\%, other or unspecified 29.9\% } \\
\text { (2000 census) }\end{array}$ \\
\hline Religions & $\begin{array}{l}\text { Muslim 86.1\%, Protestant 5.7\%, Roman Catholic 3\%, } \\
\text { Hindu 1.8\%, other or unspecified 3.4\% (2000 census) }\end{array}$ \\
\hline Economy & $\begin{array}{l}\text { agriculture: } 12.4 \% \\
\text { industry: } 47.7 \% \\
\text { services: } 39.9 \%(2007 \text { est.) }\end{array}$ \\
\hline Labour force by occupation & $\begin{array}{l}\text { agriculture: } 43.3 \% \\
\text { industry: } 18 \% \\
\text { services: } 38.7 \% \text { (2004 est.) }\end{array}$ \\
\hline
\end{tabular}




\begin{tabular}{|l|l|}
\hline Export destinations & Japan $19.4 \%$, Singapore $11.8 \%$, US $11.5 \%$, China \\
& $7.7 \%$, South Korea $6.4 \%$, Taiwan 4.2\% (2006) \\
\hline Import sources & $\begin{array}{l}\text { Singapore } 29.6 \% \text {, China } 11.2 \%, \text { Japan } 8.8 \%, \text { South } \\
\text { Korea 5.3\%, Malaysia 4.8\% }(2006)\end{array}$ \\
\hline
\end{tabular}

\section{Aceh Special Region and Gayo Mountain Coffee Growing Area}

The province of Aceh comprises the northern portion of the island of Sumatra. The population of Aceh was 3,855,000 in 2003. Indonesia has for a long time supported the resettlement of people from more densely populated regions into the provinces. This was one of the causes of the separatist violence that affected the province for many years. The coastal regions were devastated by the December 2004 tsunami. The tsunami killed about 170,000 people in Aceh, and left hundreds of thousands homeless. Following the tsunami the government and the separatists reached a peace agreement that gives Aceh a degree of self government. The Gayo Mountains are a part of the range of mountains through the centre of the island, and are a significant coffee growing area ${ }^{81}$.

\footnotetext{
${ }^{81}$ See http://encarta.msn.com/encyclopedia_761557582_2/Aceh.html
} 


\section{Kyrgyzstan}

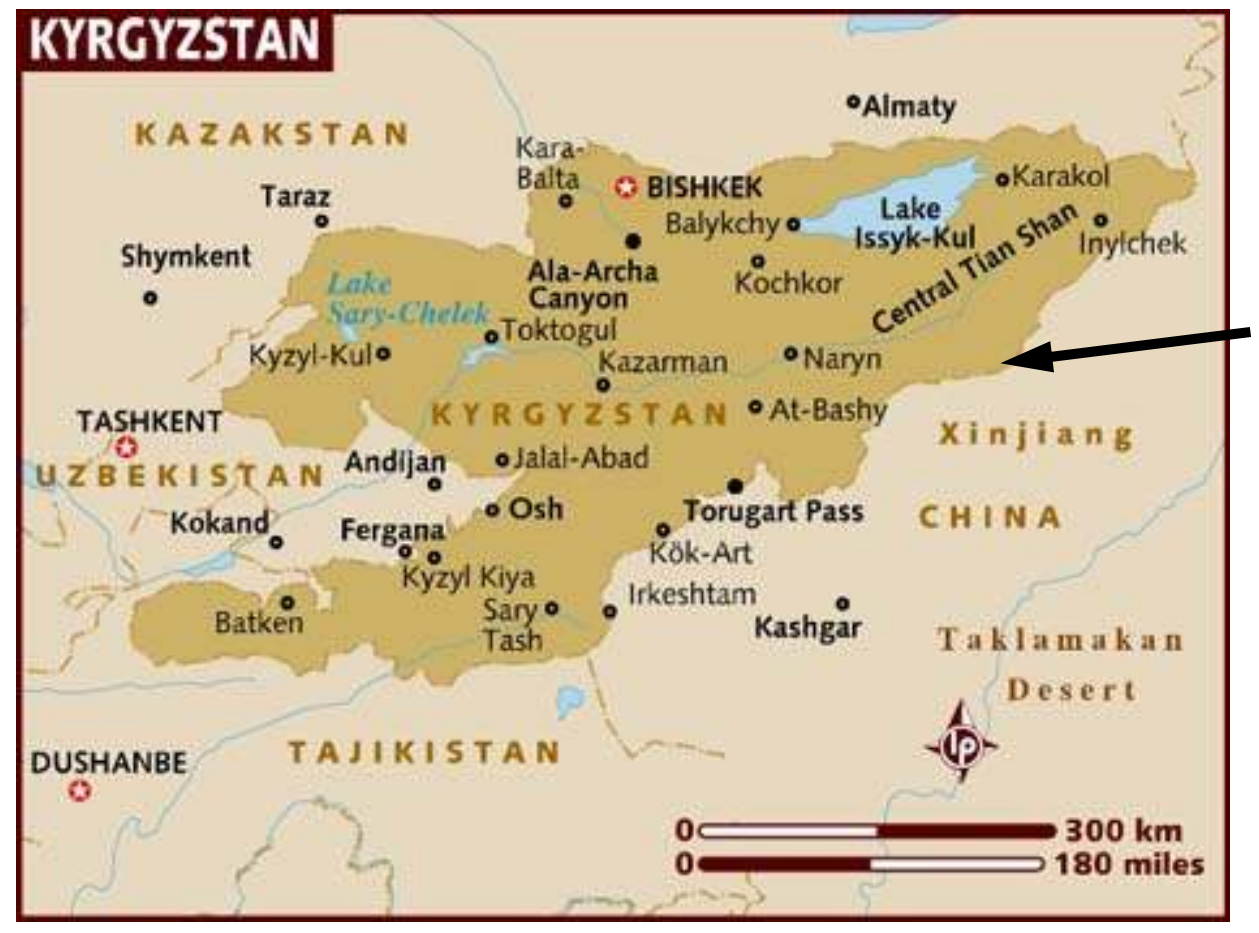

(Map source: Lonely Planet.com)

\section{History}

Most of Kyrgyzstan was annexed to Russia by the Tsarists in 1876. It became a Soviet Republic in 1936, and, with the dissolution of the USSR in 1991 became an independent state. Following independence Kyrgyzstan was the first Commonwealth of Independent States (CIS) country to join the WTO, and entered a vigorous market, land and regulatory systems reform policy in line with IMF policy.

The Kyrgyz Republic is classified by the World Bank as a 'low income' country.

\section{Country Data}

\begin{tabular}{|l|l|}
\hline People & \\
\hline Ethnic Groups & $\begin{array}{l}\text { Kyrgyz 64.9\%, Uzbek 13.8\%, Russian 12.5\%, } \\
\text { Dungan 1.1\%, Ukrainian 1\%, Uygur 1\%, other 5.7\% } \\
\text { (1999 census) }\end{array}$ \\
\hline Religions & $\begin{array}{l}\text { Muslim 75\%, Russian Orthodox Christian, 20\%, } \\
\text { Other 5\% }\end{array}$ \\
\hline Economy & $\begin{array}{l}\text { agriculture: } 31.7 \%, \\
\text { industry: } 19.8 \%, \\
\text { services: } 48.4 \%(2007 \text { est. })\end{array}$ \\
\hline GDP composition by Sector & $\begin{array}{l}\text { agriculture: } 55 \%, \\
\text { industry: } 15 \%, \\
\text { services: } 30 \%(2000 \text { est.) }\end{array}$ \\
\hline Labour force by occupation
\end{tabular}




\begin{tabular}{|l|l|}
\hline Export destinations & Switzerland 26.1\%, Kazakhstan 20.4\%, Russia \\
& $19.3 \%$, Afghanistan 9.4\%, China 4.8\% (2006) \\
\hline Import sources & $\begin{array}{l}\text { Russia 38.1\%, China 14.4\%, Kazakhstan 11.7\%, US } \\
5.7 \%(2006)\end{array}$ \\
\hline
\end{tabular}

Naryn Oblast (District/Province)

The largest of 6 administrative regions of Kyrgyzstan, but also the least developed and poorest. Transport infrastructure in the province, and to the rest of the country is poor. It is the south eastern part of the country, bordering with China. Most of the population are the original Kyrgyz people (99\%). Semi-nomadic sheep farming is the main occupation.

Population (2005) 266,200

Area 46,710 square $\mathrm{Km}$

\section{Naryn City}

The city is the administrative centre for the Naryn Oblast (district). The city lies along the Naryn river at an altitude of around 2100 metres. The city was originally founded as a fortified point on the old silk trading route from China to Europe.

The city population is around 40,000 to 45,000 . The town suffered in the economic decline that followed the breakup of the Soviet Union and the withdrawal of Russian administration. 


\section{Thailand}

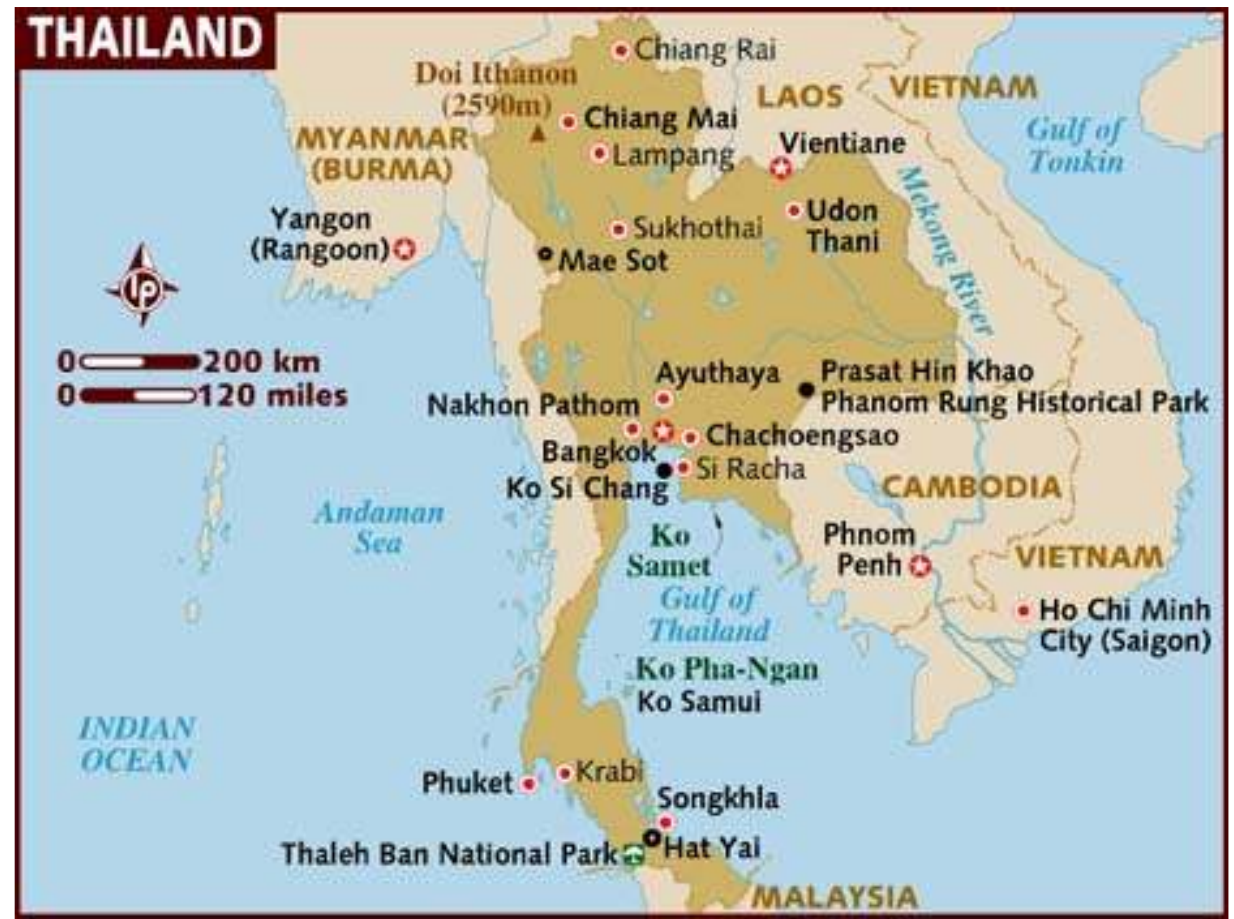

(Map Source: Lonely Planet.com)

A Buddhist Thai Kingdom was established by the mid fourteenth century. Thailand is one Asian country that was never taken over by any of the European colonial powers. By careful diplomacy they were always able to avoid this, even when all the surrounding countries were taken over.

\section{Country Data}

\begin{tabular}{|l|l|}
\hline People & \\
\hline Ethnic Groups & Thai $75 \%$, Chinese $14 \%$, other $11 \%$ \\
\hline Religions & Buddhist $94.6 \%$, Muslim $4.6 \%$, Christian $0.7 \%$, \\
\hline Economy & $\begin{array}{l}\text { agriculture: } 10.8 \% \\
\text { industry: } 45.3 \% \\
\text { services: } 43.8 \%(2007 \text { est. })\end{array}$ \\
\hline LDP composition by Sector & $\begin{array}{l}\text { agriculture: } 49 \% \\
\text { industry: } 14 \% \\
\text { services: } 37 \%(2000 \text { est.) }\end{array}$ \\
\hline Export destinations & $\begin{array}{l}\text { US } 15 \%, \text { Japan } 12.6 \%, \text { China } 9 \%, \text { Singapore } 6.4 \%, \\
\text { Hong Kong 5.5\%, Malaysia 5.1\% }(2006)\end{array}$ \\
\hline Import sources & $\begin{array}{l}\text { Japan } 19.9 \%, \text { China } 10.6 \%, \text { US } 7.5 \%, \text { Malaysia } 6.6 \%, \\
\text { UAE 5.5\%, Singapore 4.4\% }(2006)\end{array}$ \\
\hline
\end{tabular}




\section{Appendix 3 Country Information Sources}

Columbia Encyclopedia, Sixth Edition 2007, www.encyclopedia.com

Encyclopaedia Britannica Online 2008 www.britannica.com

Lonely Planet Guides, www.lonelyplanet.com/

Scott, R. (2001). Handcrafts of Naryn Oblast, Kyrgyzstan, with reference to export prospects into the UK. www.onevillage.org. London, One Village, UK

United Nations Development Programme (UNDP) Human Development Reports. See http://hdr.undp.org/en/

World Bank, http://geo.worldbank.org/ 


\section{Bibliography}

Abu-Lughod, J., \& Hay, R., Jr. (Eds.). (1977). Third World Urbanization. Chicago: Maaroufa Press Inc.

Aceh Coffee Forum. (2006). Draft Minutes of meeting at Takengon, August 2006. Retrieved 25 February, 2008, from http://www.humanitarianinfo.org/sumatra/reliefrecovery/livelihood/docs/minu tes/ba/Draft-CoffeeForumMeetingMinutes-10Aug06.pdf

Allal, M. (1999). Micro And Small Enterprise Development \& Poverty Alleviation In Thailand. Bangkok: ILO/UNDP.

Amin, A. (2002). Spatialities of Globalisation. Environment and Planning A, 34, 385399.

Andersen, M., \& Skovgaard, R. G. (2008). Small suppliers in global supply chains. Retrieved 4 June 2008, from http://www.eldis.org/go/topics/resourceguides/corporate-responsibility\&id $=36514 \&$ type $=$ Document

Angel, S., Sheppard, S. C., \& Civco, D. L. (2005). The Dynamics of Global World Expansion. Transport and Urban Development Department, World Bank Retrieved 26 September, 2007, from http://www.williams.edu/Economics/UrbanGrowth/DataEntry.htm

AP Report. (2008, 4 March). Attack Threatens Aceh Peace. The Dominion Post, p. B2.

Ariana Eunjung Cha. (2008, 14 April). New Law Gives Chinese Workers Power, Gives Businesses Nightmares. Washington Post, p. A01.

Azzoni, C., Brooks, J., Guilhoto, J., \& McDonald, S. (2007). Who in Brazil Will Gain from Global Trade Reforms? The World Economy, 30(10), 1568-1593.

Barrientos, S., \& Smith, S. (2007). Do workers benefit from ethical trade? Assessing codes of labour practice in global production systems. Third World Quarterly, 28(4), 713-729.

Beaverstock, J. V., Smith, R. G., Taylor, P. J., Walker, D. R. F., \& Lorimer, H. (2000). Globalization and world cities: some measurement methodologies. Applied Geography, 20(1), 43-63.

Begley, T. M., Wee-Liang Tan, \& Schoch, H. (2005). Politico-Economic Factors Associated with Interest in Starting a Business: A Multi-Country Study Entrepreneurship Theory And Practice 29(1), 35 - 55.

Bird, K., \& Hughes, D. R. (1997). Ethical Consumerism: The Case Of "FairlyTraded" Coffee. Business Ethics: A European Review, 6(3), 159-167.

Birdsall, N. (2005). Rising Inequality in the New Global Economy. World Institute for Development Economics Research (WIDER)(2/2005), 1-3.

Birdsall, N., De la Torre, A., \& Menezes, R. (2008). Fair Growth: Economic Policies for Latin America's Poor and Middle Income Majority. Washington: Center for Global Development.

Blowfield, M. (2007). Reasons to be Cheerful? What we know about CSR's Impact. Third World Quarterly, 28(4), 683-695.

Bouët, A. (2006). How Much Will Trade Liberalization Help the Poor? Comparing Global Trade Models. Washington DC: International Food Policy Research Institute.

Burnett, P., \& Manji, F. (Eds.). (2007). From the Slave Trade to 'Free' Trade:How trade undermines democracy and justice in Africa. Nairobi \& Oxford: Fahamu - Networks for Social Justice.

Carmichael, A., \& Rice, J. (2006). Fostering Social Entrepreneurship: A Comparative Study of the Legal, Regulatory and Tax Issues in Brazil, Germany, India, 
Poland, UK and USA. World Economic Forum; Davos, Switzerland: Linklaters, Schwab Foundation.

Collins, A., Stuart, L., Bailey, M., \& Fowler, P. (2005). Making Trade Work for Development in 2005: What the EU should do. Oxfam Briefing Papers \#75 Retrieved 13 March, 2007, from http://www.oxfam.org/en/files/bp75_eu_trade_2005.pdf

Colman, D., \& Nixson, F. (1978). Economics of Change in Less Developed Countries. Oxford: Philip Allan Publishers.

Dahle, C. (2006). Next: A nonprofit IPO. Fast Company 104. Retrieved 13 February, 2007, from http://www.fastcompany.com/magazine/104/next-socialcapital.html

Dang Thanh Ha, \& Shively, G. (2007). Coffee Boom, Coffee Bust and Smallholder Response in Vietnam's Central Highlands. Review of Development Economics, 12(2), 312-326.

DiCaprio, A., \& Gallagher, K. P. (2006). The WTO and the Shrinking of Development Space: How Big is the Bite? The Journal of World Investment and Trade, 7(5), 781-803.

Dominique van der Mensbrugghe. (2005). Estimating the Benefits of Trade Reform: Why Numbers Change. Retrieved 6 December 2007, from http://siteresources.worldbank.org/INTRANETTRADE/Resources/2390541126812419270/4.EstimatingThe.pdf

Ecumenical News International. (2007, 20 July). Africa should halt European trade agreements, says church head. CWM News.

Ellis, K. (2008). Is CSR just Corporates Saying the Right Things? ODI Opinion Retrieved 14 May, 2008, from http://www.odi.org.uk/publications/opinions/100_private_sector_karen_ellis_a pr08.pdf

Evenett, S. J., \& Meier, M. (2008). An Interim Assessment of the US Trade Policy of 'Competitive Liberalization'. The World Economy, 31(1), 31-66.

Fisher, C. (2007). Selling Coffee, or Selling Out?: Evaluating Different Ways to Analyze the Fair-Trade System. Culture and Agriculture, 29(2), 77-88.

Fowler, P. (2001). Harnessing Trade for Development. Oxfam Briefing Papers Retrieved August, 2007, from http://www.oxfam.org/en/files/pp0108_Harnessing_trade_for_development.pd f/download

Fricke, T. (2005). Aceh Sustainable Coffee Program End of Year 2005 Report. Retrieved 21 March, 2008, from http://www.tradeaid.org.nz/IM_Custom/ContentStore/Assets/11/67/03238098 3c530dd97f7ac75a1fc0f9fa/Aceh\%20Sustainable $\% 20$ Coffee $\% 20$ Program $\% 20$ 2005\%20Annual\%20Report.pdf

Friedman, T. L. (2006). The World is Flat: the globalized world in the twenty-first century. London: Penguin Books.

Gereffi, G. (1999). A Commodity Chains Framework for Analyzing Global Industries. Retrieved September, 2007, from http://galatai.com/Reading\%20Backup/Society\%20and\%20Space/Spring/GCC $\% 20$ Analysis.pdf

Ghosh, J. (2004). West Bengal Human Development Report. Kolkata: Development and Planning Department, Government of West Bengal.

Gilbert, A. (2007). Inequality and Why it Matters. Geography Compass, 1 (3), 422447.

Glenny, M. (2008). McMafia: Crime without frontiers. London: Bodley Head. 
Glinavos, I. (2007). Development beyond Neoliberalism? Governance, Poverty Reduction and Political Economy by David Craig and Douglas Porter. Development and Change, 38(4), 764-765.

Goodman, P. S. (2007, 16 March). Labor Rights in Guatemala Aided Little by Trade Deal. Washington Post, p. A01.

Grant, M. (2004). Girl-trafficking hampers Aids fight. Retrieved 12 June, 2008, from http://news.bbc.co.uk/go/pr/fr/-/2/hi/south_asia/4055143.stm

Green, D. (2008). Growth, Trade, Integration and Policy Space. Retrieved 19 April, 2008, from http://www.progressivegovernance.net/uploadedFiles/Publications/Publications/Duncan_Green.pdf

Gries, T., \& Naude, W. (2008). Trade and Endogenous Formation of Regions in a Developing Country. Review of Development Economics, 12(2), 248-275.

Ha-Joon Chang. (2007). Bad Samaritans: Rich Nations, Poor Policies, and the Threat to the Developing World. London: Random House Business Books.

Hagar International. (2005). Annual Report 2005. Retrieved 14 March, 2008, from www.hagarinternational.org

Hagar International. (2006). Annual Report 2006. Retrieved 14 March, 2008, from www.hagarinternational.org

Heintz, J. (2008). 'Fighting Poverty: The Development-Employment Link' by Rizwanul Islam - Book review. Development and Change, 39(2), 338-340.

Jensen, M. F., \& Gibbon, P. (2007). Africa and the WTO Doha Round: An Overview. Development Policy Review, 25(1), 5-24.

Jessop, B., \& Ngai-Ling Sum. (2000). An Entrepreneurial City in Action: Hong Kong's Emerging Strategies in and for (inter)Urban Competition. Urban Studies, 37(12), 2287-2313.

Kaushik Basu. (2006). Globalization, Poverty, and Inequality: What is the Relationship? What Can Be Done? World Development, 34(8), 1361-1373.

Kumar Utsav, \& Prachi Misra. (2008). Trade Liberalization and Wage Inequality: Evidence from India. Review of Development Economics, 12(2), 291-311.

Laquian, A. A. (2005). Beyond Metropolis: The Planning and Governance of Asia's Mega-Urban Regions. Baltimore: John Hopkins University Press.

Larner, W., \& Le Heron, R. (2002). The spaces and subjects of a globalising economy: a situated exploration of method. Environment and Planning D: Society and Space, 20(6), 753-774.

Lyon, S. (2006). Evaluating fair trade consumption: politics, defetishization and producer participation. International Journal of Consumer Studies, 30(5), 452-464.

Madhusree Mukerjee. (2006). The Prostitutes' Union. Scientific American. Retrieved 12 June, 2008, from http://www.sciam.com/article.cfm?id=the-prostitutesunion

Maxwell, S. (2008). Stepping up the ladder: how business can help achieve the MDGs. ODI Opinion Retrieved 14 May, 2008, from http://www.odi.org.uk/publications/opinions/99_private_sector_simon_maxwe 11_apr08.pdf

McGee, T. G. (1967). The Southeast Asian City: a social geography of the primate cities of southeast Asia. London: G. Bell \& Sons Ltd.

McGee, T. G. (1995). Metrofitting the Emerging Mega-Urban Regions of ASEAN: An Overview. In T. G. McGee \& I. M. Robinson (Eds.), The Mega-Urban Regions of Southeast Asia. Vancouver: UBC Press. 
Neilson, J. (2007). Institutions, the governance of quality and on-farm value retention for Indonesian specialty coffee. Singapore Journal of Tropical Geography, 28(2), 188-204.

Nissanke, M., \& Thorbecke, E. (2005). Channels and Policy Debate in the Globalization-Inequality-Poverty Nexus. Retrieved 19 June, 2007, from http://people.cornell.edu/pages/et17/Erik\%20Thorbecke\%20files/DP-05-08Nissanke\%20and\%20Thorbecke2.pdf

NZAID. (n.d.). Trade Can Reduce Poverty. Retrieved March, 2007, from http://www.nzaid.govt.nz/library/publications/policies.html

OECD, \& World Trade Organisation. (2007). Aid For Trade At A Glance 2007:1st Global Review. Retrieved 21 March, 2008, from http://www.oecd.org/document/46/0,3343,fr_2649_34665_39619566_1_1_1_ $1,00 . \mathrm{html}$

Omara-Otunnu, A. (2007). Western Humanitarianism Or Neo-Slavery? Retrieved 21 March, 2008, from http://blackstarnews.com/

Oxfam. (2006). Rich countries not off the hook after breakdown of WTO talks. Oxfam Press Release Retrieved 25 June, 2008, from http://www.oxfam.org/en/news/pressreleases2006/pr060726_wto

Oxfam. (2007). Urgent need for change in Europe's approach to trade negotiations. Retrieved 19 April, 2008, from www.oxfam.org.uk/resources/policy/trade/downloads/epasfactsheets.pdf

Oxfam. (2008). Partnership or Power play? Retrieved June, 2008, from http://www.oxfam.org.uk/resources/policy/trade/downloads/bp110_epas.pdf

Oxfam International. (2001). Harnessing Trade for Development. Retrieved 25 June, 2008, from

http://www.oxfam.org/en/policy/briefingpapers/bp0108_Harnessing_trade_for development

Padam Simkhada. (2008). Life Histories and Survival Strategies Amongst Sexually Trafficked Girls in Nepal Children \& Society, 22(3), 235-248.

Plugge, L., \& Wiemer, J. (2008). Small, Smart and Sustainable: Experiences of SME Reporting in Global Supply Chains: Global Reporting Initiative.

Prasad, E., Rogoff, K., Shang-Jin Wei, \& Kose, M. A. (2003). Effects of Financial Globalization on Developing Countries: Some Empirical Evidence. Retrieved 13 April 2008, from http://www.imf.org/external/np/apd/seminars/2003/newdelhi/prasad.pdf

Rodrigue, J.-P. (2004). Freight, Gateways And Mega-Urban Regions: The Logistical Integration Of The Bostwash Corridor. Tijdschrift voor Economische en Sociale Geografie, 95(2), 147-161.

Roodman, D. (2005). Production-weighted Estimates of Aggregate Protection in Rich Countries toward Developing Countries - Working Paper 66. Washington: Center for Global Development.

Scott, R. (2001). Handcrafts of Naryn Oblast, Kyrgyzstan, with reference to export prospects into the UK. Retrieved 9 April, 2008, from www.onevillage.org/Kyrgyzstan.htm

Sinclair, J. (Writer) (2005). Calcutta Hilton [DVD]. In J. Sinclair (Producer). New Zealand: Sinclair Enterprises.

Stiglitz, J. E. (2003). Globalization and its Discontents. New York: WW Norton \& Co.

Storm, S. (2008a). 'Adam's Fallacy: A Guide to Economic Theology' by Duncan K. Foley - Book Review. Development and Change, 39(2), 336-338. 
Storm, S. (2008b). 'Development with Dignity: A Case for Full Employment' by Amit Bhaduri - Book review. Development and Change, 39(2), 342-343.

Storm, S., \& Naastepad, C. W. M. (2007). Sukhamoy Chakravarty: The Feasibility of Equitable Growth. Development and Change, 38(6), 1173-1185.

Susie Mesure, \& Steve Bloomfield. (2008, 24 February ). Fair Trade Profits Rise. The Independent on Sunday.

Tanburn, J., Trah, G., \& Hallberg, K. (2001). Business Development Services for Small Enterprises: Guiding Principles for Donor Intervention. Retrieved 1 May, 2008, from http://www.ilo.org/public/english/employment/ent/papers/guide.htm

Taylor, P. J. (2007). Atlas of Hinterworlds. Retrieved 20 September, 2007, from http://www.lboro.ac.uk/gawc/visual/hwatlas.html

Taylor, P. J., \& Walker, D. R. F. (2004). Urban Hinterworlds Revisited. Geography, 89(2), 145-151.

The Allen Consulting Group. (2007). Business for Poverty Relief: a business case for business action. Melbourne: Report Commissioned by the Business for Poverty Relief Alliance.

Trade Aid. (n.d.). Alternative Trade in a Conventional World. Christchurch, New Zealand: Publicity booklet. www.tradeaid.org.nz.

TransFair USA. (2005). PPKGO, Indonesia. Fair Trade Producer Profile Retrieved 25 February, 2008, from www.transfairusa.org

UNDP. (2005). Coffee Industry Forum Minutes 12 September 2005. Banda Aceh: United Nations Development Programme.

United Nations Economic and Social Commission for Asia and the Pacific. (nd). Business Incubation Through Technology Support for Small and Medium Sized Enterprises in Asia and the Pacific. Small Industry Bulletin for Asia and the Pacific, 31, 31 - 37.

University of Michigan. (2006). Urbanization and Global Change. Global Change Program Retrieved 25 September, 2007, from www.globalchange.umich.edu/globalchange $2 /$ current/lectures/urban $\% 5 \mathrm{Fgc} /$

Vater, T. (2004). Welcome to Sonagachi - Calcutta's largest brothel area is thriving. Retrieved 12 June, 2008, from http://www.tomvater.com/sonagachi.html

WTO. (2007). Understanding the WTO. Lausanne: World Trade Organisation 